\title{
IntechOpen
}

\section{Mobile Health Technologies}

Theories and Applications

Edited by Wilfred Bonney 



\section{MOBILE HEALTH \\ TECHNOLOGIES - \\ THEORIES AND \\ APPLICATIONS}

Edited by Wilfred Bonney 
Mobile Health Technologies - Theories and Applications

http://dx.doi.org/10.5772/61446

Edited by Wilfred Bonney

\section{Contributors}

Marcia Friesen, Chin-Feng Lin, Shere-Er Wang, Yen-Chiao Lu, Zhong-Yi Lin, Chung-Cheng Chang, Tim Yeh, Candice Lee, Jeffson Huang, Chic-Erh Weng, Sue-Hsien Chen, Bing-Leung Sun, Chao-Sheng Wang, Shiue-Li Cheng, Xiu-Yu Li, Lan-Yu Wu, Fang Zhao, Meng Li, Joe Tsien, Dejan Dinevski, Matjaž Krošel, Lana Švegl, Luka Vidmar, Gonzalo Segrelles, Niloofar Mohammadzadeh, Reza Safdari

\section{(c) The Editor(s) and the Author(s) 2016}

The moral rights of the and the author(s) have been asserted.

All rights to the book as a whole are reserved by INTECH. The book as a whole (compilation) cannot be reproduced, distributed or used for commercial or non-commercial purposes without INTECH's written permission.

Enquiries concerning the use of the book should be directed to INTECH rights and permissions department (permissions@intechopen.com).

Violations are liable to prosecution under the governing Copyright Law.

\section{(cc) BY}

Individual chapters of this publication are distributed under the terms of the Creative Commons Attribution 3.0 Unported License which permits commercial use, distribution and reproduction of the individual chapters, provided the original author(s) and source publication are appropriately acknowledged. If so indicated, certain images may not be included under the Creative Commons license. In such cases users will need to obtain permission from the license holder to reproduce the material. More details and guidelines concerning content reuse and adaptation can be foundat http://www.intechopen.com/copyright-policy.html.

\section{Notice}

Statements and opinions expressed in the chapters are these of the individual contributors and not necessarily those of the editors or publisher. No responsibility is accepted for the accuracy of information contained in the published chapters. The publisher assumes no responsibility for any damage or injury to persons or property arising out of the use of any materials, instructions, methods or ideas contained in the book.

First published in Croatia, 2016 by INTECH d.o.o.

eBook (PDF) Published by IN TECH d.o.o.

Place and year of publication of eBook (PDF): Rijeka, 2019.

IntechOpen is the global imprint of IN TECH d.o.o.

Printed in Croatia

Legal deposit, Croatia: National and University Library in Zagreb

Additional hard and PDF copies can be obtained from orders@intechopen.com

Mobile Health Technologies - Theories and Applications

Edited by Wilfred Bonney

p. cm.

Print ISBN 978-953-51-2634-8

Online ISBN 978-953-51-2635-5

eBook (PDF) ISBN 978-953-51-7304-5 


\section{We are IntechOpen, \\ the world's leading publisher of Open Access books}

Built by scientists, for scientists

\section{$3,800+$}

Open access books available

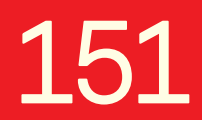

Countries delivered to

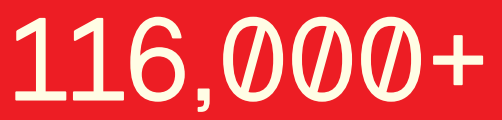

International authors and editors
$120 \mathrm{M}+$

Downloads

Our authors are among the

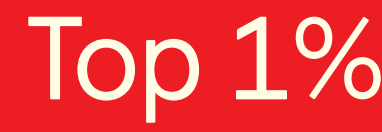

most cited scientists

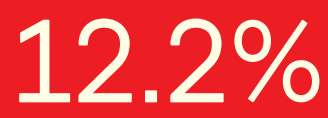

Contributors from top 500 universities

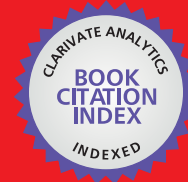

WEB OF SCIENCE ${ }^{\mathrm{TM}}$

Selection of our books indexed in the Book Citation Index in Web of Science ${ }^{\mathrm{TM}}$ Core Collection (BKCI)

Interested in publishing with us?

Contact book.department@intechopen.com

Numbers displayed above are based on latest data collected.

For more information visit www.intechopen.com

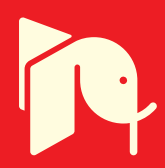





\section{Meet the editor}

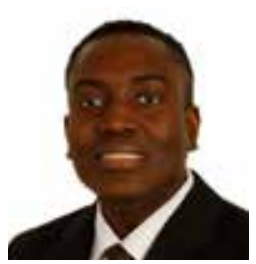

Dr. Wilfred Bonney is an Associate Health Informatics Specialist at the University of Dundee, Scotland, UK. He holds a Ph.D. degree in Information Technology from Capella University. He is affiliated with HL7 International and is a certified HL7 V3 RIM Specialist. He is also a professional member of the British Computer Science. 



\section{Contents}

Preface XI

\section{Section 1 mHealth Theories 1}

Chapter 1 The Emerging Wearable Solutions in mHealth 3 Fang Zhao, Meng Li and Joe Z. Tsien

Chapter 2 Empowering Diabetes Patient with Mobile Health Technologies 31

Matjaž Krošel, Lana Švegl, Luka Vidmar and Dejan Dinevski

Chapter 3 Telemedicine Programs in Respiratory Diseases $\mathbf{5 7}$ Gonzalo Segrelles-Calvo and Daniel López-Padilla

Chapter 4 Mobile Health Monitoring $\mathbf{7 9}$

Niloofar Mohammadzadeh and Reza Safdari

Section 2 mHealth Applications 97

Chapter 5 Mobile Cloud-Based Blood Pressure Healthcare for Education 99

Chin-Feng Lin, Shere-Er Wang, Yen-Chiao Lu, Chung-I Lin, ChungCheng Chang, Tim Yeh, Candice Lee, Jeffson Huang, Chic-Erh Weng, Sue-Hsien Chen, Bing-Leung Sun, Chao-Sheng Wang, ShiueLi Cheng, Shiou-Yu Li and Lan-Yu Wu

Chapter 6 An mHealth Technology for Chronic Wound Management 115 Marcia R. Friesen, Bennet Gigliotti and Tik Wai (Kiral) Poon 



\section{Preface}

Mobile Health Technologies, also known as mHealth technologies, have emerged, amongst healthcare providers, as the ultimate Technologies-of-Choice for the 21st century in delivering not only transformative change in healthcare delivery, but also critical health information to different communities of practice in integrated healthcare information systems. mHealth technologies nurture seamless platforms and pragmatic tools for managing pertinent health information across the continuum of different healthcare providers. mHealth technologies commonly utilize mobile medical devices, monitoring and wireless devices, and/or telemedicine in healthcare delivery and health research. Today, mHealth technologies provide opportunities to record and monitor conditions of patients with chronic diseases such as asthma, Chronic Obstructive Pulmonary Diseases (COPD) and diabetes mellitus. The intent of this book is to enlighten readers about the theories and applications of mHealth technologies in the healthcare domain. The book is divided into two sections, with Section 1 consisting of four chapters and Section 2 consisting of two chapters.

Section 1, including Chapter 1 through 4, illustrates the opportunities, benefits and challenges of mHealth technologies in managing patients with chronic diseases. Chapter 1 reviews recent progress in the field of wearable technologies, with a focus on key solutions for fall detection and prevention, Parkinson's disease assessment, cardiac disease, blood pressure and blood glucose management. Chapter 2 explores the use of mHealth technologies for the empowerment of patients with diabetes so as to improve their health outcomes and wellbeing. Chapter 3 explores the opportunities and challenges in adopting telemedicine programs for the management of patients with respiratory diseases. Chapter 4 presents opportunities and challenges of monitoring chronic disease patients with mHealth technologies.

Section 2, including Chapter 5 and 6, illustrates the applications of mHealth technologies in streamlining the management of chronic diseases. Chapter 5 discuses a mobile Cloud-based blood pressure application for healthcare education. Chapter 6 presents the development of a mHealth application called SmartWoundCare, designed to document and assess chronic wounds on Smartphones and tablets.

Dr. Wilfred Bonney, University of Dundee, Scotland, UK 

Section 1

mHealth Theories 



\title{
Chapter 1
}

\section{The Emerging Wearable Solutions in mHealth}

\author{
Fang Zhao, Meng Li and Joe Z. Tsien \\ Additional information is available at the end of the chapter \\ http://dx.doi.org/10.5772/63557
}

\begin{abstract}
The marriage of wearable sensors and smartphones have fashioned a foundation for mobile health technologies that enable healthcare to be unimpeded by geographical boundaries. Sweeping efforts are under way to develop a wide variety of smartphonelinked wearable biometric sensors and systems. This chapter reviews recent progress in the field of wearable technologies with a focus on key solutions for fall detection and prevention, Parkinson's disease assessment and cardiac disease, blood pressure and blood glucose management. In particular, the smartphone-based systems, without any external wearables, are summarized and discussed.
\end{abstract}

Keywords: wearable inertial sensors, accelerometer, gyroscope, ECG patch, classification algorithm, smartphone, fall detection and prevention, Parkinson's disease, cardiac rhythm, blood glucose, blood pressure

\section{Introduction}

Nowadays, dramatic advances in microelectromechanical systems (MEMS) technology have paved the way for wearable sensors to make inroads into mHealth, providing the potential for medical care and research to take place outside the standard doctor's office or hospital. A wide variety of wearable biometric sensors, such as bracelets, watches, skin patches, headbands, earphones, and clothing [1, 2], have been designed and developed. Regardless of the various forms and functions of these sensors, their unifying design focus is to allow for unobtrusive, passive, and continuous monitoring. Beyond sensing capability, another key characteristic is their ability to seamlessly connect with a mobile device to transfer all biometric data into a software application (APP) that can be shared with healthcare providers, researchers or family members. Inertial sensors, the most ubiquitous wearables, combined with dedicated algorithms are able to "count" steps (i.e., pedometers), gauge physical activity levels, indirectly 
estimate energy expenditure [3], and implement activity recognition [4]. Today, the Holter monitor, the most commonly used ambulatory electrocardiography device for assessing cardiac abnormalities, is one of the technologies that may soon become obsolete, since prolonged continuous rhythm monitoring is available by wearing an electrocardiogram (ECG) patch on the chest [5]. Other notable examples of sensor technologies under development which allow for a more personalized understanding of our health include cuffless blood pressure monitoring and noninvasive blood glucose tracking. Through progressively miniaturized, smartphones are equipped with comparatively advanced sensing capabilities (i.e., accelerometer, gyroscope, magnetometer, camera, and many more) and powerful computing capabilities, making it the ideal platform for remote health monitoring without the extra expense of purchasing and inconvenience of using dedicated wearables. As a result, smartphone-based solutions have emerged most recently for fall detection and prevention [6], activity recognition [7], Parkinson's disease (PD) assessment [8], and cardiac rhythm measurement in mHealth.

This chapter provides a review of recent progress in the field of wearable systems and solutions that have already entered into or have the potential to apply in mHealth. Aging of the population is a global issue, and it presents tremendous challenges to society and healthcare systems all over the world. The most common healthcare issues of the aging population include the following: (i) falls that are considered as one of the major hazards for the elderly, especially for those living alone [9]; (ii) neurological disorders that are categorized as major chronic diseases inducing motor impairments, with PD as one of the most frequently occurring conditions [10]; and (iii) cardiac disease, hypertension and diabetes are the most common chronic diseases affecting the elderly [11]. Therefore, a critical analysis of the state-of-the-art wearable solutions for these age-related care issues and chronic diseases are presented.

The remainder of this chapter can be separated into five sections. The wearable solutions for motion monitoring are discussed in Section 2. Firstly, the basic architecture of the wearable motion monitoring systems is described, followed by a summary of the state-of-the-art smartphone-based fall detection and prevention systems, with a focus on the sensor used, extracted features, the classification algorithm, and the outcomes in each system. The wearable solutions for PD are then discussed. A selection of external wearable solutions and smartphone-based systems that used pattern recognition algorithms to classify motor signs of functional activities impairment in PD are presented and compared. Section 3 illustrates the wearable solutions for cardiac activity monitoring. Several commercially available portable devices are presented. Section 4 describes the approaches for cuffless blood pressure monitoring and noninvasive blood glucose monitoring. Unfortunately, these approaches are not satisfactory to date. Finally, conclusion offered in Section 5 points out important observations and areas that need further research.

\section{Wearable solutions for motion monitoring}

Mirroring the increasingly widespread adoption of wearable inertial sensors in personalized healthcare is an equally remarkable development in algorithms to classify human activity [7]. 
As a result, inertial sensor technologies can go well beyond step counts to a wealth of personalized activity information to help guide health and wellness. Earlier work by Bouten et al. [12] established a significant relationship $(r=0.89)$ between accelerometer output and energy expenditure due to physical activity, impelling wearable sensor to become capable of estimating energy expenditure in diabetes or obesity management. Subsequent work by Najafi et al. [13] founded a significant correlation between postural transition (PT) and falling risk using a gyroscope, which led to a variety of other works to exemplify the prominence of wearable inertial sensors in fall detection and prevention in elderly care. The activity recognition by wearable inertial sensors has also been used in the assessment and rehabilitation of many neurological diseases [14], such as Parkinson's disease (PD), stroke, cerebral palsy (CP), multiple sclerosis (MS), and Huntington's disease (HD), which can induce motor impairment. Transformations are under way in movement monitoring to provide care in the daily lives of those afflicted with these diseases as a result of all these breakthroughs.

\subsection{Architecture}

The basic architecture of motion monitoring systems for mHealth consists of three common phases namely, sensing, processing and communication (Figure 1). Feature extraction and motion classification algorithm used in the processing phase may differ greatly from system to system.

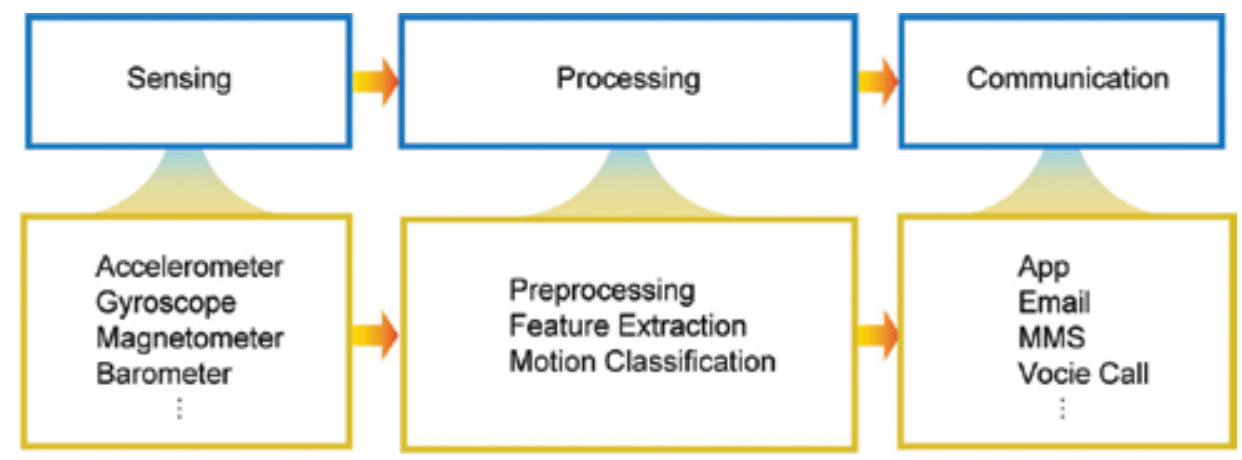

Figure 1. Basic architecture of activity tracking systems for mHealth.

\subsubsection{Sensing}

Multimodal MEMS sensors can be utilized to identify physical activities, including accelerometer, gyroscope, magnetometer, barometer, etc. The terms accelerometer, gyroscope, and magnetometer will refer to triaxial accelerometers, triaxial gyroscopes and triaxial magnetometers, respectively, unless otherwise stated. Each type of sensor is sensitive to a kinematic quantity: accelerometer for sensing acceleration along three orthogonal directions; gyroscope for detecting angular momentum; magnetometer for gauging changes in orientation by measuring the strength of the local magnetic field along three orthogonal axes; and barometer for determining rapid changes in altitude (e.g., walking up/down stairs) by measuring absolute 
atmospheric pressure to infer altitude above sea level. Their combination can even estimate three-dimensional (3D) orientation and displacement.

\subsubsection{Processing}

The processing phase encompasses preprocessing, feature extraction and physical motion classification steps. Preprocessing needs to be first applied to the raw data collected from MEMS sensors to improve the signal-to-noise ratio. The signals are often smoothed by median filters of a short sliding window to remove spurious noise [15]. Accelerometer data are often high-pass filtered to separate acceleration caused by gravity from acceleration due to body movement [16].

After preprocessing of MEMS data, features are generally extracted from sequential epochs of time using window techniques. The most commonly used approach is the sliding window often with $50 \%$ overlap between consecutive windows [17], which is the most suitable for realtime or online applications. Statistical measures of the time domain and frequency domain features are widely used to reduce the MEMS data of each window epoch to a finite number of derived parameters from which a physical movement can be inferred.

Prior to classification, feature selection techniques [18] may be applied to find the optimal feature subset, which can best distinguish between movements, from all of the features generated. Feature selection is of particular importance as inappropriate or redundant features may deteriorate the overall classification performance. The selected features from the MEMS sensor data are exploited by the classification algorithms in the development of a model that can identify specific physical movements. Classification methods used in activity recognition include (but are not limited to) hidden Markov models (HMM), K nearest neighbors (KNN), support vector machines (SVM), discrete wavelet transform (DWT), decision tree classifiers (DTC), random forests (RFs), linear discriminant analysis (LDA) or feed-forward neural network (Bpxnc).

\subsubsection{Communication}

After processing, the classified motion data can then be sent to medical staff (e.g., a caregiver or a physician) for remote monitoring or back to the user or patient for self-monitoring. Once an abnormal movement (i.e., fall event) is detected, the wearable mHealth systems sent out a signal to seek help from the monitoring center or a caregiver via smartphones.

\subsection{Fall detection and prevention}

Falls are one of the major causes of injuries and hospital admissions of elderly people. Those who suffer from neurological diseases (e.g., stroke, PD) also give rise to increased fall risks. Falls can potentially cause severe physical injuries, such as bleeding, fracture and central nervous system (CNS) damage, and long lie times (remaining involuntarily on the ground for a prolonged period) after the fall can lead to disability, paralysis, even death. Therefore, the first line of defence against fall hazards is to prevent them and the second line of defence is to provide emergency treatment in time. 


\subsubsection{Smartphone-based systems}

Initially, dedicated wearable kinematic sensors have been developed with the ability to assist in identifying falls $[19,20]$ and estimating the likelihood of future falls by monitoring activity levels or analyzing the individual's gait [21,22]. However, their widespread adoption has been limited by the cost associated with purchasing the device and the low utilization coefficient by the user (who may often forget or refuse to wear the specially designed wearables). There has been a shift toward smartphones in recent years, as the smartphone with multimodal builtin MEMS sensors, coupled with its ubiquitous nature and increased computational power, make it the ideal platform for fall monitoring in mHealth. The first smartphone-based fall detection app iFall [23] utilized an integrated accelerometer to recognize the difference in position before and after the fall. Later in 2010, the PreFallD [24] was developed considering both the wearer's acceleration and orientation during the fall event. Table 1 summarizes and compares the features of the existing smartphone-based fall detection and prevention systems or applications. The literatures that presented very preliminary investigations and did not declare the performance of their proposed solutions are not included here.

\begin{tabular}{|c|c|c|c|c|c|}
\hline $\begin{array}{l}\text { Arti } \\
\text { cle }\end{array}$ & $\begin{array}{l}\text { Appli } \\
\text { cation }\end{array}$ & $\begin{array}{l}\text { Sensors } \\
\text { (Placement) }\end{array}$ & Algorithm & Performance & $\begin{array}{l}\text { Notification } \\
\text { (Information) }\end{array}$ \\
\hline [23] & Detection & $\begin{array}{l}\text { Accelerometer } \\
\text { (Any) }\end{array}$ & Threshold & $\begin{array}{l}\text { Demonstrated fall can be } \\
\text { detected by smartphone. }\end{array}$ & $\begin{array}{l}\text { SMS (time, GPS } \\
\text { coordinates), audible } \\
\text { notification. }\end{array}$ \\
\hline [24] & Detection & $\begin{array}{l}\text { Accelerometer \& } \\
\text { gyroscope \& } \\
\text { magnetometer } \\
\text { (chest, waist, thigh) }\end{array}$ & Threshold & $\begin{array}{l}2.67 \% \text { (Average } F N \text { ), } 8.7 \% \\
\text { (Average } F P \text { ) }\end{array}$ & $\begin{array}{l}\text { Audio alarm, voice } \\
\text { call. }\end{array}$ \\
\hline [25] & Detection & $\begin{array}{l}\text { Accelerometer } \\
\text { (trouser pocket) }\end{array}$ & DWT & $85 \%(R C), 95 \%(P R)$ & $\begin{array}{l}\text { SMS (GPS } \\
\text { coordinates), email } \\
\text { (Google map), } \\
\text { twitter. }\end{array}$ \\
\hline [30] & Detection & $\begin{array}{l}\text { Accelerometer } \\
\text { (chest, waist, thigh) }\end{array}$ & Threshold & $\begin{array}{l}97 \%(P R), 2.67 \% \text { (average } F N \text { ), } \\
8.7 \% \text { (Average } F P \text { ) }\end{array}$ & $\begin{array}{l}\text { Audio alarm, voice } \\
\text { call }\end{array}$ \\
\hline [26] & Detection & $\begin{array}{l}\text { Accelerometer } \\
\text { (Waist) }\end{array}$ & C4.5 DT, NB, SVM & $\begin{array}{l}98.85 \%(A C \text { for } \mathrm{DT}) ; 86.47 \%(A C \\
\text { for SVM); } 87.78 \% \text { ( } A C \text { for } \mathrm{NB})\end{array}$ & SMS \\
\hline [97] & Detection & $\begin{array}{l}\text { Accelerometer } \\
\text { (waist) }\end{array}$ & Threshold & $\begin{array}{l}\text { Detected } 54 \text { out of } 67 \text { simulated } \\
\text { falls. }\end{array}$ & Email, SMS. \\
\hline [31] & Detection & $\begin{array}{l}\text { Accelerometer } \\
\text { (waist) }\end{array}$ & Threshold & $0.81(S P), 0.77(S E)$ & SMS (time, location) \\
\hline
\end{tabular}




\begin{tabular}{|c|c|c|c|c|c|}
\hline $\begin{array}{l}\text { Arti } \\
\text { cle }\end{array}$ & $\begin{array}{l}\text { Appli } \\
\text { cation }\end{array}$ & $\begin{array}{l}\text { Sensors } \\
\text { (Placement) }\end{array}$ & Algorithm & Performance & $\begin{array}{l}\text { Notification } \\
\text { (Information) }\end{array}$ \\
\hline [39] & Detection & $\begin{array}{l}\text { Accelerometer \& } \\
\text { gyroscope } \\
\text { (hand, shirt, or trouser } \\
\text { pocket) }\end{array}$ & $\begin{array}{l}\text { Threshold, } \\
\text { One-class SVM }\end{array}$ & $\begin{array}{l}75 \% \text { ( } A C \text { for hand); } \\
77.9412 \% \text { ( } A C \text { for shirt pocket); } \\
84.2857 \% \\
\text { ( } A C \text { for trouser } \\
\text { pocket) }\end{array}$ & Undisclosed \\
\hline [98] & Detection & $\begin{array}{l}\text { Accelerometer } \\
\text { (waist) }\end{array}$ & Threshold & $\begin{array}{l}\text { Capability of differentiate } \\
\text { between running and } \\
\text { falling }\end{array}$ & $\begin{array}{l}\text { SMS (time, GPS } \\
\text { coordinates) }\end{array}$ \\
\hline$[44]$ & Detection & $\begin{array}{l}\text { Accelerometer } \\
\text { (waist) }\end{array}$ & Threshold, ANN & $\begin{array}{l}100 \% \text { success rate for a total } \\
\text { of } 500 \text { epochs. }\end{array}$ & $\begin{array}{l}\text { Message (GPS } \\
\text { coordinates) }\end{array}$ \\
\hline [6] & $\begin{array}{l}\text { Detection, } \\
\text { prevention }\end{array}$ & $\begin{array}{l}\text { Accelerometer \& } \\
\text { gyroscope (waist) }\end{array}$ & Threshold & $\begin{array}{l}\text { The uFall and uTUG can ran } \\
\text { on a smartphone to realize } \\
\text { long-term and real-time } \\
\text { monitoring. }\end{array}$ & $\begin{array}{l}\text { Audio alarm, email, } \\
\text { SMS. }\end{array}$ \\
\hline [99] & Detection & $\begin{array}{l}\text { Accelerometer } \\
\text { (shirt, or trouser } \\
\text { pocket) }\end{array}$ & Threshold & $\begin{array}{l}97 \% \text { (average } S E \text { ), } 100 \% \\
\text { (average } S P \text { ) }\end{array}$ & Undisclosed \\
\hline [32] & Detection & $\begin{array}{l}\text { Accelerometer (Shirt } \\
\text { pocket) }\end{array}$ & threshold & $92.75 \%(S E), 86.75 \%(S P)$ & Text message \\
\hline [40] & Detection & $\begin{array}{l}\text { Accelerometer } \\
\text { (trouser pocket) }\end{array}$ & SVM & $95.7 \%(P R), 90 \%$ (average $R C$ ) & $\begin{array}{l}\text { vibration, audio } \\
\text { alarm, SMS (time, } \\
\text { location) }\end{array}$ \\
\hline [27] & Detection & $\begin{array}{l}\text { Accelerometer \& } \\
\text { gyroscope (hand, } \\
\text { pocket, waist) }\end{array}$ & $\begin{array}{l}\text { Semisupervised } \\
\text { learning }\end{array}$ & $85.3 \%(S E), 90.5 \%(S P)$ & Undisclosed \\
\hline [33] & Detection & $\begin{array}{l}\text { Accelerometer } \\
\text { (chest, waist, thigh) }\end{array}$ & Threshold & $72.22 \%(S E), 73.78(S P)$ & SMS \\
\hline [34] & Detection & $\begin{array}{l}\text { Accelerometer \& } \\
\text { gyroscope (hand, } \\
\text { pocket) }\end{array}$ & Threshold & $80 \%(S E), 96.25 \%(S P), 85 \%(A C)$ & Undisclosed \\
\hline [41] & Detection & $\begin{array}{l}\text { Accelerometer } \\
\text { \& Wi-Fi module } \\
\text { (waist) }\end{array}$ & $\begin{array}{l}\text { DT, SVM, NB, } \\
\text { RSSI }\end{array}$ & $\begin{array}{l}100 \% \& 75.8 \%(P R \& R C \\
\text { for DT); } 99.81 \% \& 75.43 \%(P R \& \\
R C \text { for } S V M) ; 98.67 \% \& 73.20 \%\end{array}$ & $\begin{array}{l}\text { SMS (name, time, } \\
\text { location) }\end{array}$ \\
\hline
\end{tabular}




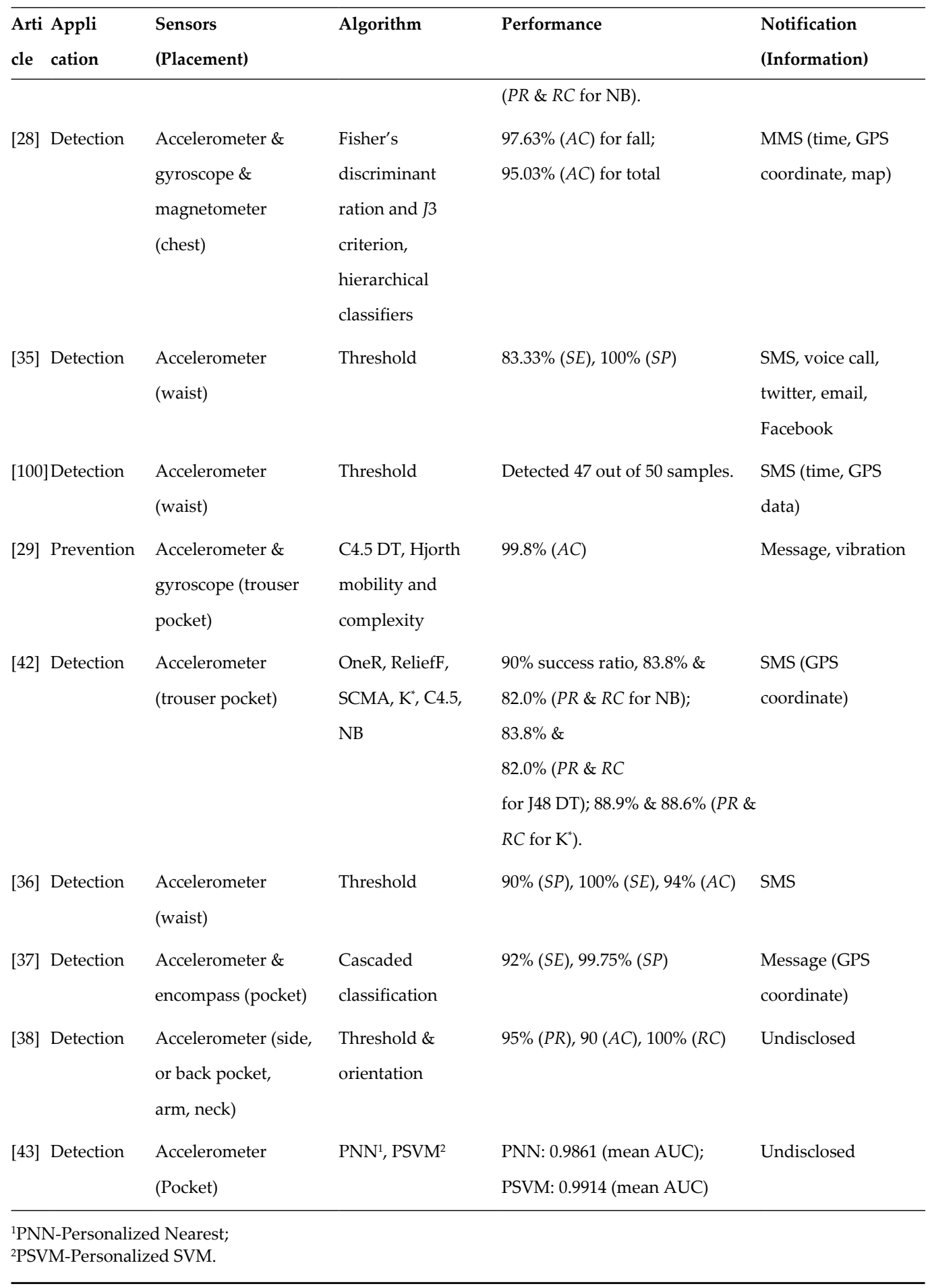

Table 1. Smartphone-based fall detection and prevention systems. 
The most common sensor used in fall detection and prevention was the accelerometer, followed by the gyroscope (Table 1). In most of the studies, threshold-based algorithm was adopted for fall detection due to its low complexity. The most commonly used feature for threshold-based algorithm is the magnitude vector of acceleration signal:

$$
\left|A_{T}\right|=\sqrt{\left|A_{x}\right|^{2}+\left|A_{y}\right|^{2}+\left|A_{z}\right|^{2}}
$$

where $A_{x}, A_{y, y}$ and $A_{z}$ represent accelerometer signals of the $x$-, $y$-, and $z$-axis, respectively. The threshold value could be predefined (fixed) or adaptive (changed with user-provided physiological data, such as height, weight).

The surge in computing power has fashioned a foundation for complex machine-learning classification algorithms for fall detection and prevention to be implemented in smartphones. The classification algorithms used in the processing phase vary considerably across systems. Yavuz et al. [25] utilized DWT and achieved a better true-positive (TP) performance while decreasing the false positives (FP) when compared to threshold-based algorithm. Zhao et al. [26] implemented three machine-learning algorithms - namely C4.5 DTC, NB, and SVM and compared their performances based on recognition accuracy. Fahmi et al. [27] designed a semisupervised algorithm to detect a genuine fall event with smartphone. He and $\mathrm{Li}$ [28] employed a combined algorithm of Fisher's discriminant ratio (FDR) criterion and J3 criterion for feature selection and hierarchical classifiers to recognize 15 activities including fall events. Majumder et al. [29] applied Hjorth mobility and complexity to identify high-risk gait patterns, hence developed a fall prevention system called iPrevention.

Once a fall event is detected, the systems send out notifications including audible alarms, vibrations, automatic voice calls, short message service (SMS), multimedia messaging service (MMS), E-mails, Twitter messaging, etc., (Table 1). Notification messages may contain information regarding time and location (GPS coordinates or Google Map).

\subsubsection{Performance evaluations}

There is no uniform standard for outcome evaluations of fall detection or prevention systems now. The outcomes are often represented by four possible situations [24,30]: $T P$, a fall occurred and was correctly detected; $F P$, the system declared a fall that did not occur; true negative (TN), a fall-like event was not misclassified as a fall event; false negative (FN), a fall occurred, but the system missed it. The reliability of systems is usually evaluated based on the following parameters: sensitivity $(S E)=T P /(T P+F N)$, which is the ratio of fallers correctly classified as fall event [27, 31-34]; specificity $(S P)=T N /(T P+F N)$, which is the ratio of fall-like events correctly classified as nonfallers [35-38]; accuracy $=(T P+T N) /(T P+F P+F N+T N)$, which is the ratio of true results in the whole data set $[26,28,29,39]$. Some works measured the performance in a different way; they utilized precision $=(\cap) /$ and recall - namely, the number of correct results divided by the total outputs - as the performance indexes [40-42]. Some other works evaluated the proposed system by measuring the area under the receiver operating characteristic curve (AUC), where the curve represented SE versus FN [43]. 


\subsubsection{Limitations and challenges}

Despite the expanding body of evidence to support the use of smartphones for fall detection and prevention, it is important to recognize the limitations in this area of science. The prominent weakness is problems induced by the limited battery life of the smartphone. The rate at which the smartphone's battery is consumed is dependent on both internal and external factors. Internal factors are built-in sensor dependent, including the sampling rate and resolution mode. High-resolution mode can dramatically increase the rate of power consumption. External factors are related to the number of sensors used, data recording time, and complexity of the algorithms. Mellone et al. [6] showed that a battery could power a smartphone (Samsung Galaxy S II) for $30 \mathrm{~h}$ with only one sensor used and $16 \mathrm{~h}$ with three sensors activated. Majumder et al. [29] reported that a fully charged battery can only power an iPhone for $3 \mathrm{~h}$ at the most, when running a machine learning algorithm. Energy efficiency will continue to be an important criterion when choosing the algorithm, unless advancements in battery technology could lead to higher density energy storage.

\begin{tabular}{|c|c|c|c|}
\hline Model & Sensors & Dynamic ranges & Resolution \\
\hline \multirow[t]{4}{*}{ Samsung S4 } & Accelerometer & $\pm 2 \mathrm{~g}$ & $\pm 0.001 \mathrm{~ms}^{-2}$ \\
\hline & Gyroscope & $\pm 500 \% \mathrm{~s}$ & $\pm 0.057^{\circ} / \mathrm{s}$ \\
\hline & Magnetometer & $\pm 1200 \mu \mathrm{T}$ & $\pm 0.15 \mu \mathrm{T}(\mathrm{x} / \mathrm{y}$ axis $) \pm 0.25 \mu \mathrm{T}$ (z axis) \\
\hline & Barometer & $300-1100 \mathrm{hPa}$ & $\pm 1 \mathrm{hPa}$ \\
\hline \multirow[t]{4}{*}{ Samsung S3 } & Accelerometer & $\pm 2 \mathrm{~g}$ & $\pm 0.01 \mathrm{~ms}^{-2}$ \\
\hline & Gyroscope & $\pm 500^{\circ} / \mathrm{s}$ & $\pm 0.015^{\circ} / \mathrm{s}$ \\
\hline & Magnetometer & $\pm 1200 \mu \mathrm{T}$ & $\pm 0.30 \mu \mathrm{T}$ \\
\hline & Barometer & $260-1260 \mathrm{hPa}$ & $\pm 0.24 \mathrm{hPa}$ \\
\hline \multirow[t]{4}{*}{ Galaxy Nexus } & Accelerometer & $\pm 2 \mathrm{~g}$ & $\pm 0.61 \mathrm{~m} \cdot \mathrm{s}^{-2}$ \\
\hline & Gyroscope & $\pm 2000^{\circ} / \mathrm{s}$ & $\pm 0.06^{\circ} / \mathrm{s}$ \\
\hline & Magnetometer & $\pm 800 \mu \mathrm{T}$ & $\pm 0.15 \mu \mathrm{T}(x / y$ axis $) \pm 0.30 \mu \mathrm{T}$ ( $z$ axis $)$ \\
\hline & Barometer & $300-1100 \mathrm{hPa}$ & $\pm 1 \mathrm{hPa}$ \\
\hline \multirow[t]{3}{*}{ HTC One } & Accelerometer & $\pm 4 \mathrm{~g}$ & $\pm 0.039 \mathrm{~m} \cdot \mathrm{s}^{-2}$ \\
\hline & Gyroscope & $\pm 2000^{\circ} / \mathrm{s}$ & $\pm 0.06^{\circ} / \mathrm{s}$ \\
\hline & Magnetometer & $\pm 4900 \mu \mathrm{T}$ & $\pm 0.15 \mu \mathrm{T}$ \\
\hline \multirow[t]{4}{*}{ LG Nexus 4} & Accelerometer & $\pm 4 \mathrm{~g}$ & $\pm 0.001 \mathrm{~m} \cdot \mathrm{s}^{-2}$ \\
\hline & Gyroscope & $\pm 500^{\circ} / \mathrm{s}$ & $\pm 0.015^{\circ} / \mathrm{s}$ \\
\hline & Magnetometer & $\pm 4912 \mu \mathrm{T}$ & $\pm 0.15 \mu \mathrm{T}$ \\
\hline & Barometer & $0-1100 \mathrm{hPa}$ & $\pm 1 \mathrm{hPa}$ \\
\hline \multirow[t]{3}{*}{ iPhone 5/5s } & Accelerometer & $\pm 8 \mathrm{~g}$ & $\pm 0.002 \mathrm{~m} \cdot \mathrm{s}^{-2}$ \\
\hline & Gyroscope & $\pm 2000^{\circ} / \mathrm{s}$ & $\pm 0.06^{\circ} / \mathrm{s}$ \\
\hline & Magnetometer & $\pm 1200 \mu \mathrm{T}$ & $\pm 0.30 \mu \mathrm{T}$ \\
\hline \multirow[t]{4}{*}{ iPhone 6/6plus } & Accelerometer & $\pm 8 \mathrm{~g}$ & $\pm 0.002 \mathrm{~m} \cdot \mathrm{s}^{-2}$ \\
\hline & Gyroscope & $\pm 2000^{\circ} / \mathrm{s}$ & $\pm 0.06^{\circ} / \mathrm{s}$ \\
\hline & Magnetometer & $\pm 4900 \mu \mathrm{T}$ & $\pm 0.15 \mu \mathrm{T}$ \\
\hline & Barometer & $300-1100 \mathrm{hPa}$ & $\pm 0.16 \mathrm{hPa}$ \\
\hline
\end{tabular}

Table 2. Specifications of the built-in sensors in some currently available smartphones. 
The resolution and dynamic range of the built-in inertial sensors vary considerably across smartphones (Table 2). Acceptable dynamic ranges for accelerometers from $\pm 4 \mathrm{~g}$ to $\pm 16 \mathrm{~g}$ ( $\mathrm{g}$ $=9.81 \mathrm{~ms}^{-2}$ ) have been reported for fall detection applications $[35,44]$, which is beyond the typical dynamic ranges of most currently available smartphone accelerometers $( \pm 2 \mathrm{~g})$. The newest high-end commercially available smartphones (i.e., iPhone 6/6plus) have accelerometers with higher dynamic ranges $( \pm 8 \mathrm{~g})$, making these devices more suitable for detecting falls.

In addition, a major limitation of using smartphones to detect fall is that it requires the smartphone to be consistently located and/or oriented in the same position. It may be difficult to do so due to the multifunctional nature of smartphones. Habib et al. [45] showed that individuals may not place their smartphone on their body whilst at home so, that being said, it may limit the ability of the smartphone to detect fall in the home. At present, smartphone placement and usability issues should be handled carefully.

\subsection{Functional activities assessment for Parkinson' s disease}

For a population that is shifting toward an older age range, PD is categorized in the most common chronic neurological disorders. PD is characterized as an age-related neurodegenerative disorder due to the loss of dopamine-producing brain neurons, an important neurotransmitter involved in the regulation of movement. Progressive tremor, bradykinesia, hypokinesia, rigidity, and impaired postural control are common and disabling features of most patients with PD. The motor disorder analysis is generally performed in a clinical setting to provide subjective assessments. However, the motor fluctuation measurements in the clinical setting might not precisely reveal the real functional disability experienced by patients in natural environment. With the existing and on-going advance developments in MEMS technologies, continuous, unsupervised, objective and reliable monitoring of mobility and functional activities in natural environments is now possible, allowing for long-term, homebased intensive care and improvement of the individual healthcare and well being.

\subsubsection{Wearable inertial sensor-based methods}

A growing body of literature studied the use of wearable inertial sensors to detect and quantify tremor, bradykinesia and levodopa-induced dyskinesia (LID) in PD populations. Most studies were focused on finding the features derived from sensor signals that are effective for detecting differences between people with PD and healthy controls [46-49]. Results from these studies presented a range of outcomes which included the root mean square (RMS) of accelerations, the deviation of acceleration, step or stride variability, gait regularity or symmetry, FFT features, entropy and many more. Only a few works established and validated motion analysis methods or systems that used pattern recognition algorithms to classify motor signs of functional activities impairment in PD. Table 3 provides a detailed comparison of these different methodological approaches. Leave-one-subject-out method and cross-validation method were used for validating the approaches. 


\begin{tabular}{|c|c|c|c|c|c|}
\hline Arti & $\begin{array}{l}\text { Sensors } \\
\text { (Placement) }\end{array}$ & Algorithm & Features & Performance & Validity \\
\hline 57 & $\begin{array}{l}\text { Accelerometer \& } \\
\text { gyroscopes } \\
\text { (shanks, trunk) }\end{array}$ & $\begin{array}{l}\text { Logistic regression } \\
\text { model with } \\
\text { Mamdani } \\
\text { fuzzy rule-based } \\
\text { classifier }\end{array}$ & $\begin{array}{l}\text { Duration of transition, } \\
\text { amplitude, range, } \\
\text { minimum value, } \\
\text { maximum value, } \\
\text { relative time. }\end{array}$ & $\begin{array}{l}\text { Differentiate between } \\
\text { sit-to-stand and } \\
\text { stand-to-sit transitions } \\
\text { with } 83.8 \% \text { SE. }\end{array}$ & $\begin{array}{l}\text { Cross- } \\
\text { validation }\end{array}$ \\
\hline 52 & $\begin{array}{l}\text { Accelerometer } \\
\text { (limbs, trunk, belt) }\end{array}$ & $\begin{array}{l}\text { KNN, Parzen, } \\
\text { Parzen density, } \\
\text { binary decision tree, } \\
\text { Bpxnc, SVM. }\end{array}$ & RMS, range. & $\begin{array}{l}\text { Detect the severity of } \\
\text { bradykinesia with an } \\
A C \text { range of } 70-86 \% \\
\text { depending on the } \\
\text { algorithm. }\end{array}$ & Cross validation \\
\hline 55 & $\begin{array}{l}\text { Accelerometer \& } \\
\text { gyroscopes } \\
\text { (wrist, thigh, foot, } \\
\text { sternum) }\end{array}$ & DT & $\begin{array}{l}\text { IAA }^{1} \text { and change in thing } \\
\text { inclination per second } \\
\text { (thigh); differentiate an } \\
\text { upright position from a } \\
\text { horizontal one (trunk, } \\
\text { thigh); } \text { AAM }^{2} \text { (wrist); } \\
\text { peak detection (foot). }\end{array}$ & $\begin{array}{l}98.9 \% \text { (overall } A C \text { ); Detect } \\
\text { significant changes in rest } \\
\text { and kinetic tremor with an } \\
A C \text { range from } 78.8-94.1 \% \\
\text { depending on the activity } \\
\text { performed. }\end{array}$ & $\begin{array}{l}\text { Leave-one- } \\
\text { subject-out } \\
\text { method }\end{array}$ \\
\hline 53 & $\begin{array}{l}\text { Accelerometer \& } \\
\text { gyroscopes (shoes) }\end{array}$ & $\begin{array}{l}\text { Boosting with } \\
\text { decision stump, } \\
\text { LDA and SVM with } \\
\text { linear } \\
\text { and RBF kernel. }\end{array}$ & $\begin{array}{l}\text { Step duration, entropy, } \\
\text { variance, energy } \\
\text { ratio, } 0.5-3 \mathrm{~Hz} \text { energy } \\
\text { band. }\end{array}$ & $\begin{array}{l}\text { Classify patients with } \\
\text { PD and healthy controls } \\
\text { using LDA with } \\
88 \% \text { SE and } \\
86 \% S P ; \\
\text { Distinguish mild from } \\
\text { severe gait } \\
\text { impairments with } \\
100 \% S E \text { and } S P \text {. }\end{array}$ & $\begin{array}{l}\text { Leave-one- } \\
\text { subject-out } \\
\text { method }\end{array}$ \\
\hline 54 & $\begin{array}{l}\text { Accelerometer \& } \\
\text { gyroscopes (shoes) }\end{array}$ & $\begin{array}{l}\text { LDA, AdaBoost, } \\
\text { SVM with linear } \\
\text { and RBF } \\
\text { kernel. }\end{array}$ & $\begin{array}{l}\text { Single steps, } \\
\text { complete gait sequence, } \\
\text { FFT of gait } \\
\text { sequences. }\end{array}$ & $\begin{array}{l}\text { Distinguish patients with } \\
\text { PD from controls with an } \\
\text { overall } A C \text { of } 81 \% \text {; } \\
\text { Differentiate between } \\
\text { Hoehn and } \\
\text { Yahr III patients to controls } \\
\text { with } \\
91 \% A C \text {. }\end{array}$ & Cross validation \\
\hline 51 & Accelerometer & $\begin{array}{l}\text { Supervised } \\
\text { machine-learning } \\
\text { models }\end{array}$ & $\begin{array}{l}\text { FFT features: } \\
P_{\text {total }} \text { between } 0.5-8 \mathrm{~Hz} \text {, } \\
P_{\text {locomotion }}\end{array}$ & $94.94 \%(A C), 94 \%(S P)$ & Undisclosed \\
\hline
\end{tabular}




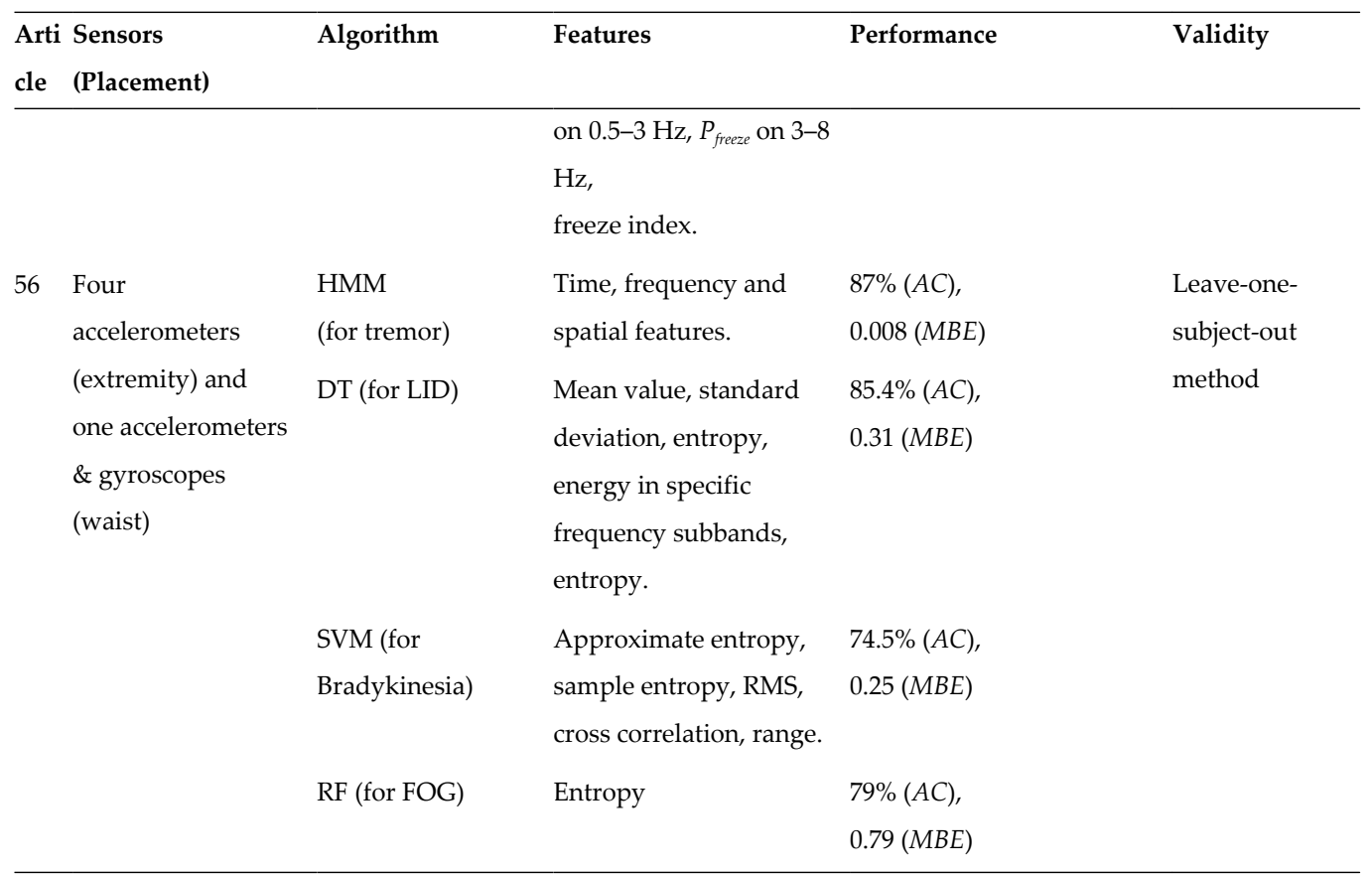

${ }^{1}$ IAA-Integrals of the absolute value of the accelerometer output;

${ }^{2} \mathrm{AAM}$-active arm movement.

Table 3. Wearable inertial sensor-based methods for Parkinson's disease.

These methods were founded on various machine-learning classifiers. Salarian et al. [50] applied a fuzzy classifier combined with a logistic regression model to categorize sit-to-stand (STS) transitions. Three inertial sensors were used to detect the kinematic features of the trunk movements during the transitions. Compared to video recordings reference system, it demonstrated the ability to differentiate sit-to-stand from stand-to-sit with a sensitivity of 83.3\% in PD and 94.4\% in controls. Another study by Mazilu et al. [51] presented the GaitAssist system to detect FoG with two ankle-mounted IMUs, streaming data via Bluetooth to an Android phone. Supervised machine-learning models, trained offline using several FFT features, were utilized with an overall FoG hit rate of $94.94 \%$ and a specificity of $94 \%$.

Some studies, on the other hand, evaluated various classifiers to identify ambulatory activities. Cancela et al. [52] implemented six activity recognition algorithms, - namely KNN, Parzen, Parzen density, DTC, Bpxnc, and SVM, to detect the severity of bradykinesia and found out that the SVM revealed the best classification results with $86 \%$ sensitivity by using two features (RMS and range). Barth et al. [53] employed three classifiers, including boosting with decision stump, LDA and SVM, to measure gait patterns in PD to distinguish mild and severe gait impairment. The system was able to classify PDs and controls with $88 \%$ sensitivity and $86 \%$ specificity using the LDA classifier based on three activities - namely $10 \mathrm{~m}$ walking, heel-toe tapping, and foot circling. It reached a 100\% sensitivity and specificity to distinguish mild from severe using optimal features - namely step duration, entropy, variance, energy ratio, and a 
0.5-3 Hz energy band. Klucken et al. [54] used 694 features and three pattern recognition algorithms (LDA, AdaBoost, and SVM) to categorize patients in different stages. The developed eGaIT system, which consists of accelerometers and gyroscopes attached to shoes, was able to successfully distinguish patients from controls with an overall classification rate of $81 \%$. The classification accuracy increased to $91 \%$ for more severe motor impairment or H\&Y III patients.

Besides evaluating classifier, other works provided a complete motor assessment by analyzing the severity of several PD motor symptoms. Zwartjes et al. [55] used DTC to analyze motor activity and the severity of tremor, bradykinesia, and hypokinesia in patients with PD at three different levels of deep brain stimulation (DBS) treatment. An overall accuracy of $99.3 \%$ was achieved. Tzallas et al. [56] developed a system called PERFORM, using four accelerometers at each extremity and one accelerometer/gyroscope on the waist, to evaluate and quantify various symptom severity. The severity and type of tremor were classified by HMM classifier based on several time and frequency domain characteristics with $87 \%$ accuracy and 0.008 mean absolute error $(M B E)$. The C4.5 DCT algorithm was used for LID detection and severity classification with an accuracy of $85.4 \%$ and a $M B E$ of 0.31 . A SVM classifier with optimum features (including approximate entropy, across correlation value, and range value) achieved $74.5 \%$ accuracy and $0.25 \mathrm{MBE}$ for bradykinesia assessment. The detection of FoG was realized by an RFs classifier using the boot strap technique with $79 \%$ accuracy and $0.79 M B E$. The PERFORM system also included a local base unit and a centralized hospital unit, allowing for the continuous remote monitoring and management of patients with PD.

\subsubsection{Smartphone-based solutions}

Given that smartphones are ubiquitous and have advanced built-in inertial sensors, research has recently sought to develop smartphone-based systems for PD assessments, which can keep the patient "connected" to his physician on a daily basis. The important features of existing smartphone-based solutions are summarized and compared in Table 4.

\begin{tabular}{|c|c|c|c|c|c|}
\hline $\begin{array}{l}\text { Arti } \\
\text { cle }\end{array}$ & $\begin{array}{l}\text { Sensors } \\
\text { (Placement) }\end{array}$ & Features & Algorithm & Performance & Validity \\
\hline 57 & $\begin{array}{l}\text { Accelerometer } \\
\text { (undisclosed) }\end{array}$ & $\begin{array}{l}\text { Mean, } \mathrm{SD}^{1}, 25 \text { th percentile, } \\
\text { 75th percentile, } \mathrm{IQR}^{2} \text {, median, } \\
\text { mode, range, skewness, kurtosis, } \\
\text { mean squared energy, entropy, cross } \\
\text { correlation, mutual information, cross } \\
\text { entropy, DFA }{ }^{3} \text {, instantaneous changes in } \\
\text { energy, auto-regression coefficient, zero- } \\
\text { crossing rate, dominant frequency } \\
\text { component, radial distance, polar angle, } \\
\text { azimuth angle. }\end{array}$ & RFs & $\begin{array}{l}\text { Discriminate patients } \\
\text { with PD from controls } \\
\text { with an average } S E \text { of } \\
98.5 \% \text { and average } S P \\
\text { of } 97.5 \% \text {. }\end{array}$ & $\begin{array}{l}\text { Cross } \\
\text { validation }\end{array}$ \\
\hline
\end{tabular}




\begin{tabular}{|c|c|c|c|c|c|}
\hline $\begin{array}{l}\text { Arti } \\
\text { cle }\end{array}$ & $\begin{array}{l}\text { Sensors } \\
\text { (Placement) }\end{array}$ & Features & Algorithm & Performance & Validity \\
\hline 8 & $\begin{array}{l}\text { Accelerometer \& } \\
\text { gyroscope } \\
\text { \& touch screen \& } \\
\text { microphone }\end{array}$ & $\begin{array}{l}\text { Average frequencies, } \\
\text { RMS angular velocity, } \\
\text { speed of movement, } \\
\text { amplitude of dominant } \\
\text { rhythm, CV }{ }^{4} \text {, PSD, } \\
\text { RMS values. }\end{array}$ & SVM, RFs & $\begin{array}{l}94.5 \%(A C),> \\
0.85(\mathrm{AUC})\end{array}$ & $\begin{array}{l}\text { Cross } \\
\text { validation }\end{array}$ \\
\hline 58 & $\begin{array}{l}\text { Accelerometer } \\
\text { (hips) }\end{array}$ & $\begin{array}{l}\text { Freeze index, energy, } \\
\text { cadency variation, the ratio of the } \\
\text { derivative } \\
\text { of the energy. }\end{array}$ & $\begin{array}{l}\text { fuzzy Logic } \\
\text { algorithm }\end{array}$ & $89 \%(S E), 97 \%(S P)$ & Undisclosed \\
\hline 60 & $\begin{array}{l}\text { Accelerometer \& } \\
\text { gyroscope } \\
\text { (hand) }\end{array}$ & $\begin{array}{l}\text { Magnitude of acceleration and } \\
\text { rotational velocity, SD of acceleration, } \\
\text { mean magnitude of rotation rate. }\end{array}$ & BagDT & $\begin{array}{l}82 \% \text { ( } A C \text { in patients), } \\
90 \% \text { ( } A C \text { in controls) }\end{array}$ & $\begin{array}{l}\text { Cross } \\
\text { validation }\end{array}$ \\
\hline 59 & $\begin{array}{l}\text { Accelerometer \& } \\
\text { gyroscope } \\
\text { (ankle, trouser } \\
\text { pocket, waist, } \\
\text { chest pocket) }\end{array}$ & $\begin{array}{l}\text { Mean, variance, SD, entropy, } \\
\text { energy, Fi, power, RMS, interquantile } \\
\text { range, kurtosis, frequency domain } \\
\text { features. }\end{array}$ & $\begin{array}{l}\text { AdaBoost. } \\
\text { M1, }\end{array}$ & $\begin{array}{l}86 \% \& 84 \% \& 81 \% \\
\text { (SE at the waist, in the } \\
\text { trouser pocket and at the } \\
\text { ankle, respectively). }\end{array}$ & $\begin{array}{l}\text { Cross } \\
\text { validation }\end{array}$ \\
\hline 61 & $\begin{array}{l}\text { Accelerometer } \\
\text { (hand or ankle) }\end{array}$ & $\begin{array}{l}\text { Hand tremor: power between } \\
4-6 \mathrm{~Hz} \text {, fraction of power, } \\
\text { power ration in } 3.5-15 \mathrm{~Hz} \text { to } 0.15- \\
3.5 \mathrm{~Hz} \text {, total power from } 0- \\
20 \mathrm{~Hz} \text {, peak power, average } \\
\text { acceleration.Gait: average gait } \\
\text { cycle, average stride length, average } \\
\text { walking speed, average acceleration, the } \\
\text { number of steps and the speed } \\
\text { of turning } 360^{\circ} .\end{array}$ & SVM & $\begin{array}{l}77 \% \& 82 \% \\
\text { (SE \& AC for hand } \\
\text { resting tremor detection), } \\
89 \% \& 81 \% \text { (SE \& } A C \text { for } \\
\text { gait } \\
\text { difficulty detection). }\end{array}$ & $\begin{array}{l}\text { Cross- } \\
\text { validation }\end{array}$ \\
\hline $\begin{array}{l}{ }^{1} \mathrm{SD}-\mathrm{S} \\
{ }^{2} \mathrm{IQR} \\
\mathrm{I} \mathrm{DFA} \\
{ }^{4} \mathrm{CV}-\end{array}$ & $\begin{array}{l}\text { Standard Deviatio } \\
\text {-Inter-quartile ran } \\
\text { A-Extent of randor } \\
\text { Coefficient of vari }\end{array}$ & $\begin{array}{l}\text { ess; } \\
\text { on. }\end{array}$ & & & \\
\hline
\end{tabular}

Table 4. Smartphone-based solutions for Parkinson's disease.

These smartphone-based solutions use the signal from the integrated accelerometers or gyroscopes in consumer-grade smartphones and in conjunction with machine learning 
algorithms to quantify key movement severity symptoms (i.e., bradykinesia, FoG, hand tremor) and discriminate patients with PD from controls. Arora et al. [57] using an RFs classifier with a range of different time and frequency features of the acceleration time series, achieved $98.5 \%$ average sensitivity and $97.5 \%$ average specificity in differentiating patients with PD from controls. Another study by Printy et al. [8] developed an iPhone application using embedded hardware of a smartphone, including gyroscope, accelerometer, capacitive touch screen, microphone, and the front-facing camera, and a SVM algorithm to discriminate between more severe and less severe bradykinesia with an accuracy of $94.5 \%$. The accurate classification of bradykinesia severity was not achieved in this work.

Some studies, on the other hand, aimed to detect FoG, a common motor impairment to suffer an inability to walk in PD patients. Pepa et al. [58] presented a smartphone-integrated accelerometer-based system to detect the FoG. They developed a linguistic fuzzy modelling (LFM) with Mamdani rule structure by fusing the information of freeze index, energy sum, cadency variation, and energy derivative ratio with a sensitivity of $89 \%$ and a specificity of $97 \%$. In the smartphone-based system for FoG detection proposed by Kim et al. [59], data are derived from both embedded accelerometer and gyroscope. An AdaBoost.M1 classifier using several time and frequency domain features showed the best sensitivity of $86 \%$ at the waist, $84 \%$ and $81 \%$ in the trouser pocket and at the ankle, respectively.

Two other studies used the smartphone to measure the hand tremor symptom. Kostikis et al. [60] utilized a Breiman's RFs to classify upper limb tremor and achieved 82\% accuracy in patients with PD and 90\% accuracy in controls, with 0.9435 AUC. The feature metrics were derived from the acceleration vector and rotational velocity vector when patients performed two MDS-UPDRS postures-namely "Extended" and "Rest". Pan et al. [61] designed a prototype mobile cloud-based mHealth app on the Android platform called "PD Dr" to measure the severity of both hand resting tremor and gait difficulty, using the built-in accelerometer. The SVM classifier was used with a sensitivity of $77 \%$ and a specificity of $82 \%$ for hand resting tremor detection, and $89 \%$ sensitivity and $81 \%$ specificity in gait difficulty detection. Lasso regression approach was built to estimate the symptom severity. There was a strong correlation with PD disease stage $(r=0.81)$, hand resting tremor severity $(r=0.74)$, and gait difficulty severity $(r=0.79)$.

\subsubsection{Limitations and challenges}

Given the relatively small number of classifier-based studies in this area and the wide variety of research questions addressed, ranging from activity classification to different symptom severity level assessment, it is currently difficult to address which classifier is ideal in PD populations for mHealth. Meanwhile, the accuracy levels of the classifiers were generalized on small sample sizes ranging from 5 to 27 subjects [50-53, 55-61]. Only one out of these studies enlisted a relatively larger sample of 92 patients with PD and 81 controls [54]. It is therefore important to evaluate the performance of classifiers according to larger, homogeneous population sets. Moreover, It is difficult to evaluate how effective or well performing of a classifier, because its performance also depends on the selected features and the properties of 
wearable sensors (i.e., resolution, noise level). Therefore, the effectiveness of wearable inertialbased methods in mHealth regimens still has to be further examined.

Using a smartphone for PD management seems promising in mHealth, yet there are the same issues as those in smartphone-based fall detection systems. The performance and usability of smartphone-based solutions remain limited by the relatively lower quality of embedded sensors, and the limited battery life of smartphones, as well as the need to wear the smartphone in a fixed position.

Only very few studies provided a complete overall assessment of PD [55, 56]. Most of the existing solutions with external wearables sensors or the smartphones built-in sensors have limited focus on a particular motor symptom, and lack the important characteristic for PDmonitoring services, such as long-term recording, qualitative and quantitative assessments. Therefore, more effort should be put into providing a complete tool that comprises the most common PD motor disabilities, such as tremor, bradykinesia, LID, and FoG.

\section{Wearable solutions for cardiac monitoring}

Heart disease, a worldwide chronic condition, is the leading cause of death in many countries. There are various parameters that capture the characteristics of cardiac activity. Among them, resting HR is one of the simplest, yet most informative, cardiovascular parameters. Heart rate variability (HRV) has been identified as a prognostic marker for cardiac abnormalities. Although the "gold standard" for assessing cardiac abnormalities remains a 12-lead Holter, a large number of innovative and versatile wearable devices, including chest strips, wrist-worn devices, earphones, and smart clothing, have emerged as alternatives, which can provide the opportunity for prolonged, continuous cardiac rhythm tracking in real-world environments. Today, several portable devices are commercially available for determining cardiac status via a single-lead ECG, either by wearing a patch for continuous rhythm tracking [5] or using a smartphone for rhythm capture whenever needed. If multiple leads are needed to increase the accuracy of arrhythmia diagnosis, there are smart shirts that allow for 3- to 12-lead ECG monitoring [2].

\subsubsection{ECG patch monitor}

An ECG patch monitor (EPM) attached to the skin on the chest via an adhesive carrier generally consists of electrodes, a signal-processing subsystem, and a wireless data transmission subsystem. The two most representative examples of single-lead EPM are the Zio Patch recorder [62] and NUVANT PiiX event recorder [63].

The Zio Patch can be categorized as a single-lead Holter with a memory of up to 14 days of stored rhythms. The Zio Patch has a frequency response of $0.15-34 \mathrm{~Hz}$, an input impedance greater than $3 \mathrm{M} \Omega$, a differential range of $\pm 1.65 \mathrm{mV}$, and a resolution of 10 bits. There is a button on the patch allowing the patient to mark a symptomatic episode. Once the recording period is complete, the patient mails the patch back to iRhythm Clinical Centers (iCC), where 
the recorded ECG data will be processed and analyzed by the Zio ECG Utilization Service (ZEUS) system with the capability of detecting up to 10 categories of rhythms. Rosenberg et al. [64] compared the Zio Patch with a 24-h Holter monitor in 74 consecutive patients. The mean wear time was $10.8 \pm 2.8$ days. Compared with the first $24 \mathrm{~h}$ of monitoring, there was an excellent agreement between the Zio Patch and Holter in identifying atrial fibrillation (AF) events. In another study, Turakhia et al. [65] evaluated the performance of the Zio Patch in 26,751 consecutive patients. The Zio Patch was well tolerated, with a mean monitoring period of $7.6 \pm 3.6$ days, and the median analyzable time was achieved $99 \%$ of the total wear time. The overall diagnostic yield of the Zio Patch was $62.2 \%$ for any arrhythmia and $9.7 \%$ for any symptomatic arrhythmia.

The NUVANT system consists of a $15-\mathrm{cm}$ adhesive patch named the PiiX, a wireless data transmitter called zLink ${ }^{\circledR}$ and a patient trigger magnet [66]. The PiiX sensor samples the ECG signal at $200 \mathrm{~Hz}$ with a resolution of 10 bits. The PiiX patch that is integrated with multiple sensors cannot only continuously monitor many physiological parameters, including $\mathrm{HR}$, HRV, RR, fluid status, body position, activity, and body temperature, but also automatically identify nonlethal cardiac arrhythmias [67], including bradycardia $\leq 40 \mathrm{bpm}$, pause $\geq 3$ seconds, atrial fibrillation, ventricular tachycardia or ventricular fibrillation, tachycardia HR $>130 \mathrm{bpm}$, a-Fib/a-Flutter (all rates), heart block, and fall-associated arrhythmia. When an arrhythmia is detected, the PiiX sends the data to zLink via Bluetooth. The zLink then transmits the data to the monitoring center or a caregiver using cellular communication. The clinical experience of the NUVANT/PiiX is currently lacking. One study with regard to patient compliance of the NUVANT system has shown no reduction in the on-patient longevity or performance of the device [66].

The ECG patch capable of recording up to three lead signals is on its way for the public's use [69]. A three-lead PEM, developed by IMEC and the Holst Center [70], integrates an ultra-low power ECG chip and a Bluetooth Low Energy (BLE) ratio, allowed to run continuously for 1 month on a $200 \mathrm{mAh}$ Li-Po battery. The IMEC patch can monitor not only three channels ECG, but also the contact impedance, providing real-time information on the sensor contact quality that is important for aiding in filtering motion artifacts. The recording data are processed and analyzed locally on ECG SoC to reduce motion artifacts using adaptive filtering or principal component analysis and compute beat-to-beat HR based on discrete or continuous wavelet transforms.

PEM is considered to be a promising technology for its unobtrusive, wireless, and long-term recording capabilities. Further studies are necessary to examine the sensitivity and specificity of the recordings and long-term impact of the use of EPM in AF.

\subsubsection{Smartphone-based monitor}

Recently, a flood of smartphone-based monitors has been designed for heart rhythm monitoring, which falls into two broad categories, namely smartphone-only and smartphone with external sensors. 
The most representative in the smartphone-only category is the camera-based apps, which measure the cardiovascular blood volume pulse (BVP) generated by repeated, rhythmic heart contractions (that can be registered by photoplethysmogram (PPG)) using the embedded camera in the smartphone. Researchers have shown that pulse rhythm and phase information regarding the BVP waveform can be deduced from the brightness change in the red (R), green (G), or blue (B) channels [68]. Several approaches to deal with the motion artifacts in the camera signals have been proposed to improve the measurement accuracy. The MIT laboratory used the blind source separation (BSS) to separate RGB color channels into independent components, which demonstrated its ability to extract the HR with digital, off-the-shelf webcams in normal ambient lighting in the presence of a limited range of motion artifacts [71,72] Fang et al. [73] uncovered the underlying PPG signal from a single-channel recording using the dynamic embedding technique followed by ICA. This method relies only on the inherent temporal dynamic of the single-channel signal, making it suitable for all kinds of cameras. Thus, the built-in camera in smartphones could easily double as a heart rate monitor. Camerabased apps were subsequently brought into being based on these methods. Azumio's Instant Heart Rate app [74] is one of the most popular health apps on the market, which uses the smartphone's built-in camera and flash to compute HR and update the number through placing the tip of one's finger on the camera for about $10 \mathrm{sec}$. Many apps with advanced algorithms have also been launched for noncontact measurement of heart and respiration rate, such as a Vital Signs Camera app developed by Philips Innovation [75], extracting HR from the changes in color of the face and RR from the motion of the chest.

On the other hand, some external sensors, wired or wirelessly connecting with a smartphone, are used for sensing cardiac signals. These sensors transmit raw data to the smartphone for processing and analyzing based on computational algorithms embedded on smartphones. One example of these significant achievements is the most recent FDA approved AliveCor Heart Monitor platform [76], which supports both iPhone and Android platforms. It has been designed as a smartphone case with finger electrodes that snaps onto the back of a smartphone to measure the single-channel ECG and wirelessly communicate with the app on the phone. With secure storage in the cloud, the data can be retrieved confidentially by users themselves or their physician anytime, anywhere.

Documented clinical outcomes in the scientific literature with smartphone-based monitors is lacking at present. More work still needs to be done to examine the accuracy and sensitivity of the smartphone-based monitors.

\section{Wearable solutions for other physiological parameters}

There are no satisfactory wearable solutions that can provide continuous, stable, and reliable measurements for blood pressure and blood glucose at this stage [77]. Standard technology to monitor blood pressure requires an inflatable cuff to be pressurized, which may not suitable for continuous monitoring. Several approaches have been proposed for cuffless blood pressure measurement, such as arterial tonometry [78], measuring blood pressure over the radial artery 
by placing a pressure transducer on the wrist to capture the radial pulse waveform, or indirectly estimating blood pressure from pulse wave transit time (PTT) [79-81]. However, their consistency and reliability are still under investigation compared to the conventional method.

Currently, glucose-level measurements usually require a blood sample via the finger-pricking method. The so-called "minimally-invasive" approaches, using a disposable biosensor needle inserted under the skin on the abdomen to derive the glucose level in interstitial fluid, have been developed for continuous blood glucose monitoring. The invasiveness currently required is a high barrier to realize a practical wearable device. Many efforts targeted the field of noninvasive glucose-monitoring (NGM) techniques have been reported. Many NGM approaches - namely reverse iontophoresis [82], impedance spectroscopy [83], electromagnetic sensing [84, 85], optical methods [86-90], and photoacoustic spectroscopy [91]-have been proposed. However, key challenges to apply these technologies to wearable blood glucose monitoring are the inherent lack of specificity behind these technologies, interference from other tissue components, and poor signal to noise ratio. Other studies have aimed to develop a glucose sensor on a contact lens to monitor the glucose level in tear fluid [92-96]. Google Inc. and the University of Washington have announced a prototype of "smart" contact lenses embedded with a fully integrated sensor with signal processing circuits and a wireless coil [96]. A drawback of this technique is the glucose concentration in tears is on the sub-mm level that is almost 10 times lower than the glucose concentration in blood. A microfabricated amperometric glucose sensor, prepared by immobilizing glucose oxidase (GOx) in a titania sol-gel layer [95], can enhance sensitivity at the same level as a glucose sensor can do directly in blood.

\section{Summary}

The wearable technologies highlighted in this chapter can improve the accessibility and convenience of healthcare by bringing clinic and hospital quality monitoring to the point of need. The greatest potential of the continuous and ubiquitous monitoring with wearables might be in enhancing our understanding of the evolving process of poorly defined chronic conditions and allowing for more personalized or precise treatment. However, the performance and usability of current technologies and systems according to larger, homogeneous population sets are currently lacking. The high-quality clinical evidence for the use of wearable systems in mHealth to improve chronic disease management and inpatient care is very limited. Future research should be aimed at high-quality clinical evidence related to the usability, accuracy, and robustness of wearable technologies. In addition, there are still many technical issues and limitations yet to be resolved to realize high robustness and reliability in long-term recordings. These include the lack of a full range of appropriate sensors, susceptibility to motion artifacts, battery life, lack of interoperability, security and privacy issues in data communication, the low reliability and poor specificity of cuffless blood pressure and noninvasive blood glucose-monitoring methods. Despite all the potential hurdles, we envision that there will be further evolvement and improvement in this field in the upcoming years. 


\section{Author details}

Fang Zhao ${ }^{1^{*}}$, Meng $\mathrm{Li}^{1}$ and Joe Z. Tsien ${ }^{1,2}$

*Address all correspondence to: fzhao@augusta.edu

1 Brain and Behavior Discovery Institute and Department of Neurology, Medical College of Georgia, Augusta University, Augusta, Georgia, USA

2 Banna Biomedical Research Institute, Xi-Shuang-Ban-Na Prefecture, Yunnan Province, China

\section{References}

[1] Di Rienzo M., Rizzo F., Parati G., Brambilla G., Ferratini M., Castiglioni P. MagIC system: a new textile-based wearable device for biological signal monitoring applicability in daily life and clinical setting. In: Conference Proceedings IEEE Engineering in Medicine and Biology Society; 2005; Shanghai, China. IEEE; 2005. p. 7167-7169. DOI: 10.1109/IEMBS.2005.1616161.

[2] Lee Y.D., Chung W.Y. Wireless sensor network based wearable smart shirt for ubiquitous health and activity monitoring. Sensor Actuat. B-Chem. 2009;140(2):390-395. DOI: 10.1016/j.snb.2009.04.040.

[3] Jakicic J.M., Winters C., Lagally K., Ho J., Robertson R.J., Wing, R.R. The accuracy of the TriTrac-R3D accelerometer to estimate energy expenditure. Med. Sci. Sports Exerc. 1999;31(5):747-754. DOI: 00005768-199905000-00020.

[4] del Rosario M.B., Redmond S.J., Lovell N.H. Tracking the evolution of smartphone sensing for monitoring human movement. Sensors. 2015;15:18901-18933. DOI: 10.3390/ s150818901.

[5] Lobodzinski S.S. ECG patch monitors for assessment of cardiac rhythm abnormalities. Prog. Cardiovasc. Dis. 2013;56(2):224-229. DOI: 10.1016/j.pcad.2013.08.006.

[6] Mellone S., Tacconi C., Schwickert L., Klenk J., Becker C., Chiari L. Smartphone-based solutions for fall detection and prevention: the FARSEEING approach. Z. Gerontol. Geriatr. 2012;45(8):722-727. DOI: 10.1007/s00391-012-0404-5.

[7] Attal F., Mohammed S., Dedabrishvili M., Chamroukhi F., Oukhellou L., Amirat Y. Physical human activity recognition using wearable sensors. Sensors. 2015;15(12): 31314-31338. DOI: 10.3390/s151229858.

[8] Printy B.P., Renken L.M., Herrmann J.P., Lee I., Johnson B., Knight E., et al. Smartphone application for classification of motor impairment severity in Parkinson's disease. In: 36th Annual International Conference Proceedings of the IEEE Engineering in Medi- 
cine and Biology Society (EMBC); 26-30 Aug. 2014; Chicago, IL, USA. IEEE; 2014. p. 2686-2689. DOI: 10.1109/EMBC.2014.6944176.

[9] Elliott S., Painter J., Hudson, S. Living alone and fall risk factors in community-dwelling middle age and older adults. J. Community Health. 2009;34:301-310. DOI: 10.1007/ s10900-009-9125-x.

[10] Hobert M.A., Maetzler W., Aminian K., Chiari L. Technical and clinical view on ambulatory assessment in Parkinson's disease. Acta Neurol. Scand. 2014;130(3):139_ 147. DOI: $10.1111 /$ ane.12248.

[11] Topol E.J. Transforming medicine via digital innovation. Sci. Transl. Med. 2010;2(16): 16cm4. DOI: 10.1126/scitranslmed.3000484.

[12] Bouten C.V., Koekkoek K.T., Verduin M., Kodde R., Janssen J.D. A triaxial accelerometer and portable data processing unit for the assessment of daily physical activity. IEEE Trans. Biomed. Eng. 1997;44(3):136-147. DOI: 10.1109/10.554760.

[13] Najafi B., Aminian K., Loew F., Blanc Y., Robert P.A. Measurement of stand-sit and sitstand transitions using a miniature gyroscope and its application in fall risk evaluation in the elderly. IEEE Trans. Biomed. Eng. 2002;49(8):843-851. DOI: 10.1109/TBME. 2002.800763 .

[14] Steins D., Dawes H., Esser P., Collett J. Wearable accelerometry-based technology capable of assessing functional activities in neurological populations in community settings: a systematic review. J. Neuroeng. Rehabil. 2014;11:36. DOI: 10.1186/1743-0003-11-36.

[15] Karantonis D.M., Narayanan M.R., Mathie M., Lovell N.H., Celler B.G. Implementation of a real-time human movement classifier using a triaxial accelerometer for ambulatory monitoring. IEEE Trans. Inf. Technol. Biomed. 2006;10(1):156-167. DOI: 10.1109/TITB. 2005.856864 .

[16] Mathie M.J., Coster A.C., Lovell N.H., Celler B.G., Lord S.R., Tiedemann A. A pilot study of long-term monitoring of human movements in the home using accelerometry. J. Telemed. Telecare. 2004;10(3):144-151. DOI: 10.1258/135763304323070788.

[17] Bao L., Intille S. Activity recognition from user-annotated acceleration data. In: Pervasive Computing. 2004;3001:1-17.

[18] Huan L., Lei, Y. Toward integrating feature selection algorithms for classification and clustering. IEEE Trans. Knowl. Data Eng. 2005;17:491-502. DOI: 10.1109/TKDE.2005.66.

[19] Bianchi F., Redmond S.J., Narayanan M.R., Cerutti S., Celler B.G., Lovell N.H. Falls event detection using triaxial accelerometry and barometric pressure measurement. In: In Proceedings of the Annual International Conference of the IEEE Engineering in Medicine and Biology Society; 3-6 September 2009; MN, USA; 2009. p. 6111-6114. DOI: 10.1109/IEMBS.2009.5334922. 
[20] Qiang L., Stankovic J.A., Hanson M.A., Barth A.T., Lach J., Gang Z. Accurate, fast fall detection using gyroscopes and accelerometer-derived posture information. In: In Proceedings of the Sixth International Workshop on Wearable and Implantable Body Sensor Networks; 3-5 June 2009; Berkeley, CA, USA; 2009. p. 138-143. DOI: 10.1109/ BSN.2009.46.

[21] Dadashi F., Mariani B., Rochat S., Büla C., Santos-Eggimann B., Aminian K. Gait and foot clearance parameters obtained using shoe-worn inertial sensors in a largepopulation sample of older adults. Sensors. 2014;14(1):443-457. DOI: 10.3390/ s140100443.

[22] Pogorelc B., Gams M. Detecting gait-related health problems of the elderly using multidimensional dynamic time warping approach with semantic attributes. Multimed. Tools Appl. 2013;66:95-114. DOI: 10.1007/s11042-013-1473-1.

[23] Sposaro, F., Tyson, G. iFall: an android application for fall monitoring and response. In: Proceedings of the Annual International Conference of the IEEE on Engineering in Medicine and Biology Society (EMBC); 3-6 September 2009; Minneapolis, MN, USA. IEEE; 2009. p. 6119-6122. DOI: 10.1109/IEMBS.2009.5334912.

[24] Dai J., Bai X., Yang Z., Shen Z., Xuan D. Mobile phone-based pervasive fall detection. Pers. Ubiquitous Comput. 2010;14(7):633-643. DOI: 10.1007/s00779-010-0292-x.

[25] Yavuz G., Kocak M., Ergun G., Alemdar H., Yalcin H., Incel, O.D., et al. A smartphone based fall detector with online location support. In: In Proceedings of the International Workshop on Sensing for App Phones; 2 November 2010; Zurich, Switzerland; 2010. p. 31-35.

[26] Zhao Z., Chen Y., Liu J. Fall detecting and alarming based on mobile phone. In: In Proceedings of the 7th International Conference on Ubiquitous Intelligence \& Computing and 7th International Conference on Autonomic \& Trusted Computing (UIC/ ATC); 26-29 October 2010; Shanxi, China; 2010. p. 494-497. DOI: 10.1109/UIC-ATC. 2010.44.

[27] Fahmi P., Viet V., Deok-Jai C. Semi-supervised fall detection algorithm using fall indicators in smartphone. In: In Proceedings of the 6th International Conference on Ubiquitous Information Management and Communication; 20-22 February 2012; Kuala Lumpur, Malaysia. 2012. DOI: 10.1145/2184751.2184890.

[28] He Y., Li Y. Physical activity recognition utilizing the built-in kinematic sensors of a smartphone. Int. J. Distrib. Sens. Netw. 2013; 2013, p. 1-10. DOI: 10.1155/2013/481580.

[29] Majumder A.J.A., Rahman F., Zerin I., Ebel W., Jr., Ahamed S.I. iPrevention: towards a novel real-time smartphone-based fall prevention system. In: In Proceedings of the 28th Annual ACM Symposium on Applied Computing; 18-22 March 2013; Coimbra, Portugal; 2013. p. 513-518. DOI: 10.1145/2480362.2480462.

[30] Dai J., Bai X., Yang Z., Shen Z., Xuan D. PerFallD: a pervasive fall detection system using mobile phones. In: In Proceedings of the 8th IEEE International Conference on 
Pervasive Computing and Communications Workshops (PERCOM Workshops); 29 March-2 April 2010; Mannheim, Germany. IEEE; 2010. p. 292-297. DOI: 10.1109/ PERCOMW.2010.5470652.

[31] Lee R.Y., Carlisle A.J. Detection of falls using accelerometers and mobile phone technology. Age Ageing. 2011;40(6):690-696. DOI: 10.1093/ageing/afr050.

[32] Cao Y., Yang Y., Liu W. E-FallD: A fall detection system using android-based smartphone. In: In Proceedings of the 9th International Conference on Fuzzy Systems and Knowledge Discovery (FSKD); 29-31 May 2012; Sichuan, China. IEEE; 2012. p. 1509_ 1513. DOI: 10.1109/FSKD.2012.6234271.

[33] Fang S.-H., Liang Y.-C., Chiu K.-M. Developing a mobile phone-based fall detection system on android platform. In: In Proceedings of the Computing, Communications and Applications Conference (ComComAp); 11-13 January 2012; Hong Kong, China. IEEE; 2012. p. 143-146. DOI: 10.1109/ComComAp.2012.6154019.

[34] Viet V.Q., Lee G., Choi D. Fall detection based on movement and smart phone technology. In: In Proceedings of the IEEE RIVF International Conference on Computing and Communication Technologies, Research, Innovation, and Vision for the Future (RIVF); 27 February-1 March 2012; Ho Chi Minh City, Vietnam. IEEE; 2012. p. 1-4. DOI: 10.1109/rivf.2012.6169847.

[35] Mehner S., Klauck R., Koenig H. Location-independent fall detection with smartphone. In: In Proceedings of the 6th International Conference on PErvasive Technologies Related to Assistive Environments; 28-31 May 2013; Rhodes, Greece. 2013. DOI: $10.1145 / 2504335.2504346$.

[36] Koshmak G.A., Linden M., Loutfi A. Evaluation of the android-based fall detection system with physiological data monitoring. In: In Proceedings of the 35th Annual International Conference of the IEEE on Engineering in Medicine and Biology Society (EMBC); 3-7 July 2013; Osaka, Japan. IEEE; 2013. p. 1164-1168. DOI: 10.1109/EMBC. 2013.6609713.

[37] Kau L.J., CHen C.S. A smart phone-based pocket fall accident detection, positioning, and rescue system. IEEE J. Biomed. Health Inform. 2014;19(1):44-56. DOI: 10.1109/JBHI. 2014.2328593.

[38] Suryadevara V.K., Rizkalla M. Smartphone based fall detection and logic testing application using android SDK. J. Biomed. Sci. Eng. 2015;8(9):616-624. DOI: 10.4236/ jbise.2015.89057.

[39] Viet V., Choi D.J. Fall detection with smart phone sensor. In: In Proceedings of the 3rd International Conference on Internet (ICONI); 15-19 December 2011; Sepang, Malaysia; 2011. p. 27-31.

[40] Shi Y., Shi Y., Wang X. Fall detection on mobile phones using features from a five-phase model. In: In Proceedings of the 9th International Conference on Ubiquitous Intelligence \& Computing and 9th International Conference on Autonomic \& Trusted 
Computing (UIC/ATC); 4-7 September 2012; Fukuoka, Japan. IEEE; 2012. p. 951-956. DOI: $10.1109 /$ UIC-ATC.2012.100.

[41] Zhao Z., Chen Y., Wang S., Chen Z. FallAlarm: smart phone based fall detecting and positioning system. Procedia Comput. Sci. 2012;10:617-624. DOI: FallAlarm: Smart Phone Based Fall Detecting and Positioning System.

[42] Kansiz A.O., Guvensan M.A., Turkmen H.I. Selection of time-domain features for fall detection based on supervised learning. In: In Proceedings of the World Congress on Engineering and Computer Science; 23-25 October 2013; San Francisco, CA, USA; 2013.

[43] Medrano C., Plaza I., Igual R., Sánchez Á., Castro M. The effect of personalization on smartphone-based fall detectors. Sensor. 2016;16(1):E117. DOI: 10.3390/s16010117.

[44] Abbate S., Avvenuti M., Bonatesta F., Cola G., Corsini P., Vecchio A. A smartphonebased fall detection system. Pervasive Mobile Comput. 2012;8(6):883-899. DOI: 10.1016/ j.pmcj.2012.08.003.

[45] Habib M., Mohktar M., Kamaruzzaman S., Lim K., Pin T., Ibrahim F. Smartphone-based solutions for fall detection and prevention: challenges and open issues. Sensors. 2014;14(4):7181-7208. DOI: 10.3390/s140407181.

[46] Goetz C.G., Stebbins G.T., Wolff D., DeLeeuw W., Bronte-Stewart H., Elble R., et al. Testing objective measures of motor impairment in early Parkinson's disease: feasibility study of an at-home testing device. Mov. Disord. 2009;24(4):551-556. DOI: 10.1002/ mds.22379.

[47] Dijkstra B., Kamsma Y.P., Zijlstra W. Detection of gait and postures using a miniaturized triaxial accelerometer-based system: accuracy in patients with mild to moderate Parkinson's disease. Arch. Phys. Med. Rehabil. 2010;91(8):1272-1277. DOI: 10.1016/ j.apmr.2010.05.004.

[48] Moore S.T., MacDougall H.G., Ondo W.G. Ambulatory monitoring of freezing of gait in Parkinson's disease. J Neurosci Methods. 2008;167(2):340-348.

[49] Bächlin M., Roggen D., Plotnik M., Hausdorff J.M., Giladi N., Tröster G. Online detection of freezing of gait in Parkinson's disease patients: a performance characterization. In: Proceedings of the 4th International Conference on Body; Brussels, Belgium; 2009. p. 693-698. DOI: 10.4108/ICST.BODYNETS2009.5852.

[50] Salarian A., Russmann H., Vingerhoets F.J.G., Burkhard P.R., Aminian K. Ambulatory monitoring of physical activities in patients with Parkinson's disease. IEEE Trans. Biomed. Eng. 2007;54(12):2296-2299. DOI: 10.1109/TBME.2007.896591.

[51] Mazilu S., Blanke U., Hardegge M., Tröster G., Gazit E., Dorfman M., et al. GaitAssist: a wearable assistant for gait training and rehabilitation in Parkinson's disease. 2014 IEEE International Conference on Pervasive Computing and Communications Workshops (PERCOM Workshops); 24-28 March 2014; Budapest. IEEE; 2014. p. 135-137. DOI: 10.1109/PerComW.2014.6815179. 
[52] Cancela J., Pansera M., Arredondo M.T., Estrada J.J., Pastorino M., Pastor-Sanz L. A comprehensive motor symptom monitoring and management system: the bradykinesia case. In: In Proceeding of the 32nd Annual Conference of the IEEE Engineering; 31 Aug 2010-4 Sept 2010; Buenos Aires. IEEE; 2010. p. 1008-1011.

[53] Barth J., Klucken J., Kugler P., Kammerer T., Steidl R., Winkler J., et al. Biometric and mobile gait analysis for early diagnosis and therapy monitoring in Parkinson's disease. In: In Proceedings of the 33rd Annual Conference of the IEEE Engineering in Medicine and Biology Society; 30 Aug 2011-3 Sept 2011; Boston, MA, USA. IEEE; 2011. p. 868871. DOI: 10.1109/IEMBS.2011.6090226.

[54] Klucken J., Barth J., Kugler P., Schlachetzki J., Henze T., Marxreiter F., et al. Unbiased and mobile gait analysis detects motor impairment in Parkinson's disease. PLoS One. 2013;8(2):e56956. DOI: 10.1371/journal.pone.0056956.

[55] Zwartjes D.G.M., Heida T., van Vugt J.P.P., Geelen J.A.G., Veltink P.H. Ambulatory monitoring of activities and motor symptoms in Parkinson's disease. IEEE Trans. Biomed. Eng. 2010;57(11):2778-2786. DOI: 10.1109/TBME.2010.2049573.

[56] Tzallas A.T., Tsipouras M.G., Rigas G., Tsalikakis D.G., Karvounis E.C., Chondrogiorgi M. PERFORM: a system for monitoring, assessment and management of patients with Parkinson's disease. Sensor. 2014;14(11):21329-21357. DOI: 10.3390/s141121329.

[57] Arora S., Venkataraman V., Donohue S., Biglan K.M., Dorsey E.R., Little M.A. High accuracy discrimination of Parkinson's disease participants from healthy controls using smartphones. In: 2014 IEEE International Conference on Acoustics, Speech and Signal Processing (ICASSP); 4-9 May 2014; Florence. IEEE; 2014. p. 3641-3644. DOI: 10.1109/ ICASSP.2014.6854280.

[58] Pepa L., Ciabattoni L., Verdini F., Capecci M., Ceravolo M.G. Smartphone based fuzzy logic freezing of gait detection in Parkinson's disease. In: 2014 IEEE/ASME 10th International Conference on Mechatronic and Embedded Systems and Applications (MESA); 10-12 Sept 2014; Senigallia. IEEE; 2014. p. 1-6. DOI: 10.1109/MESA. 2014.6935630.

[59] Kim H., Lee H.J., Lee W., Kwon S., Kim S.K., Jeon H.S., et al. Unconstrained detection of freezing of Gait in Parkinson's disease patients using smartphone. In: 2015 37th Annual International Conference of the IEEE Engineering in Medicine and Biology Society (EMBC); 25-29 Aug. 2015; Milan. IEEE; 2015. p. 3751-3754. DOI: 10.1109/EMBC. 2015.7319209.

[60] KostikisN., Hristu-Varsakelis D., Arnaoutoglou M., Kotsavasiloglou C. A smartphonebased tool for assessing Parkinsonian hand tremor. IEEE Trans. Biomed. Eng. 2015;19(6):1835-1842. DOI: 10.1109/JBHI.2015.2471093.

[61] Pan D., Dhall R., Lieberman A., Petitti D.B. A mobile cloud-based Parkinson's disease assessment system for home-based monitoring. JMIR Mhealth Uhealth. 2015;3(1):e29. DOI: 10.2196/mhealth.3956. 
[62] iRhythm. Available from: http://www.irhythmtech.com/ [Accessed: Mar. 2016].

[63] Corventis [Internet]. Available from: http://www.corventis.com/ [Accessed: Mar. 2016].

[64] Rosenberg M.A., Samuel M., Thosani A., Zimetbaum P.J. Use of a noninvasive continuous monitoring device in the management of atrial fibrillation: a pilot study. Pacing Clin. Electrophysiol. 2012;36(3):328-333. DOI: 10.1111/pace.12053.

[65] Turakhia M.P., Hoang D.D., Zimetbaum P., Miller J.D., Froelicher V.F., Kumar U.N., et al. Diagnostic utility of a novel leadless arrhythmia monitoring device. Am. J. Cardiol. 2013;112(4):520-524. DOI: 10.1016/j.amjcard.2013.04.017.

[66] Engel J.M., Chakravarthy N., Katra R.P., Mazar S., Libbus I., Chavan A. Estimation of patient compliance in application of adherent mobile cardiac telemetry device. In: 2011 Annual International Conference of the IEEE Engineering in Medicine and Biology Society; 30 Aug 2011-3 Sept 2011; Boston, MA, USA. IEEE; 2011. p. 1536-1539. DOI: 10.1109/IEMBS.2011.6090448.

[67] Higgins S.L. A novel patch for heart rhythm monitoring: is the Holter monitor obsolete? Future Cardiol. 2013;9(3):325-333. DOI: 10.2217/fca.13.13.

[68] Verkruysse W., Svaasand L.O., Nelson J.S. Remote plethysmographic imaging using ambient light. Opt. Express. 2008;16(26):21434-21435.

[69] Lobodzinski S.S., Laks M.M. New devices for very long-term ECG monitoring. Cardiol. J. 2012;19(2):210-214.

[70] Imec. [Updated: Mar. 2016]. Available from: www2.imec.be.

[71] Poh M.Z., McDuff D.J., Picard R.W. Non-contact, automated cardiac pulse measurements using video imaging and blind source separation. Opt Express. 2010;18(10): 10762-10774. DOI: 10.1364/OE.18.010762.

[72] Poh M.Z., McDuff D.J., Picard R.W. Advancements in noncontact, multiparameter physiological measurements using a webcam. IEEE Trans. Biomed. Eng. 2011;58(1):711. DOI: 10.1109/TBME.2010.2086456.

[73] Zhao F., Li M., Qian Y., Tsien J.Z. Remote measurements of heart and respiration rates for telemedicine. PLoS One. 2013;8(10):e71384. DOI: 10.1371/journal.pone.0071384.

[74] Azumio. Instant Heart Rate [Internet]. Available from: http://www.azumio.com/apps/ heart-rate/ [Accessed: Mar. 2016].

[75] Philips. VitalSigns Camera [Internet]. Available from: http://www.vitalsignscamera.com/ [Accessed: Mar. 2016].

[76] AliveCor. Available from: http://www.alivecor.com/home [Accessed: Mar. 2016]. 
[77] Zhao F., Li M., Tsien J.Z. Technology platforms for remote monitoring of vital signs in the new era of telemedicine. Expert Rev. Med. Devices. 2015;12(4):411-429. DOI: 10.1586/17434440.2015.1050957.

[78] Tensys Medical. TL-300 [Internet]. Available from: http://tensysmedical.com/us/ products/.

[79] Eeftinck Schattenkerk D.W., van Lieshout J.J., van den Meiracker A.H., Wesseling K.R., Blanc S., Wieling W., et al. Nexfin noninvasive continuous blood pressure validated against Riva-Rocci/Korotkoff. Am. J. Hypertens. 2009;22(4):378-383. DOI: 10.1038/ajh. 2008.368.

[80] Garnier R.P., van der Spoel A.G., Sibarani-Ponsen R., Markhorst D.G., Boer C. Level of agreement between Nexfin non-invasive arterial pressure with invasive arterial pressure measurements in children. Br. J. Anaesth. 2012;109(4):609-615. DOI: 10.1093/bja/aes295.

[81] Saugel B., Meidert A.S., Hapfelmeier A., Eyer F., Schmid R.M., Huber W. Non- invasive continuous arterial pressure measurement based on radial artery tonometry in the intensive care unit: a method comparison study using the T- Line TL-200pro device. Br. J. Anaesth. 2013;111(2):185-190. DOI: 10.1093/bja/aet025.

[82] Leboulanger B., Guy R.H., Delgado-Charro M.B. Non-invasive monitoring of phenytoin by reverse iontophoresis. Eur. J. Pharm. Sci. 2004;22(5):427-433.

[83] Tao D., Adler A. In Vivo Blood Characterization From Bioimpedance Spectroscopy of Blood Pooling . IEEE Trans. Instrum. Meas. 2009;58(11):3831-3838. DOI: 10.1109/TIM. 2009.2020836.

[84] Caduff A., Talary M.S., Mueller M., Dewarrat F., Klisic J., Donath M., et al. Non-invasive glucose monitoring in patients with Type 1 diabetes: a multisensor system combining sensors for dielectric and optical characterisation of skin. Biosens. Bioelectron. 2009;24(9):2778-2784. DOI: 10.1016/j.bios.2009.02.001.

[85] Tura A., Sbrignadello S., Cianciavicchia D., Pacini G., Ravazzani P. A low frequency electromagnetic sensor for indirect measurement of glucose concentration: in vitro experiments in different conductive solutions. Sensors. 2010;10(6):5346-5358. DOI: $10.3390 / \mathrm{s} 100605346$.

[86] Arnold M.A., Small G.W. Noninvasive glucose sensing. Anal. Chem. 2005;77(17):54295439.

[87] Vonlilienfeldtoal H., Weidenmuller M., Xhelaj A., Mantele W. A novel approach to noninvasive glucose measurement by mid-infrared spectroscopy: the combination of quantum cascade lasers (QCL) and photoacoustic detection. Vib. Spectrosc. 2005;38(12):209-215. DOI: 10.1016/j.vibspec.2005.02.025.

[88] Ellis D.I., Goodacre R. Metabolic fingerprinting in disease diagnosis: biomedical applications of infrared and Raman spectroscopy. Analyst. 2006;131(8):875-885. 
[89] Larin K.V., Eledrisi M.S., Motamedi M., Esenaliev R.O. Noninvasive blood glucose monitoring with optical coherence tomography: a pilot study in human subjects. Diabetes Care. 2002;25(12):2263-2267.

[90] Malik B.H., Coté G.L. Real-time, closed-loop dual-wavelength optical polarimetry for glucose monitoring. J. Biomed. Opt. 2010;15(1):017002. DOI: 10.1117/1.3290819.

[91] Lee S., Nayak V., Dodds J., Pishko M., Smith N.B. Glucose measurements with sensors and ultrasound. Ultrasound Med. Biol. 2005;31(7):971-977.

[92] March W.F., Mueller A., Herbrechtsmeier P. Clinical trial of a noninvasive contact lens glucose sensor. Diabetes Technol. Ther. 2004;6(6):782-789.

[93] Alexeev V.L., Das S., Finegold D.N., Asher S.A. Photonic crystal glucose-sensing material for noninvasive monitoring of glucose in tear fluid. Clin. Chem. 2004;50(12): 2353-2360.

[94] Yao H., Shum A.J., Cowan M., Lähdesmäki I., Parviz B.A. A contact lens with embedded sensor for monitoring tear glucose level. Biosens. Bioelectron. 2011;26(7):3290-3296. DOI: 10.1016/j.bios.2010.12.042.

[95] Patel J.N., Gray B.L., Kaminska B., Gates B.D. Flexible three-dimensional electrochemical glucose sensor with improved sensitivity realized in hybrid polymer microelectromechanical systems technique. J. Diabetes Sci. Technol. 2011;5(5):1036-1043.

[96] Liao Y.T., Yao H., Lingley A., Parviz B., Otis B.P. A 3- \mu \hbox CMOS glucose sensor for wireless contact-lens tear glucose monitoring. IEEE J. Solid-St. Circ. 2012;47(1):335344. DOI: 10.1109/JSSC.2011.2170633.

[97] Tacconi C., Mellone S., Chiari L. Smartphone-based applications for investigating falls and mobility. In: In Proceedings of the 5th International Conference on Pervasive Computing Technologies for Healthcare (PervasiveHealth); 23-26 May 2011; Dublin, Ireland; 2011. p. 258-261.

[98] Bai Y.W., Wu S.C., Tsai C.L. Design and implementation of a fall monitor system by using a 3-axis accelerometer in a smart phone. IEEE Trans. Consum. Electron. 2012;58(4):1269-1275. DOI: 10.1109/TCE.2012.6414995.

[99] Hsieh S.L., Su M.H., Liu L.F., Jiang W.W. A finite state machine-based fall detection mechanism on smartphones. In: In Proceedings of the 9th International Conference on Ubiquitous Intelligence \& Computing and 9th International Conference on Autonomic \& Trusted Computing (UIC/ATC); 4-7 September 2012; Fukuoka, Japan. IEEE; 2012. p. 735-739. DOI: 10.1109/UIC-ATC.2012.153.

[100] Bai Y.W., Wu S.C., Yu C.H. Recognition of direction of fall by smartphone. In: In Proceedings of the 26th Annual IEEE Canadian Conference on Electrical and Computer Engineering (CCECE); 5-8 May 2013; Regina, SK, Canada. IEEE; 2013. p. 1-6. DOI: 10.1109/CCECE.2013.6567781. 
Chapter 2

\title{
Empowering Diabetes Patient with Mobile Health Technologies
}

\author{
Matjaž Krošel, Lana Švegl, Luka Vidmar and \\ Dejan Dinevski
}

Additional information is available at the end of the chapter

http://dx.doi.org/10.5772/64620

\begin{abstract}
Chronic diseases, especially diabetes mellitus, are huge public health burden. Therefore, new health care models for sharing the responsibility for care among health care providers and patients themselves are needed. The concept of empowerment promotes patient's active involvement and control over their own health. It can be achieved through education, self-management, and shared decision making. All these aspects can be covered by mobile health technologies, the so-called mHealth. This term comprises mobile phones, patient monitoring devices, tablets, personal digital assistants, other wireless devices, and numerous apps. Many challenges of diabetics can be addressed by mHealth, including glycemic control, nutrition control, physical activity, high blood pressure, medication adherence, obesity, education, diabetic retinopathy screening, diabetic foot screening, and psychosocial care. However, mHealth plays only minor role in diabetes management, despite numerous apps on the market. Namely, these apps have many shortcomings and the majority of them does not include important functions. Moreover, these apps lack the perceived additional benefit by the user and the ease of use, important factors for acceptance of mHealth. Studies of diabetes apps regarding usability and accessibility have shown moderate results. Beside improvements of apps usability, the future of diabetes mHealth lies probably in personalized education and self-management with the help of decision support systems. At the same time, work on artificial pancreas is in progress and smartphone could be used as user interface.
\end{abstract}

Keywords: mobile health, diabetes, empowerment, smartphone, chronic disease management 


\section{Introduction}

Aging and chronic conditions represent a huge burden on the health care budgets. Moreover, in the future this burden will only increase [1]. At the same time, the patients require a better service, while there are fewer health care professionals and lesser resources. The states currently actmainly in two dimensions. On theonehand, they are strengthening theirefforts on prevention. They develop or update existing programs, which promote healthy and active life styles. On the other hand, they are transforming the existing health care. Namely, the health care systems as we know them were developed to treat the acute diseases. However, the chronic diseases spent more than $70 \%$ of the health care budgets $[2,3]$. The prevention programs can prolong the healthy period of each individual, but some chronic diseases, such as diabetes, cannot eliminate. Therefore, there is a need for transformation of the existing health care whose goals are better health results, better quality of service and quality of patient life, and economic feasibility. This transformation is as follows [2]:

- from the health care model centered on acute medical care to the model adopted to the needs of chronic patients,

- from reactive model to proactive model to cure, care for and prevent based on risk factors,

- from passive patients to a model with a patient in the center, actively managing his disease,

- from a fragmented model with lack of coordination to a model enabling continuity of care, and

- from activities primarily in acute hospitals to activities in more suitable environments, such as homes.

The key enablers for such transformation are patient empowerment, use of information and communications technology (ICT), integrated care, and adopted business models.

This chapter explores the concept of empowerment of diabetes patients by presenting current and future possibilities of mobile health technology.

\section{Diabetes mellitus}

Number of diabetes patients around the world has reached 415 million and it is predicted to climb up to 642 million by the year 2040. Diabetes can also be linked to around 5 million deaths each year and it is associated with high financial burden, since health spending on diabetes accounts for around $12 \%$ of total health expenditure worldwide. The costs include increase use of health services as well as loss of productivity or disability and are estimated to range from 673 billion USD to 1197 billion USD [4]. With such troubling predictions, we are obligated to look for new methods to facilitate patient care. Introduction of new methods should be done with the understanding that more than $95 \%$ of diabetes care is done by the patients themselves [5]. This is just one of several reasons why diabetes patients are excellent candidates for 
managing their disease with the help of mobile health technologies (mHealth) and why this may improve many aspects of personal and public health.

Diabetes is medically defined by the following criteria: patient fasting plasma glucose level $\geq 126 \mathrm{mg} / \mathrm{dl}(7.0 \mathrm{mmol} / \mathrm{l})$ or HbA1c (glycated hemoglobin) $\geq 6.5 \%$ or patient plasma glucose level 2-h after OGTT (oral glucose tolerance test) $\geq 200 \mathrm{mg} / \mathrm{dl}$ (11.1 mmol/l) or patient random plasma glucose level $\geq 200 \mathrm{mg} / \mathrm{dl}(11.1 \mathrm{mmol} / \mathrm{l})$ [6]. After the diagnosis, diabetes patients need to endure life-long management of their disease, which include medications and significant lifestyle changes. Disease progress should be monitored with the help of health care professionals in order to ensure prevention and quick diagnosis of long-term complications of hyperglycemia. Most commonly seen diabetes complications are retinopathy with a potential loss of vision, nephropathy that can result in renal failure, peripheral neuropathy leading to foot ulcers, Charcot foot and amputation, autonomic neuropathy that can causes gastrointestinal, genitourinary, and cardiovascular symptoms. The patients with a chronically elevated glucose level have high incidence of atherosclerotic vascular changes, which cause development of peripheral arterial disease, cerebrovascular, and cardiovascular complications [6, 7]. Number of complications can be reduced, if patients maintain good glycemic control. Every patient who reduces $\mathrm{HbA} 1 \mathrm{c}$ level for $1 \%$ decreases the risk of microvascular complication for $37 \%$ and the risk for diabetes related deaths for $21 \%$ [8].

\section{Adherence to treatment}

World Health Organization defines adherence as an extent to which a person's behavior: taking medication, following a diet, and/or executing lifestyle changes, corresponds with agreed recommendations from a health care provider [9]. One of the key challenges in diabetes management is a lack of adherence to medication regime and lack of lifestyle changes. Adherence to oral hypoglycemic agents is between 36 and 93\% for the first 9-24 months of treatment and adherence to insulin treatment for type 2 diabetes patients is between 62 and $64 \%$. Patients even less complain when it comes to dietary and other lifestyle recommendations [10,11]. Regardless of the type of treatment, it was proven that introduction of selfmonitoring of blood glucose level is associated with better glycemic control [12], but there are still around $29 \%$ patients treated with insulin, $65 \%$ patients treated with oral hypoglycemic agents, and $80 \%$ patients treated with dietary restriction, who do not practice self-monitoring or they do it less than once a month [13]. Poor adherence is also a public health issue. For every $10 \%$ increase in adherence, there is $8.6 \%$ decrease in annual health care cost. Furthermore, there is evidently a link between number of hospitalizations and adherence to medication therapy, which is reduced by $23.3 \%$ when adherence had increased from 50 to $100 \%$. Even more evident reduction of $46.2 \%$ is seen in number of emergency department visits. Both events, i.e., number of hospitalization and emergency department visits are associated with lower costs [14, 15]. When dealing with nonadherence, it is valuable to consider various reasons why this phenomenon occurs. It can be attributed to demographic factors, psychological factors, social factors, medical system factors, disease and treatment characteristic, but 
mostly it is a result of combinations of multiple factors [11, 16]. For example, glycemic control and treatment outcomes are less promising among racial minorities, men and people with depression or anxiety disorders [17, 18]. Those differences emphasize the importance of individualized and patient-centered care.

\section{Concept of empowerment}

Patient empowerment is a paradigm of transferring the responsibility of patient's health care in the hands of patients. Such paradigm is in contradiction with the traditional health care where the care was in the hands of the medical staff.

Compliance and adherence are concepts that arise from an idea of patient submitting and agreeing with health professional, who acts as an authority, whereas empowerment promotes patient active involvement and control over their own health [19].

The empowerment can be achieved through education, self-management, and shared decision making.

To obtain satisfactory outcome, there is more to be done than just encourage patients to selfmanage their chronic disease. Patients need to be educated about their disease, motivated, provided with patient-centered care, which means that self-management plan needs to be tailored to fit patient priorities, goals, resources, culture, and lifestyle [19].

The education typically occurs at the clinic by the doctor and/or nurse. At Stanford School of Medicine, a Chronic Disease Self-Management Program (CDSMP) [20] was developed which empowers patients through a series of workshops in community settings. Its success is evident in Denmark, which decided to implement it in its health care. As a result, Danish patients are the most empowered [21]. This program was also used in EU project EMPOWER [22].

While face-to-face patient education has positive effects, not much work has been done to evaluate the effect of virtual education. Moreover, patient knowledge is a necessary, but not a sufficient factor for change in the self-care behavior [23]. Patients require self-management support. It can be achieved through face-to-face interaction, through self- and telemonitoring and virtually [24-27].

Collaborative decision making represents collaboration and exchange of knowledge among patients, formal and informal care givers. Because it currently occurs in face-to-face meetings in most cases, there is no evidence for the effects of virtual collaborative decision making.

The goal of such efforts is to shape individuals that make rational health care decisions regarding their health and wellness, are less depended on health care service and contribute to more cost-effective use of health care resources [28].

Finally, in the diabetes treatment, notions of compliance and adherence were replaced with the concept of patient empowerment [29]. With Diabetes Empowerment Scale, significant correlation between level of empowerment and better medication adherence, extensive 
diabetes knowledge, improved general diet and exercise, blood glucose control, and foot care, can be established [30]. In diabetes management, mobile health technologies are already offering different means for introduction of the concept of empowerment into patients' everyday life.

\section{Use of information communication technologies (ICT) for patients with chronic diseases}

Patients with chronic diseases need to monitor and record several biometric health parameters. For this purpose, in current health care system, they mainly note observations on a paper, although most devices in use enable storage of such biometric measurements. While there are issues with reading noted values from the papers or even with losing the papers, there are issues with transferring the stored data on the devices to general practitioners (GPs) or specialists. Moreover, the doctors would appreciate to monitor more parameters that are relevant for a holistic care.

On the market, there are devices that can automatically measure and transfer the measurements to the smartphones and dedicated servers: Fitbit wristlets measure user activity and sleep periods [31]; BitBite measures user nutrition habits [32]; iHealth [33], VitaDock [34], VPD [35], and Abbott [36] products measure temperature, blood pressure, pulse, blood oxygen saturation, and glucose level. The current trend is geared toward wearables and gadgets that help diagnose very specific diseases, such as peripheral neuropathy [37] and retinopathy [38], toward gadgets that can measure several parameters [39] and toward integration of functionalities from gadgets to smartphone applications, such as in Google Fit [40] and in Moves [41]. These applications perform comparably well as standalone devices [42].

Furthermore, there are numerous smartphone applications, working with manual data input or data from previously mentioned devices, that assist users in managing their health $[43,44]$ or diabetes in particular $[45,46]$. Such applications do not only display the status of health parameters, but also provide personalized recommendations based on the input data. They mostly encourage users to change their behavior [47].

However, wearable devices and smartphone applications are only facilitators and not drivers of patient empowerment. The design of engagement strategies is more important for successful use and potential health benefits of these devices than the features of technology [48].

Several pilots have been conducted, suggesting positive effects on health and diabetes care, and a need for 24/7 support [49-51]. However, in use, there are mainly only solutions that enable patients to informatively monitor their health status. Solutions that would be used as a part of the general health care service are in the stage of pilots and are only very rarely deployed as part of the standard practice. 


\section{Why mobile health?}

Mobile health is defined as a use of mobile communication devices, which include mobile phones, patient monitoring devices, tablets, personal digital assistants, and other wireless devices for health services, and information [52]. Currently, growing use of those devices can be seen in practically every part of the world. Number of mobile phone owners in the United States has reached $92 \%$ of a population and even number of smartphone owners has grown to $68 \%$, while $45 \%$ of people own a tablet computer. Desktop or laptop computers were bought by $73 \%$ of Americans [53]. Surprisingly, similar rise in mobile technology use is also recorded among people in developing countries, where average share of people with mobile phones is around $83 \%$ [54]. With a vast majority of world population having an access to some type of mobile technology, this can certainly become a widely used to deliver deferent health care solutions to people. Role of mHealth is very broad and includes education and rising awareness, remote data collection, remote monitoring, communication with health care workers, support with diagnostic and treatment, and tracking diseases and epidemic outbreaks [55]. Most of these tasks are already performed by various mHealth applications for diabetes selfmanagement.

\section{Features of diabetes apps}

There are different classifications of diabetes app features and in this section we present some of them.

Review of accessible diabetes applications has shown that they mostly focus on blood glucose monitoring, medications, physical exercise, and diet management, while they also include other features such as education, communication, weight or BMI and blood pressure tracking, integration with public health records, decision support systems, and social networking. Blood glucose monitoring is available in all reviewed applications, while other features are more rarely present. Educational tools are brought to use in just $18 \%$ of applications and only around $30 \%$ of applications offer means to monitor weight, blood pressure, and physical exercise [56]. Still, among all medical conditions, diabetes with weight control represents the most addressed medical issue by mHealth applications in mHealth research [57].

In a recent systematic review, 53\% of apps offered documentation function (recording and displaying data), $17.8 \%$ analysis function (the possibility to analyze the recorded data and to graphically display the results), $11.4 \%$ reminder function (reminds the user of its periodic, predefined medication), $34.5 \%$ of apps offered an information function (inform about the illness). Data forwarding/communication function (opportunity to send the recorded data) was present in $31.1 \%$ of apps. Surprisingly, only $8.8 \%$ of the diabetes apps provided an advisory function (use of the recorded data to create individualized advice) or any other kind of therapeutic support. Besides, the previously described functions, $14.5 \%$ of the apps included suggestions for recipes suitable for the needs of diabetics. The majority of apps, i.e., $54.1 \%$ were limited to only one function, while there were only $28.2 \%$ with two and $17.7 \%$ with three and 
more functions [58]. In another classification, features of apps were grouped into three classes on the basis of prevalence. In class A, there were insulin and medication management, communication and patient monitoring by primary care providers, diet management, and physical activity. Class B included weight management, blood pressure management, and connection to personal health record (PHR). In class C, there were education, social media, and alerts. Class A comprised four major features and class B had significantly higher prevalence than class C [59].

mHealth research platform Few Touch Application (FTA) was developed to support management of diabetes. Applications and studies based on FTA allow automatic monitoring of blood glucose information, receiving short message service information about type 1 diabetes, mobile diary for type 2 diabetes, sharing diaries with doctor or nurse, mobile diary for type 1 diabetes, a food picture data, transfer of physical activity data on mobile phone, nutrition advices, context sensitivity, and modeling of blood glucose. Performance of each of the 10 FTA-based apps was analyzed and the conclusion was that all FTA apps are beneficial [60].

In the next sections, we will present 11 problems of diabetes disease that can be addressed by mHealth.

\subsection{Glycemic control}

Monitoring of blood glucose level is a base function of all available mHealth diabetes applications, because even without technology interventions self-monitoring of blood glucose (SMBG) is still an integral component of daily diabetes management, especially for insulintreated patients $[56,61]$. Unstructured SMBG is not recommended and does not produce the same results as structured SMBG, which links to behavioral changes, optimization of therapy, and improved clinical outcome. An example of such structured SMBG is a 7-point glucose profile, where blood glucose is measured every day of the week preprandially, postprandially, and at bedtime [62]. A pilot of such structured SMBG demonstrated a reduction in $\mathrm{HbA1c}$ levels up to $1.2 \%$ in 12 months [63]. To help patients in keeping up with structured SMBG, mHealth offers personal goal setting and various types of reminders [64]. Most commercially available devices for glucose monitoring enable patients to store and follow their blood glucose pattern. For this, patients need to transfer measurements to a computer through an USB cable or to a mobile phone with a direct connection through Bluetooth or Wi-Fi. Even more accurate glucose profile can be obtained with a use of continuous glucose monitor [61]. Regardless of a type of a mHealth intervention used, there is evidence in its positive impacts on reduction of $\mathrm{HbA} 1 \mathrm{c}$ values by a mean of $0.5 \%$ over 6 months [65]. However, a review of 24 papers has shown that the effectiveness of mHealth interventions (blood glucose reading and transmission to server) measured in $\mathrm{HbA1c}$ value was inconsistent for both types of diabetes [66].

\subsection{Nutrition control}

For education, most of the technologies used for nutrition therapy rely on videoconferencing, while for food tracking and food selection various mobile apps [47]. Distinct features are being formed among behavior mHealth modalities. Food intake can be recorded to determine the 
quantity of calories consumed each day and the targeted quantity of calories automatically adjusted, based on patient's daily physical activities [67]. More widely adopted are different nutrition databases containing a rage of food items, including different brands and restaurant food, and real-time calculations of consumed calories. Similarly, there exists also a possibility to scan the barcode of brand names to see the nutrient content [47]. Growing number of possibilities provide a new generation of mHealth devices also known as wearables. For example, in diet self-management wrist monitors and electronic utensils can be used to track the amount and speed of bites, but such devices are practically not used yet [68]. Furthermore, mHealth may enable calories calculations with recognition of food from photography in freeliving conditions. Even more promising are mobile applications that suggest appropriate meal based on preprandial blood glucose reading, which can facilitate patients' educated decision making [64].

\subsection{Physical activity}

Sixty nine percent of diabetes patients describe their exercise practices as nonexistent or less than recommended level [69]. It is recommended that adult patient with diabetes perform at least 150 min of moderate-intensity aerobic physical activity per week, spread over at least 3 days and with no more than two consecutive days without exercise [70]. For patients to monitor the extent of their daily physical activity, mHealth offers solutions in a form of body-worn activity monitors. Most easily accessible are pedometers, but besides number of steps taken they do not measure other forms of physical activity [64]. Meanwhile, accelerometers with a combination of gyroscope can record wider range of movements and accuracy of recordings is not dependent on person's body position [71]. When tested, people with access to fully automated system performed on average for $2 \mathrm{~h}$ and $18 \mathrm{~min}$ per week more of physical activity than people without it [72]. Wearable sensors still need to be complemented with education, planning, and feedback tools to successfully promote physical activity. Effectiveness of mHealth intervention was shown in improved daily number of steps, which was done by setting an achievable goal, providing real-time feedback about the amount of burned calories, and showing recorded progress. This raised the number of steps by $22 \%$ in 8 weeks [73].

It was observed that insufficient number of currently evaluable mHealth applications incorporate evidence-based behavior change techniques. This is especially true for techniques, such as relapse prevention, teaching to use props, time management, and agreement to form behavior contract [74].

\subsection{Weight loss}

Obesity should be diagnosed according to body mass index (BMI). BMI classes are normal weight $\left(18.5-24.9 \mathrm{~kg} / \mathrm{m}^{2}\right)$, overweight $\left(25-29.9 \mathrm{~kg} / \mathrm{m}^{2}\right)$, obesity class I $\left(30-34.9 \mathrm{~kg} / \mathrm{m}^{2}\right)$, obesity class II $\left(35-39.9 \mathrm{~kg} / \mathrm{m}^{2}\right)$, and obesity class III $\left(\geq 40 \mathrm{~kg} / \mathrm{m}^{2}\right)$. For Southeast Asians and Asian Indians, lower BMI cut-points may be appropriate. Lifestyle modifications including behavioral changes, reduced calorie diets, and appropriately prescribed physical activity should be implemented as the cornerstone of obesity management [75]. Weight loss can be achieved with $500-750 \mathrm{kcal} /$ day reduction that means intake of 1200-1800 kcal/day depending on sex and 
baseline body weight [76]. Raised BMI, i.e., above $25 \mathrm{~kg} / \mathrm{m}^{2}$, is seen in more than $75 \%$ of diabetes patients [77]. Patients with high BMI and diabetes are significantly more likely to have poor glycemic control [78]. Overweight individuals with diabetes are encouraged to lose at least 5$10 \%$ of their weight, because this importantly reduces most cardiovascular risk factors, but it is worth mentioning that lager weight loss (10-15\%) has even greater benefits [79]. Reviewed mHealth applications offer means to help achieve this recommendation by monitoring and facilitating physical activity ( $41 \%$ of the applications) and by improving users' $\operatorname{diet}(68 \%$ of the applications) [56]. An evaluation of 137 diabetes apps showed, that only 39\% of them offered weight tracking [59]. Self-monitoring of weight and of body composition by using weight scales can now be accomplished wirelessly with mHealth apps or computer applications. This minimizes the burden on the user, while it also minimizes the error in data transcription. Tracked weight and fat mass can be graphically analyzed by the patient or health care practitioner [47].

SMS interventions were investigated to promote change in diet and physical activity. Small and short randomized controlled trials proved significant weight loss, while larger and longer studies showed no statistical significance [80].

Researchers investigated dietary self-monitoring-based electronic interventions using personal digital assistants (PDAs), electronic portable devices that share some of the features of mobile phones. PDA in the study was equipped with dietary and exercise software with and without feedback message. Patients were enrolled in three groups: PDA alone, PDA with feedback (feedback algorithm that provided daily messages tailored to their entries and provided positive reinforcement and guidance for goal attainment), and paper diary/record. All participants had statistically significant weight loss, but PDA group combined with feedback had the highest proportion of participants achieving greater than $5 \%$ weight loss in six months [81].

Studies incorporating podcasts compared to podcasts that included prompting by mobile app and interaction with study counselors and other participants on Twitter, did not show enhanced weight loss in the latter group [82].

Interventions delivered by smartphone app, website, or paper diary were also compared. App incorporated goal settings, self-monitoring of diet and activity, and feedback via weekly text message. The website group used commercially available slimming website. Trial retention, adherence, and achieved weight loss were significantly higher in the smartphone app group [80].

\subsection{Blood pressure control}

Elevated blood pressure is a common condition coexisting with diabetes and it is a clear independent risk factor for the cardiovascular complications. To reduce the risk, blood pressure should be routinely monitored and maintained at a targeted level. Recommended systolic pressure for diabetes patient is $<140 \mathrm{mmHg}$ and diastolic pressure $<90 \mathrm{mmHg}$. Homemonitoring is greatly encouraged, because it is a way to exclude white coat hypertension and because research suggested better correlation between at home measurements and cardiovas- 
cular risk than office measurements [83]. Among reviewed diabetes applications, $23 \%$ of them currently offer means of self-monitoring of blood pressure [56]. Monitoring blood pressure with the help of mHealth program may detect hypertension patterns that would otherwise gone unreported [22]. Fully automatized blood pressure readings, which are immediately stored in mHealth device and send to a health care provider, enabled to $51 \%$ of diabetes patient to reach the targeted blood pressure level. This is a significant improvement compared to $37.5 \%$ of general diabetes population that succeed in lowering their blood pressure. Such improvement was achieved also due to by inclusion of daily reminders, alerts in a case of concernreassign measurement and linkage to patient support system [84]. Home-monitoring alone does not produce the same results, proving telemedicine equal, but not more effective than standard approach, so this needs to be taken into consideration for future mHealth design [85].

\subsection{Medication adherence}

Previously, already discussed lack of adherence to pharmacological intervention in diabetes patients is an issue addressed by approximately $76 \%$ of reviewed mHealth applications [56]. One of the commonly reported barriers is patient forgetfulness, when it comes to medication intake regime. Mobile health technologies can offer different solution to this problem. Daily automatic electronic or text-message reminders may improve medication intake [86]. Those reminders can be upgraded by the use of real-time medication monitoring, which is possible with a use of electronic medication dispenser that records date and time of each opening. Consequentially, alert is only send in a case of forgotten medication dose. A trail confirmed that a baseline adherence of around $62 \%$ improved to $79.5 \%$ adherence after 1 year of use. Long-term effectiveness of this mHealth method peaked at $80.4 \%$ medication adherence, whereas control group adherence remained in a range of $68.4 \%$. Majority of patients that used real-time medication monitoring also agreed that this method supported higher awareness of their medication use and reported positive experience with receiving SMS reminders [87, 88]. Considerable amount of patient, who tested real-time monitoring devices, were glad that physician knew if they took their medication and were reassured by technology supported communication [89].

\subsection{Education}

Diabetes education is a key element in patient care. To reassure adequate results, effective education strategies can be found in National Standards for Diabetes Self-Management Education and are worth applying to mHealth methods [90]. Even limited amount of education can result in improved weight control and potentially reduced cardiovascular risk [91]. Initial comparisons between in person diabetes education and education administrated through telemedicine already demonstrated a feasibility and equal effectiveness of technology supported methods [92]. Most diabetes self-management applications do not integrate educational information. When available, such information is often generic and is not personalized to the individual patient. This is more prominent in commercial applications [56]. Education and personalized feedback are still underdeveloped features, included in less than one third of reviewed mHealth applications. Only $20 \%$ of reviewed applications had an education module, 
and only $26 \%$ of these met the criteria for personalized education or feedback. Task of personalizing rapidly growing number of information is challenging, but it may be largely beneficial for diabetes patient [59]. Most widely used mHealth method for diabetes education is SMS. Meta-analysis of current findings has shown that mobile SMS education can improve glycemic control. The glycemic control is even better if diabetes education is done by a combination of SMS and internet methods, i.e., $86 \%$ effect in comparison with $44 \%$ that is achieved by SMS alone [93]. Positive results of e-mail and SMS education can also be seen in improved quality of life [94].

Numerous applications are available helping healthy people or people with risk factors to assess their risk for developing diabetes type 2 in the future. Only a few of these apps disclose the name of the risk calculator used for assessing the risk of diabetes, therefore the quality of their calculations is questionable [95].

\subsection{Diabetic retinopathy screening}

Diabetic retinopathy represents most frequent cause of newly occurring adult blindness. Incidence of diabetic retinopathy is highly depended on duration of diabetes itself. Among population with type 2 diabetes cumulative incidence after 4 years is estimated to be $26 \%, 38.1$ $41.0 \%$ after 6 years and $66 \%$ after 10 years [96]. Comprehensive eye examination should be performed after diabetes diagnosis and repeated every 2 years, if there are no visible changes, or annually, if initial retinopathy changes are already present [97]. To keep up with this requirement even with patient in remote and isolated areas, low cost smartphone-based intelligent system integrated with microscopic lens was developed and tested. System detects retinal abnormalities by a method of comparison with medical image database. Early testing has promisingly shown more than $87 \%$ accuracy rate in retinal disease detection [98].

\subsection{Diabetic foot screening}

Diabetic foot is a main cause for nontraumatic lower limb amputation and precedes $85 \%$ of the cases. Approximately $15 \%$ of diabetes patients will develop diabetic foot ulcers in their lifetime [99]. It is recommended for all diabetes patients to perform annual extensive foot examination to identify risk factors predictive of foot ulcers. Patient should be screened for signs of peripheral neuropathy and peripheral vascular disease, simultaneously paying attention to identify other risk factors such as foot deformities, past foot ulcers, visual impairment, and cigarette smoking [97]. Currently, researched mHealth method to facilitate foot care is using high quality photography to diagnose foot ulcers and preulcerative lesions. Trained professional can diagnose visible diabetic foot changes in valid and reliable manner, which implies methods usability as a monitoring tool in home environment [100]. Originally developed was a method for wound area measurement. The wound margins are recognized with the help of smartphone. First, the wound contour is copied on the foil. The area is then measured with smartphone app and compared with previous measurements [101]. 


\subsection{Psychosocial care}

Patients with diabetes should regularly be assessed for their psychosocial well-being. Care should include assessment of their attitudes about the illness and prognosis, mood changes, satisfaction with quality of life, financial, social and emotional conditions, and possible psychiatric disorders (depression, distress, anxiety, eating disorders, dementia). Screening is recommended for depression and cognitive impairment for older than 65 [76].

Telemedicine study researching depression and glycemic control in elderly showed a weak relationship between depression and $\mathrm{HbA} 1 \mathrm{C}$, but depression did not prospectively predict change in glycemic control [102]. In another study, web-based depression treatment for diabetics using cognitive behavior therapy was effective in reducing depressive symptoms, diabetes-specific emotional distress, while it had no benefit on glycemic control [103].

Telephone-based cognitive assessment (TBCA) was previously performed by conventional telephone. Because of better understanding of cognitive impairment, there is a possibility of more accurate TBCA. It needs more complex features of telephone which are easily achieved with the use of smartphones [104].

\subsection{Personal health record (PHR)/electronic medical record (EMR) and social media integration}

PHR is an internet-based set of tools that allows people to access and coordinate their lifelong health information and make appropriate parts of it available to those who need it [105]. Electronic medical record (EMR) is an electronic record with documents of patient's treatment in a clinic. Electronic health record (EHR) is a summary of individual's lifetime health status and care. Terms EMR and EHR are often used interchangeably [106].

Overall, $21 \%$ of commercial applications support synchronization of data with PHRs. Half of reviewed studies have integrated PHR with EMR and provide both patient and physician Web portal, whereas other included either a patient view or a clinician view of the EMR [56].

Social media integration is also emerging function of diabetes apps. It can help patients find similar users and communities in a dynamic fashion. But the majority of apps only provides links to their groups in well-known social networking sites such as Facebook and Twitter or maybe provides an account to a forum [59].

\section{Usability, accessibility, and acceptability of diabetes apps}

In a study of feasibility and acceptability of PDA-based (personal digital assistant-based) dietary self-monitoring of diabetes patients at the time of advent of the first smartphone high percentage of participants reported that they found PDA-monitoring useful, that the app was easy to use and that feedback was easily understandable [107]. In another study with PDAs, several limitations were found that may have contributed to perceived frustration including usability, data loss/errors (especially mistyped numbers) and time constraint (time consuming 
and tedious handling) [108]. A new study revealed that the perceived additional benefit and the perceived ease of use had the strongest impact on acceptance of diabetes smartphone technology by patients 50 or older. Less important factors were previous experiences, health status, support, confidence in own technical knowledge, perceived data security, and fault tolerance. The target group of diabetes patients aged 50 or older is a rather heterogeneous one and their needs are highly heterogeneous due to differences in previous knowledge, age, type of diabetes, and therapy. For that reason, it is impossible to address the needs of all diabetes patients adequately with one diabetes app in order to gain an additional benefit. Therefore, the contents of a helpful diabetes app should be individually adaptable [109]. There is a lack of systems that can perform automated translation of behavioral data into specific actionable suggestions that promote healthier lifestyle without any human involvement. The first attempts were made to create personalized, contextualized, actionable suggestions automatically from self-tracked information [110].

Ten percent of all available apps in 2013 were evaluated within usability evaluation by three experts considering the special requirements of diabetes patients age 50 years or older. Four main criteria were evaluated, being "comprehensibility," "presentation," "usability," and "general characteristics." The main criteria, "comprehensibility," rated best. In particular, the elderly benefit from easy, understandable semantics and easy, comprehensible, and interpretable images and depictions. It can lower inhibition thresholds, especially during the first time of use. The same is true for the influence of "easily understandable feedback" and an "intuitive usability" (main criterion "usability"). However, these two subcriteria performed worse within evaluation. Test of accessibility features indicated a very good operability of the screen readers. The criterion "fault tolerance" rated worst. Especially, inexperienced (elderly) users often have difficulties with inputting data. Some errors are unrecoverable or even cause the application to shut down [58].

\section{Type 1 diabetes mellitus}

We have to say some words about type 1 diabetes mellitus. We described until now mobile health interventions irrespective of the diabetes type. Because type 2 diabetes is much more widespread, studies included mostly or exclusively type 2 diabetes patients.

Young people with type 1 diabetes have many ideas and can help improve services and their own health-related quality of life. However, their lifestyle and their use of Web and smartphones to cope the disease are not well researched [111].

A systematic review was carried out, focused on the ability of mobile health tools to grant patients with type 1 diabetes greater glycemic control. The tools investigated took a variety of forms and provided a number of different services to a diabetic patient. The indicator demonstrating the intervention to be successful was HbA1c and it was decreased in majority of studies, but not all values were statistically significant. In addition, prospective studies were predominantly used instead of randomized controlled trials [112]. 
Qualitative interviewing and exploring how young people with diabetes type 1 make use of technology in their lives and in relation to their condition and treatment, was made. On that basis, many suggestions to develop apps were found including issues such as alcohol and diabetes, hypoglycemia and diabetes, illness and diabetes, and Twitter use for diabetics. All listed suggestions were taken forward for prototyping, with alcohol and diabetes being developed as clinically approved app. There were also many other issues suggested, that were not prototyped [111].

In UK, a competition for teams including at least one young person with diabetes to develop an app, that might help this group of patients in preparation for their diabetes appointments, was conducted. After the development, other young people with diabetes were invited to choose, test and review new apps. The competition proved successful, showing the app designers and developers a need to develop a range of new functions [113].

Insulin calculator apps for patients with diabetes were scrutinized, because self-medication errors are recognized source of avoidable harm. Users are at risk of both catastrophic overdose and more subtle-suboptimal glucose control. In a research, considering input, only 59\% calculators included clinical disclaimer and only 30\% documented the calculation formula. $91 \%$ lacked numeric input validation, problems were also with calculation with missing values, ambiguous terminology, even with numeric precision. Considering output, $67 \%$ of calculators carries a risk of inappropriate output dose recommendation that either violated basic clinical assumptions or did not match a stated formula or correctly update in response to changing user input. It is advised, that health care professionals should exercise substantial caution in recommending unregulated dose calculators to patients and take care for proper education about possible threats [114].

\section{Doctors' involvement}

Little attention has been paid to physicians' intentions to adopt mobile diabetes monitoring technology. Japan study showed that overall quality (system quality, information quality, and service quality) assessment does affect doctors' intention to use this technology, but only indirectly through perceived value. Net benefits (both ubiquitous control and health improvement) seem to be also a strong driver in both a direct and indirect manner [115].

Combined smartphone-based logging of different health parameters (e.g., blood sugar logging, insulin dose logging, bread unit logging, activity logging) can of course help doctor (diabetologist) in solving glycemic control problems. With these data, diabetologist can make individualized recommendations for every patient [116].

\section{Economic effectiveness}

It was establish that standard, technology unsupported, diabetes interventions are costeffective. Effective base therapy typically costs up to $\$ 50,000$ per each quality adjusted life year 
gained [117]. Activities that focus on intensive lifestyle changes, universal opportunistic screening for undiagnosed type 2 diabetes, intensive glycemic control, annual screening for diabetic retinopathy were proven to cost $\leq \$ 25,000$ per life year gained or per quality-adjusted life year, what categorizes them as very cost-effective [118]. If there is to be expected that mHealth interventions will be introduced in everyday diabetes patients' care, they need to show themselves to be more cost-effective than standard treatment. In other words, they should cost less than an amount that we are already willing to pay for diabetes treatment. Current diabetes cost-effectiveness studies are sparse, but promising. Findings of one such study demonstrated annual cost decrease by using mHealth glucose meter with a support of disease management call center that outweighed higher program costs by several-folds. Implementation of technology supported care meant \$50 per patient per month higher expenses than standard care, however in a year's time it was possible to register $\$ 3384$ cost decrease compared with an increase of $\$ 282$ among those with previously established course of treatment [119]. Immediate cost reduction after implementation of telehealth is primarily due to the absence of transportation costs per patient visit to outpatient clinic and productivity savings, because of eliminated need for frequent work absences. More substantial medical savings can be seen with a long term use [120]. Furthermore, it is reasonable to predict lowering of medical cost with growing number of diabetes patient included in automated telephonelinked interventions. For illustration, delivery of mHealth solution to 10,000 patients instead of 1000 can reduce expenses from $£ 444$ per patient to $£ 301$ [121]. In other economic evaluations, new management methods were determine to be associated with higher cost per quality adjusted life year and not cost-effective addition to standard care. This economic model argues that even with $80 \%$ reduction in equipment cost and full utilization of the telehealth service the probability of cost-effectiveness would only reach $61 \%$ at the $£ 30,000$ threshold of willingness to pay [122]. Still, individual research results are too heterogeneous to enable extraction of significant meaning regarding a possible medical expenditure reduction with continuous use of mHealth solution [123].

\section{Future trends}

Clinical decision support systems are active knowledge systems using two or more items of patient's data to generate case specific advice. It is in majority of cases standalone technology or integrated in provider's information system and is used by doctors or other medical staff [124]. Many mobile decision support software apps for smartphones are now available for diabetes and are intended to assist patients to make decisions for themselves in real time without having to contact their health care provider. For many minute-to-minute decisions, the questions are not sufficiently significant to warrant contacting a health care provider and there is insufficient time to wait for a reply. Mobile decision support apps can be helpful to assist patients to identify data patterns and make it easier for them to come to an immediate decision on their own [52]. With the advent of minimally invasive subcutaneous continuous glucose monitoring increasing academic and industrial effort has been focused on the development of SC-SC (subcutaneous-subcutaneous) artificial pancreas systems, using continuous 
glucose monitoring coupled with continuous subcutaneous insulin infusion. Next step is use of mobile system as user interface which is controlled by the patient. The interface is based on patient's commercial mobile phone [125].

\section{Conclusion}

Use of mobile health technology for empowerment of patients with diabetes is an emerging way to improve their health and wellbeing. It can address almost every problem of diabetic patient. But approaches are diverse and every app has its own properties and functionalities. There are many apps on the market, but only few of them are adequately certified by health care authorities. Therefore, their quality is questionable. But many studies showed, mHealth is effective and even cost-effective, though more research is needed.

The future applications should be more personally oriented, improved regarding usability and accessibility, and based on accepted clinical guidelines.

\section{Author details}

Matjaž Krošel ${ }^{1}$, Lana Švegl ${ }^{1}$, Luka Vidmar ${ }^{2}$ and Dejan Dinevski ${ }^{1 *}$

*Address all correspondence to: dejan.dinevski@uni-mb.si

1 Faculty of Medicine, University of Maribor, Maribor, Slovenia

2 Telekom Slovenije d.d., Ljubljana, Slovenia

\section{References}

[1] O'Grady MJ, Capretta JC. Health-care cost projections for diabetes and other chronic diseases: the current context and potential enhancements. Partnership to Fight Chronic Disease. [Internet]. 2009. Available from: http://www.fightchronicdisease.org/sites/ default/files/docs/PFCD_whitepaper5.21.09.pdf [Accessed: 2016-02-15]

[2] Pauws S, Schonenberg H, Maramis C, et al. ACT Programme. Deliverable: Evaluation Engine for Advancing Care Coordination and Telehealth Deployment. DG SANCO; [Internet]. 2013. Available from: http://www2.med.auth.gr/act/documents/del2.pdf [Accessed: 2016-02-15].

[3] Eriksson T. A Danish Chronic Care Model \& Risk Stratification. EQuiP. [Internet]. 2007. Available from: http://equip2.dudal.com/dcmpage/national_pages/denmark/ a_danish_chronic_care_model_risk_stratification/ [Accessed: 2016-02-15]. 
[4] International Diabetes Federation. IDF diabetes Atlas. 7th ed. [Internet]. 2015. Available from: http://www.diabetesatlas.org/ [Accessed: 2016-02-15].

[5] Funnell MM, Anderson RM. MSJAMA: The problem with compliance in diabetes. JAMA. 2000;284(13):1709. DOI: 10.1001/jama.284.13.1709-JMS1004-6-1.

[6] American Diabetes Association. Diagnosis and classification of diabetes mellitus. Diabetes Care. 2014;37(Suppl. 1):S81-S90. DOI: 10.2337/dc14-S081.

[7] Kulshrestha M, Seth S, Tripathi A, Seth A, Kumar A. Prevalence of complications and clinical audit of management of type 2 diabetes mellitus: A prospective hospital based study. J Clin Diagnostic Res. 2015;9(11):OC25-OC28. DOI: 10.7860/JCDR/ 2015/15369.6848.

[8] Stratton IM, Adler AI, Neil AHW, et al. Association of glycaemia with macrovascular and microvascular complications of type 2 diabetes (UKPDS 35): prospective observational study. BMJ. 2000;321(7258):405-412. DOI: 10.1136/bmj.321.7258.405.

[9] De Geest S, Sabaté E. Adherence to long-term therapies: evidence for action. Eur J Cardiovasc Nurs. 2003;2(4):323. DOI: 10.1016/S1474-5151(03)00091-4.

[10] Bailey CJ, Kodack M. Patient adherence to medication requirements for therapy of type 2 diabetes. Int J Clin Pr. 2011;65(3):314-322. DOI: 10.1111/j.1742-1241.2010.02544.x.

[11] Delamater AM. Improving patient adherence. Clin Diabetes. 2006;24(2):71-77. DOI: 10.2337/diaclin.24.2.71.

[12] Karter AJ, Ackerson LM, Darbinian JA, et al. Self-monitoring of blood glucose levels and glycemic control: the Northern California Kaiser Permanente Diabetes registry. Am J Med. 2001;111(1):1-9. DOI: 10.1016/S0002-9343(01)00742-2.

[13] Harris MI, National Health and Nutrition Examination Survey (NHANES). Frequency of blood glucose monitoring in relation to glycemic control in patients with type 2 diabetes. Diabetes Care. 2001;24(6):979-982. DOI: 10.2337/diacare.24.6.979.

[14] Wild H. The economic rationale for adherence in the treatment of type 2 diabetes mellitus. Am J Manag Care. 2012;18(Suppl. 3):S43-S48 [Internet]. Available from: http:// www.ajmc.com/journals/supplement/2012/A405_12Apr_Diabetes/The-EconomicRationale-for-Adherence-in-the-Treatment-of-Type-2-Diabetes-Mellitus/ [Accessed: 2016-02-15].

[15] Salas M, Hughes D, Zuluaga A, Vardeva K, Lebmeier M. Costs of medication nonadherence in patients with diabetes mellitus: a systematic review and critical analysis of the literature. Value Heal. 2009;12(6):915-922. DOI: 10.1111/j.1524-4733.2009.00539.x.

[16] Koenigsberg MR, Bartlett D, Cramer JS. Facilitating treatment adherence with lifestyle changes in diabetes. Am Fam Physician. 2004;69(2):309-316+319 [Internet]. Available from: http://www.aafp.org/afp/2004/0115/p309.html [Accessed: 2016-02-15]. 
[17] Chou AF, Brown AF, Jensen RE, Shih S, Pawlson G, Scholle SH. Gender and racial disparities in the management of diabetes mellitus among Medicare patients. Women Heal Issues. 2007;17(3):150-161.

[18] Delamater AM, Jacobson AM, Anderson B, et al. Psychosocial therapies in diabetes report of the psychosocial therapies working group. Diabetes Care. 2001;24(7):12861292. DOI: 10.2337/diacare.24.7.1286.

[19] Funnell MM, Anderson RM. Empowerment and self-management of diabetes. Clin Diabetes. 2004;22(3):123-127. DOI: 10.2337/diaclin.22.3.123.

[20] Stanford Patient Education Research Center. Chronic Disease Self-Management Program (Better Choices, Better Health ${ }^{\circledR}$ Workshop). Stanford Medicine [Internet]. Available from: http://patienteducation.stanford.edu/programs/diabeteseng.html [Accessed: 2016-02-15].

[21] Health Consumer Powerhouse AB. The Empowerment of the European Patient 2009 options and implications. 2009:1-56 [Internet]. Available from: http://www.healthpowerhouse.com/files/EPEI-2009/european-patient-empowerment-2009-report.pdf [Accessed: 2016-02-15].

[22] Aikens JE, Zivin K, Trivedi R, Piette JD. Diabetes self-management support using mHealth and enhanced informal caregiving. J Diabetes Complicat. 2014;28(2):171-176. DOI: 10.1016/j.jdiacomp.2013.11.008.

[23] Krichbaum K, Aarestad V, Buethe M. Exploring the connection between self-efficacy and effective diabetes self-management. Diabetes Educ. 2003;29(4):653-662. DOI: $10.1177 / 014572170302900411$.

[24] Norris SL, Lau J, Smith SJ, Schmid CH, Engelgau MM. Self-management education for adults with type 2 diabetes: a meta-analysis of the effect on glycemic control. Diabetes Care. 2002;25(7):1159-1171. DOI: 10.2337/diacare.25.7.1159.

[25] Chodosh J, Morton SC, Mojica W, et al. Meta-analysis: chronic disease self-management programs for older adults. Ann Intern Med. 2005;143(6):427-438. DOI: 10.7326/0003-4819-143-6-200509200-00007.

[26] Norris SL, Engelgau MM, Narayan KM. Effectiveness of self-management training in type 2 diabetes: a systematic review of randomized controlled trials. Diabetes Care. 2001;24(3):561-587. DOI: 10.2337/diacare.24.3.561.

[27] Weingarten SR, Henning JM, Badamgarav E, et al. Interventions used in disease management programmes for patients with chronic illness-which ones work? Metaanalysis of published reports. BMJ. 2002;325(7370):925. DOI: 10.1136/bmj.325.7370.925.

[28] McAllister M, Dunn G, Payne K, Davies L, Todd C. Patient empowerment: the need to consider it as a measurable patient-reported outcome for chronic conditions. BMC Heal Serv Res. 2012;12(1):1. DOI: 10.1186/1472-6963-12-157. 
[29] Aujoulat I, Marcolongo R, Bonadiman L, Deccache A. Reconsidering patient empowerment in chronic illness: a critique of models of self-efficacy and bodily control. Soc Sci Med. 2008;66(5):1228-1239. DOI: 10.1016/j.socscimed.2007.11.034.

[30] Hernandez-Tejada MA, Campbell JA, Walker RJ, Smalls BL, Davis KS, Egede LE. Diabetes empowerment, medication adherence and self-care behaviors in adults with type 2 diabetes. Diabetes Technol Ther. 2012;14(7):630-634. DOI: 10.1089/dia.2011.0287.

[31] Fitbit [Internet]. Available from: http://www.fitbit.com/uk/home\# [Accessed: 2016-02-15].

[32] BitBite Mindful Eating Habits [Internet]. Available from: http://www.thebitbite.com/ [Accessed: 2016-02-15].

[33] iHealth Innovative Mobile Healthcare Products [Internet]. Available from: https:// ihealthlabs.com/ [Accessed: 2016-02-15].

[34] Medisana. VitaDock+ [Internet]. Available from: https://cloud.vitadock.com/ [Accessed: 2016-02-15].

[35] VPD [Internet]. Available from: http://www.vpd.si/ [Accessed: 2016-02-15].

[36] Abbott [Internet]. Available from: http://www.abbott.com/ [Accessed: 2016-02-15].

[37] Najafi B. SmartSox: a smart textile to prevent diabetic foot amputation. Qatar Found Annu Res Forum Proc. 2013:BIOP 013. DOI: 10.5339/qfarf.2013.BIOP-013.

[38] Stanford School of Medicine. Smartphones become "eye-phones" with low-cost devices developed by ophthalmologists. [Internet]. 2014. Available from: https://med.stanford.edu/news/all-news/2014/03/smartphones-become-eye-phones-with-low-costdevices-developed-by-ophthalmologists.html [Accessed: 2016-02-15].

[39] Preventice Solutions. BodyGuardian [Internet]. Available from: http://www.preventicesolutions.com/healthcare-professionals.html [Accessed: 2016-02-15].

[40] Google. Google Fit [Internet]. Available from: https://fit.google.com/ [Accessed: 2016-02-15].

[41] Moves. Activity Diary of your Life [Internet]. Available from: https://www.movesapp.com/ [Accessed: 2016-02-15].

[42] Case MA, Burwick HA, Volpp KG, Patel MS. Accuracy of smartphone applications and wearable devices for tracking physical activity data. JAMA. 2015;313(6):625. DOI: 10.1001/jama.2014.17841.

[43] 24alife [Internet]. Available from: https://www.24alife.com/home [Accessed: 2016-02-15].

[44] Dacadoo. What's your Health Score? [Internet]. Available from: https://www.dacadoo.com/ [Accessed: 2016-02-15]. 
[45] LTFE. DeStress Assistant [Internet]. Available from: http://desa.ltfe.org/ [Accessed: 2016-02-15].

[46] SkyHealth LLC. Diabetes and Blood Sugar Management Software [Internet]. Available from: http://www.glucosebuddy.com/ [Accessed: 2016-02-15].

[47] Sieverdes JC, Treiber F, Jenkins C. Improving diabetes management with mobile health technology. Am J Med Sci. 2013;345(4):289-295. DOI: 10.1097/MAJ.0b013e3182896cee.

[48] Patel MS, Asch DA, Volpp KG. Wearable devices as facilitators, not drivers, of health behavior change. JAMA. 2015;3(313):459-460. DOI: 10.1001/jama.2014.14781.

[49] Polisena J, Tran K, Cimon K, Hutton B, McGill S, Palmer K. Home telehealth for diabetes management: a systematic review and meta-analysis. Diabetes Obes Metab. 2009;11(10): 913-930. DOI: 10.1111/j.1463-1326.2009.01057.x.

[50] Jackson CL, Bolen S, Brancati FL, Batts-Turner ML, Gary TL. A systematic review of interactive computer-assisted technology in diabetes care. J Gen Intern Med. 2006;21(2): 105-110.

[51] Vrbnjak D, Pajnkihar M, Stožer A, Dinevski D. M-health and diabetes mellitus. In: Proceedings of the 2014 Congress Better Information for More Health (MI'2014); 6-7 November 2014; Zreče. Ljubljana: SDMI. 2014. p. $28^{\prime} 33$.

[52] Klonoff DC. The current status of mHealth for diabetes: will it be the next big thing? J Diabetes Sci Technol. 2013;77(33):749-758. DOI: 10.1177/193229681300700321.

[53] Anderson M. Technology Device Ownership: 2015. Pew Research Center. 2015 [Internet]. Available from: http://www.pewinternet.org/2015/10/29/technologydevice-ownership-2015 [Accessed: 2016-02-15].

[54] Pew Research Center. Emerging Nations Embrace Internet, Mobile Technology. [Internet]. 2014. Available from: http://www.pewglobal.org/files/2014/02/Pew-Research-Center-Global-Attitudes-Project-Technology-Report-FINAL-February-13-20147.pdf [Accessed: 2016-02-15].

[55] Vital Wave Consulting. mHealth for Development: The Opportunity of Mobile Technology for Healthcare in the Developing World. Washington, D.C. and Berkshire, UK: UN Foundation-Vodafone Foundation Partnership; 2009 [Internet]. Available from: http://www.globalproblems-globalsolutions-files.org/unf_website/assets/ publications/technology/mhealth/mHealth_for_Development_full.pdf [Accessed: 2016-02-15].

[56] El-Gayar O, Timsina P, Nawar N, Eid W. Mobile applications for diabetes selfmanagement: status and potential. J Diabetes Sci Technol. 2013;7(1):247-262. DOI: $10.1177 / 193229681300700130$.

[57] Fiordelli M, Diviani N, Schulz PJ. Mapping mHealth research: a decade of evolution. J Med Internet Res. 2013;15(5):e95. DOI: 10.2196/jmir.2430. 
[58] Arnhold M, Quade M, Kirch W. Mobile applications for diabetics: a systematic review and expert-based usability evaluation considering the special requirements of diabetes patients age 50 years or older. J Med Internet Res. 2014;16(4):e104. DOI: 10.2196/jmir. 2968.

[59] Chomutare T, Fernandez-Luque L, Arsand E, Hartvigsen G. Features of mobile diabetes applications: review of the literature and analysis of current applications compared against evidence-based guidelines. J Med Internet Res. 2011;13(3):e65. DOI: 10.2196/jmir. 1874.

[60] Årsand E, Frøisland DH, Skrøvseth SO, et al. Mobile health applications to assist patients with diabetes: lessons learned and design implications. J Diabetes Sci Technol. 2012;6(5):1197-1206. DOI: 10.1177/193229681200600525.

[61] Georga EI, Protopappas VC, Bellos C V, Fotiadis DI. Wearable systems and mobile applications for diabetes disease management. Heal Technol. 2014;4(2):101-112. DOI: 10.1007/s12553-014-0082-y.

[62] Parkin CG, Buskirk A, Hinnen DA, Axel-Schweitzer M. Results that matter: structured vs. unstructured self-monitoring of blood glucose in type 2 diabetes. Diabetes Res Clin Pr. 2012;97(1):6-15. DOI: 10.1016/j.diabres.2012.03.002.

[63] Polonsky WH, Fisher L, Schikman $\mathrm{CH}$, et al. Structured self-monitoring of blood glucose significantly reduces A1C levels in poorly controlled, noninsulin-treated type 2 diabetes: results from the Structured Testing Program study. Diabetes Care. 2011;34(2): 262-267. DOI: 10.2337/dc10-1732.

[64] Goyal S, Morita P, Lewis GF, Yu C, Seto E, Cafazzo JA. The systematic design of a behavioural mobile health application for the self-management of type 2 diabetes. Can J Diabetes. 2016;40(1):95-104. DOI: 10.1016/j.jcjd.2015.06.007.

[65] Pal K, Eastwood S V, Michie S, et al. Computer-based interventions to improve selfmanagement in adults with type 2 diabetes: a systematic review and meta-analysis. Diabetes Care. 2014;37(6):1759-1766. DOI: 10.2337/dc13-1386.

[66] Baron J, McBain H, Newman S. The impact of mobile monitoring technologies on glycosylated hemoglobin in diabetes: a systematic review. J Diabetes Sci Technol. 2012;6(5):1185-1196.

[67] Granado-Font E, Flores-Mateo G, Sorlí-Aguilar M, et al. Effectiveness of a smartphone application and wearable device for weight loss in overweight or obese primary care patients: protocol for a randomised controlled trial. BMC Public Health. 2015;15(1):531. DOI: $10.1186 / \mathrm{s} 12889-015-1845-8$.

[68] Yu Z, Sealey-Potts C, Rodriguez J. Dietary self-monitoring in weight management: current evidence on efficacy and adherence. J Acad Nutr Diet. 2015;115(12):1931-1938. DOI: 10.1016/j.jand.2015.04.005.

[69] Nelson KM, Reiber G, Boyko EJ, NHANES III. Diet and exercise among adults with type 2 diabetes: findings from the third national health and nutrition examination 
survey (NHANES III). Diabetes Care. 2002;25(10):1722-1728. DOI: 10.2337/diacare. 25.10.1722.

[70] American Diabetes Association. Foundations of care: education, nutrition, physical activity, smoking cessation, psychosocial care, and immunization. Sec. 4. In Standards of Medical Care in Diabetes - 2015. Diabetes Care. 2015;38(Suppl. 1):S20-S30. DOI: 10.2337/dc15-S007.

[71] Wu W, Dasgupta S, Ramirez EE, Peterson C, Norman GJ. Classification accuracies of physical activities using smartphone motion sensors. J Med Internet Res. 2012;14(5):e130. DOI: 10.2196/jmir.2208.

[72] Hurling R, Catt M, Boni MD, et al. Using internet and mobile phone technology to deliver an automated physical activity program: randomized controlled trial. J Med Internet Res. 2007;9(2):e7. DOI: 10.2196/jmir.9.2.e7.

[73] Glynn LG, Hayes PS, Casey M, et al. Effectiveness of a smartphone application to promote physical activity in primary care: the SMART MOVE randomised controlled trial. Br J Gen Pr. 2014;64(624):e384-e391. DOI: 10.3399/bjgp14X680461.

[74] Direito A, Dale LP, Shields E, Dobson R, Whittaker R, Maddison R. Do physical activity and dietary smartphone applications incorporate evidence-based behaviour change techniques? BMC Public Health. 2014;14:646. DOI: 10.1186/1471-2458-14-646.

[75] Handelsman Y, Bloomgarden ZT, Grunberger G, et al. American association of clinical endocrinologists and American college of endocrinology - clinical practice guidelines for developing a diabetes mellitus comprehensive care plan - 2015. Endocr Pr. 2015;21(Suppl. 1):1-87. DOI: 10.4158/EP15672.GL.

[76] American Diabetes Association. Standards of medical care in diabetes - 2016. Diabetes Care. 2016;39(Suppl. 1):S1-S112. DOI: 10.2337/dc14-S014.

[77] Bays HE, Chapman RH, Grandy S, Group the SI. The relationship of body mass index to diabetes mellitus, hypertension and dyslipidaemia: comparison of data from two national surveys. Int $J$ Clin Pr. 2007;61(5):737-747. DOI: 10.1111/j. 1742-1241.2007.01336.x.

[78] Bae JP, Lage MJ, Mo D, Nelson DR, Hoogwerf BJ. Obesity and glycemic control in patients with diabetes mellitus: analysis of physician electronic health records in the US from 2009-2011. J Diabetes Complicat. 2015. DOI: 10.1016/j.jdiacomp.2015.11.016.

[79] Wing RR, Lang W, Wadden TA, et al. Benefits of modest weight loss in improving cardiovascular risk factors in overweight and obese individuals with type 2 diabetes. Diabetes Care. 2011;34(7):1481-1486. DOI: 10.2337/dc10-2415.

[80] Carter MC, Burley VJ, Nykjaer C, Cade JE. Adherence to a smartphone application for weight loss compared to website and paper diary: pilot randomized controlled trial. J Med Internet Res. 2013;15(4):e32. DOI: 10.2196/jmir.2283. 
[81] Burke LE, Conroy MB, Sereika SM, et al. The effect of electronic self-monitoring on weight loss and dietary intake: a randomized behavioral weight loss trial. Obes (Silver Spring). 2011;19(2):338-344. DOI: 10.1038/oby.2010.208.

[82] Turner-McGrievy G, Tate D. Tweets, Apps, and Pods: results of the 6-month mobile pounds off digitally (mobile POD) randomized weight-loss intervention among adults. J Med Internet Res. 2011;13(4):e120. DOI: 10.2196/jmir.1841.

[83] American Diabetes Association. Cardiovascular disease and risk management. Sec. 8. In Standards of Medical Care in Diabetes - 2015. Diabetes Care. 2015;38(Suppl. 1):S49_ S57. DOI: $10.2337 /$ dc15-S011.

[84] Logan AG, Irvine MJ, McIsaac WJ, et al. Effect of home blood pressure telemonitoring with self-care support on uncontrolled systolic hypertension in diabetics. Hypertension. 2012;60(1):51-57. DOI: 10.1161/HYPERTENSIONAHA.111.188409.

[85] Madsen LB, Kirkegaard P, Pedersen EB. Blood pressure control during telemonitoring of home blood pressure. A randomized controlled trial during 6 months. Blood Press. 2008;17(2):78-86. DOI: 10.1080/08037050801915468.

[86] Vervloet M, Linn AJ, van Weert JC, de Bakker DH, Bouvy ML, van Dijk L. The effectiveness of interventions using electronic reminders to improve adherence to chronic medication: a systematic review of the literature. J Am Med Informatics Assoc. 2012;19(5): 696-704. DOI: 10.1136/amiajnl-2011-000748.

[87] Vervloet M, van Dijk L, de Bakker DH, et al. Short- and long-term effects of real-time medication monitoring with short message service (SMS) reminders for missed doses on the refill adherence of people with type 2 diabetes: evidence from a randomized controlled trial. Diabet Med. 2014;31(7):821-828. DOI: 10.1111/dme.12439.

[88] Vervloet M, van Dijk L, Santen-Reestman J, et al. SMS reminders improve adherence to oral medication in type 2 diabetes patients who are real time electronically monitored. Int J Med Inf. 2012;81(9):594-604. DOI: 10.1016/j.ijmedinf.2012.05.005.

[89] Brath H, Morak J, Kästenbauer T, et al. Mobile health (mHealth) based medication adherence measurement - a pilot trial using electronic blisters in diabetes patients. $\mathrm{Br}$ J Clin Pharmacol. 2013;76(Suppl. 1):47-55. DOI: 10.1111/bcp.12184.

[90] Haas L, Maryniuk M, Beck J, et al. National standards for diabetes self-management education and support. Diabetes Care. 2014;37(Suppl. 1):S144-S153. DOI: 10.2337/ dc12-1707.

[91] Azar KMJ, Sukyung Chung M, Wang EJ, et al. Impact of education on weight in newly diagnosed type 2 diabetes: every little bit helps. PLoS One. 2015;10(6):e0129348. DOI: 10.1371/journal.pone.0129348.

[92] Izquierdo RE, Knudson PE, Meyer S, Kearns J, Ploutz-Snyder R, Weinstock RS. A comparison of diabetes education administered through telemedicine versus in person. Diabetes Care. 2003;26(4):1002-1007. DOI: 10.2337/diacare.26.4.1002. 
[93] Saffari M, Ghanizadeh G, Koenig HG. Health education via mobile text messaging for glycemic control in adults with type 2 diabetes: a systematic review and meta-analysis. Prim Care Diabetes. 2014;8(4):275-285. DOI: 10.1016/j.pcd.2014.03.004.

[94] Han Y, Faulkner MS, Fritz H, et al. A pilot randomized trial of text-messaging for symptom awareness and diabetes knowledge in adolescents with type 1 diabetes. $J$ Pediat Nurs. 2015;30(6):850-861. DOI: 10.1016/j.pedn.2015.02.002.

[95] Fijacko N, Brzan PP, Stiglic G. Mobile applications for type 2 diabetes risk estimation: a systematic review. J Med Syst. 2015;39(10):124. DOI: 10.1007/s10916-015-0319-y.

[96] Lee R, Wong TY, Sabanayagam C. Epidemiology of diabetic retinopathy, diabetic macular edema and related vision loss. Eye Vis. 2015;2:17. DOI: 10.1186/ s40662-015-0026-2.

[97] American Diabetes Association. Microvascular complications and foot care. Sec. 9. In Standards of Medical Care in Diabetes-2015. Diabetes Care. 2015;38(Suppl. 1):S58-S66. DOI: 10.2337/dc15-S012.

[98] Bourouis A, Feham M, Hossain MA, Zhang L. An intelligent mobile based decision support system for retinal disease diagnosis. Decis Support Syst. 2014;59(1):341-350. DOI: 10.1016/j.dss.2014.01.005.

[99] Shojaiefard A, Khorgami Z, Larijani B. Independent risk factors for amputation in diabetic foot. Int J Diabetes Dev Ctries. 2008;28(2):32-37. DOI: 10.4103/0973-3930.43096.

[100] Hazenberg CE, van Baal JG, Manning E, Bril A, Bus SA. The validity and reliability of diagnosing foot ulcers and pre-ulcerative lesions in diabetes using advanced digital photography. Diabetes Technol Ther.2010;12(12):1011-1017. DOI: 10.1089/dia.2010.0088.

[101] Foltynski P, Ladyzynski P, Wojcicki JM. A new smartphone-based method for wound area measurement. Artif Organs. 2014;38(4):346-352. DOI: 10.1111/aor.12169.

[102] Trief P, Morin P, Izquierdo R, et al. Depression and glycemic control in elderly ethnically diverse patients with diabetes. Diabetes Care. 2006;29(4):830-835.

[103] Baasterlar KMP, Pouwer F, Cuijpers P, Riper H, Snoek FJ. Web-based depression treatment for type 1 and type 2 diabetic patients. Diabetes Care. 2011;34:320-325. DOI: 10.2337/dc10-1248.

[104] Kwan RYC, Lai CKY. Can smartphones enhance telephone-based cognitive assessment (TBCA)? Int J Environ Res Public Health. 2013;10:7110-7125. DOI: 10.3390/ ijerph10127110.

[105] Markle Foundation. Connecting for health. A public-private collaborative. The Personal Health Working Group Final Report. [Internet]. 2003. Available from: http:// www.providersedge.com/ehdocs/ehr_articles/The_Personal_Health_Working_Group_Final_Report.pdf [Accessed: 2016-02-15]. 
[106] Shortliffe EH, Cimino JJ. Biomedical Informatics: Computer Applications in Health Care and Biomedicine. 4th ed. London: Springer-Verlag; 2014. DOI: 10.1007/978-1-4471-4474-8.

[107] Sevick MA, Zickmund S, Korytkowski M, et al. Design, feasibility, and acceptability of an intervention using personal digital assistant-based self-monitoring in managing type 2 diabetes. Contemp Clin Trials. 2008;29(3):396-409. DOI: 10.1016/j.cct.2007.09.004.

[108] Vuong A V, Huber JC, Brolin JN, et al. Factors affecting acceptability and usability of technological approaches to diabetes self-management: a case study. Diabetes Technol Ther. 2012;14(12):1178-1182. DOI: 10.1089/dia.2012.0139.

[109] Scheibe M, Reichelt J, Bellmann M, Kirch W. Acceptance factors of mobile apps for diabetes by patients aged 50 or older: a qualitative study. Med 2 0. 2015;4(1):e1. DOI: 10.2196/med20.3912.

[110] Rabbi M, Pfammatter A, Zhang M, Spring B, Choudhury T. Automated personalized feedback for physical activity and dietary behavior change with mobile phones: a randomized controlled trial on adults. JMIR mHealth uHealth. 2015;3(2):e42. DOI: 10.2196/mhealth.4160.

[111] Pulman A, Taylor J, Galvin K, Masding M. Ideas and enhancements related to mobile applications to support type 1 diabetes. J Med Internet Res. 2013;15(7):e12. DOI: 10.2196/ mhealth.2567.

[112] Peterson A. Improving type 1 diabetes management with mobile tools: a systematic review. J Diabetes Sci Technol. 2014;8(4):859-864. DOI: 10.1177/1932296814529885.

[113] Ashurst EJ, Jones RB, Abraham C, et al. The diabetes app challenge: user-led development and piloting of internet applications enabling young people with diabetes to set the focus for their diabetes consultations. Med 2 0. 2014;3(2):e5. DOI: 10.2196/ med20.3032.

[114] Huckvale K, Adomaviciute S, Prieto JT, Leow MK-S, Car J. Smartphone apps for calculating insulin dose: a systematic assessment. BMC Med. 2015;13(1):106. DOI: 10.1186/s12916-015-0314-7.

[115] Okazaki S, Castañeda JA, Sanz S, Henseler J. Factors affecting mobile diabetes monitoring adoption among physicians: questionnaire study and path model. J Med Internet Res. 2012;14(6):e83. DOI: 10.2196/jmir.2159.

[116] Tiefengrabner $M$, Domhardt $M$, Oostingh GJ, et al. Can smartphone-based logging support diabetologists in solving glycemic control problems? Stud Health Technol Inform. 2014;198:188-195. DOI: 10.3233/978-1-61499-397-1-188.

[117] Klonoff DC. Using telemedicine to improve outcomes in diabetes - an emerging technology. J Diabetes Sci Technol. 2009;3(4):624-628 [Internet]. Available from: http:// www.ncbi.nlm.nih.gov/pmc/articles/PMC2769943/ [Accessed: 2016-02-15]. 
[118] Li R, Zhang P, Barker LE, Chowdhury FM, Zhang X. Cost-effectiveness of interventions to prevent and control diabetes mellitus: a systematic review. Diabetes Care. 2010;33(8): 1872-1894. DOI: 10.2337/dc10-0843.

[119] Javitt JC, Reese CS, Derrick MK. Deployment of an mHealth patient monitoring solution for diabetes-improved glucose monitoring leads to reduction in medical expenditure. US Endocrinol. 2013;9(2):119-123.

[120] Levin K, Madsen JR, Petersen I, Wanscher CE, Hangaard J. Telemedicine diabetes consultations are cost-effective, and effects on essential diabetes treatment parameters are similar to conventional treatment: 7-year results from the Svendborg Telemedicine Diabetes Project. J Diabetes Sci Technol. 2013;7(3):587-595.

[121] Gordon LG, Bird D, Oldenburg B, Friedman RH, Russell AW, Scuffham PA. A costeffectiveness analysis of a telephone-linked care intervention for individuals with type 2 diabetes. Diabetes Res Clin Pr. 2014;104(1):103-111. DOI: 10.1016/j.diabres.2013.12.032.

[122] Henderson C, Knapp M, Fernández JL, et al. Cost effectiveness of telehealth for patients with long term conditions (Whole Systems Demonstrator telehealth questionnaire study): nested economic evaluation in a pragmatic, cluster randomised controlled trial. BMJ. 2013;346:f1035. DOI: 10.1136/bmj.f1035.

[123] Zhai YK, Zhu WJ, Cai YL, Sun DX, Zhao J. Clinical- and cost-effectiveness of telemedicine in type 2 diabetes mellitus: a systematic review and meta-analysis. Med. 2014;93(28):e312. DOI: 10.1097/MD.0000000000000312.

[124] Graschew G, Rakowsky S. Telemedicine Techniques and Applications. Intech. [Internet]. 2011. Available from: http://www.intechopen.com/books/telemedicine-techniques-and-applications [Accessed: 2016-02-15]. DOI: 10.5772/724

[125] Keith-Hynes P, Guerlain S, Mize B, et al. DiAs user interface: a patient-centric interface for mobile artificial pancreas systems. J Diabetes Sci Technol. 2013;7(6):1416-1426. DOI: $10.1177 / 193229681300700602$. 


\title{
Chapter 3
}

\section{Telemedicine Programs in Respiratory Diseases}

\author{
Gonzalo Segrelles-Calvo and Daniel López-Padilla \\ Additional information is available at the end of the chapter \\ http://dx.doi.org/10.5772/64705
}

\begin{abstract}
Telemedicine programs are widely used in respiratory diseases, more often in patients with chronic obstructive pulmonary diseases (COPD). Telemedicine platforms use several devices to measure vital signs such as heart rate, respiratory rate, pulsioximetry or blood pressure between others. It is not unusual that patients could do questionnaires about clinical situation or communicate with their nurses via telephone, videocalling and/or Skype. The majority of results has been positive, with reduction in the number of emergency visits, hospitalizations and noninvasive ventilations. Despite their promising results, telemedicine programs/platforms are slow to implement. In this chapter, we reviewed some of the factors related to telemedicine implementation such as patients' adherence, impact of telemedicine design and professionals' resistance to change between others.
\end{abstract}

Keywords: COPD, eHealth, home telemonitoring, telemedicine, telemedicine platforms

\section{Introduction}

Chronic obstructive pulmonary diseases (COPD), asthma and lung transplantation have been, by far, the respiratory diseases or conditions more studied, in terms of telemedicine. However, the interest of telehealth providers in new areas also related to neurologic conditions, such as neuromuscular diseases in need of home noninvasive ventilation (NIV) due to chronic respiratory failure, or sleep-related breathing disorders, has arisen in recent years.

Existing evidence reveals promising results regarding reliability and validity of measures across all pulmonary conditions, and patients usually show a positive attitude toward telecare technologies. Other positive effects, for instance, detection of complications, better disease 
control, immediate feedback, and adequate medication use, have also been addressed [1]. Yet, there is still somewhat decreased adherence within time, possibly secondary to poor health status, time conflicts, device problems, and lack of ability to operate the system [2]. Furthermore, there is no solid evidence about the utilization of healthcare resources, as well as costeffectiveness, paramount scenarios to advocate in favor of this new way of approaching chronic respiratory patients.

In the following section, current evidence apropos specific respiratory diseases (COPD, asthma, lung transplantation, neuromuscular diseases, and SRBD) will be disclosed, focusing on the positive results, along with the pitfalls found so far.

\subsection{Telemedicine}

Telemedicine (TM) has several definitions and all of them emphasize the role of telemedicine to enable the completion of the medical act at distance (Table 1) [3-5]. Norrit et al. define TM as a scientific area that uses information and communication technologies (ICT) to share medical information [6]. Thanks to ICT development, TM clinical opportunities are increasing. The information provided by TM programs can be useful for diagnosis and treatment of several diseases, as well as for enhancing their follow-up.

\begin{tabular}{|c|c|c|}
\hline & Ref & Definition \\
\hline WHO & [3] & $\begin{array}{l}\text { The delivery of health care services, where distance is a critical factor, by all health care } \\
\text { professionals using information and communication technologies for the exchange of valid } \\
\text { information for diagnosis, treatment and prevention of disease and injuries, research and } \\
\text { evaluation, and for the continuing education of health care providers, all in the interests of } \\
\text { advancing the health of individuals and their communities. }\end{array}$ \\
\hline ATA & {$[4]$} & $\begin{array}{l}\text { Telemedicine is the use of medical information exchanged from one site to another via electronic } \\
\text { communications to improve a patient's clinical health status. Telemedicine includes a growing } \\
\text { variety of applications and services using two-way video, email, smart phones, wireless tools, } \\
\text { and other forms of telecommunications technology. }\end{array}$ \\
\hline Bashur R & [5] & $\begin{array}{l}\text { Telemedicine is conceived of as an integrated system of health-care delivery that employs } \\
\text { telecommunications and computer technology as a substitute for face-to-face contact between } \\
\text { provider and client. }\end{array}$ \\
\hline
\end{tabular}

WHO: World Health Organization; ATA: American Telemedicine Association, Ref: Reference.

Table 1. Telemedicine's definitions.

Historically, Dr. Graham Bell performed the first TM experience, when he used the telephone calling for help when he was sick. Also, in 1923, Sahlgrenska University (Gothenburg) used the Morse code to provide medical advice. TM programs were funded by the privacy industries in 1990 for the first time, and in 1993, the first telemedicine symposium was celebrated. Over 50 years, TM has been used for different programs such as: monitored surgeries, remote assistance in rural zones of Arizona, or vital signs monitoring of astronauts in space, just like 
Bashur et al. demonstrated [7]. In fact, aerospace technology development has been one of the most important factors in TM evolution. In 1976, the Hermes satellite was put into orbit with the main objective of improving communications in remote areas of Canada. Since then, the Western Ontario University has been using it for telemonitoring of vital signs, sharing medical information between hospitals and, finally, sharing radiographies [8]. Moreover, the National Aeronautics and Space Administration (NASA) also has used TM to give medical assistance if a disaster takes place.

Generally speaking, TM applications could be classified into three groups: (a) normal clinical activity (teleconsult, telediagnosis, teletreatment, etc.), (b) remote assistance, and (c) administration labors and patient management.

\subsubsection{Clinical activity}

Almost all studies are aimed for telemonitoring patients or sharing medical data, where this medical act at distance needs a TM platform and a clinical response. We could classify the clinical response into two groups: synchronic or asynchronic response (Figure 1). The main difference is the time to response [9]. While in the first group, the clinical response is immediate and allows performing a live medical act, the second group clinical response is deferred (minutes or few hours). Asynchronic response is useful in telepatologhy or teleradiology, or in other telediagnosis programs.

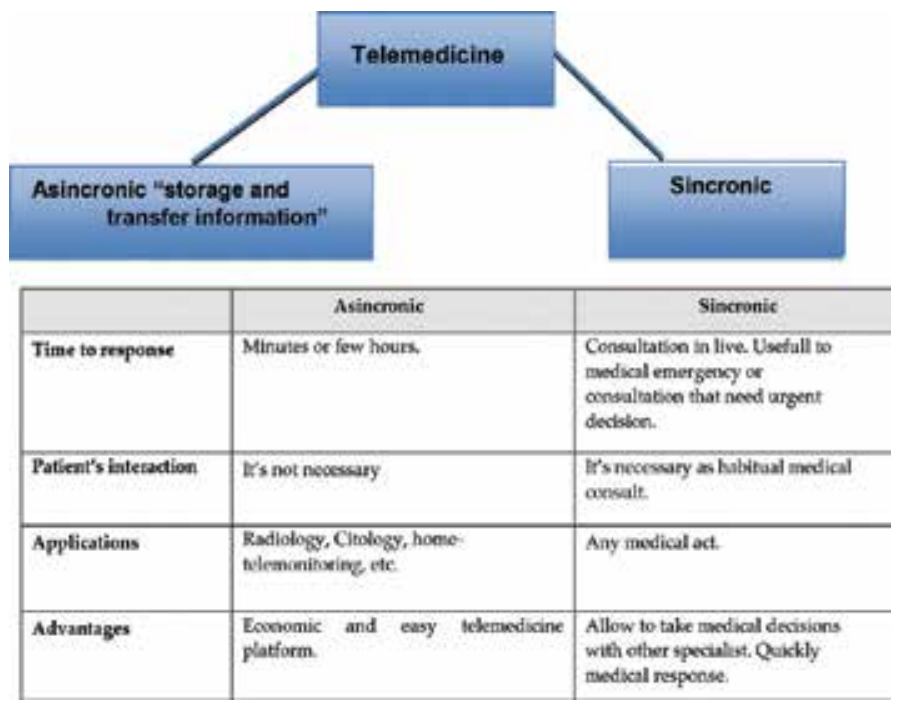

Figure 1. Telemedicine classification.

\subsubsection{Remote assistance}

In this group, several medical actions are included such as online records for consulting previous medical charts, establishing a direct communication between patients and physi- 
cians, or teleconference between primary and specialized care doctors, useful for discussing difficult cases and take decisions for complex patients (terminal disease, multiple comorbidities, social exclusion, impossibility to attend the hospital, etc.).

\subsubsection{Patients' management}

Nowadays, patients manage their medical events via Internet more often, and their doctors can use the same way to give medical recommendations (rehabilitation, nutritional care, tobacco information, or health life recommendations). Obviously, TM is a helpful tool for health care personnel as well. In this case, TM is used to access scientific information or as a type of communication for multicentric and international clinical trials.

\subsection{Telemedicine: barriers and benefits}

According to the Europe Institute of Technologies findings, only 14.2\% of citizens had used the Internet to solve their health related doubts. The more frequent searches regarding these issues were: disease description, clinical trials, medical literature, or patients' disease associations (Table 2).

\begin{tabular}{|l|l|l|l}
\hline \multicolumn{2}{l}{$\begin{array}{l}\text { Information } \\
\text { related to }\end{array}$} & 68,49 & 55,78 \\
\hline \multirow{3}{*}{ Patients } & $\begin{array}{l}\text { Disease } \\
\text { description }\end{array}$ & 33,14 & 21,93 \\
\cline { 2 - 4 } & Clinical Trials & 81,51 & 58,74 \\
\cline { 2 - 4 } & Medical literature & 27,81 & 30,11 \\
\cline { 2 - 4 } & Disease associations & 65,91 & 57,23 \\
\hline \multirow{3}{*}{ Professionals } & $\begin{array}{l}\text { Disease } \\
\text { description }\end{array}$ & 39,94 & 50,21 \\
\cline { 2 - 4 } & Clinical Trials & 90,58 & 89,36 \\
\cline { 2 - 4 } & Medical literature & 18,18 & 16,17 \\
\cline { 2 - 4 } & Disease associations & & \\
& & &
\end{tabular}

Table 2. Search topics by patients and healthcare professionals.

There are several studies that have showed important barriers for applying TM programs. Segrelles-Calvo et al. suggested that healthcare policy, lacking studies about economic burden and cost-effectiveness of TM, no laws regarding the handling of information in TM programs and the resistance to change "usual medicine conception," are some causes that explain slow TM implantation [10]. According to the concept of "resistant to change usual care," Mira-Solves et al. presented the results of the ValCrònic program [11], in which authors discussed the causes to leave a TM program. The main reasons were: (1) difficulty to use the devices, (2) complex 
measures, (3) nonadherence with TM program, (4) technical problems, and (5) caregivers preferences.

Another important barrier not well studied is the opinion of health professionals toward TM programs. Telemedicine collects a lot of information and their belief is that TM increases workload. However, this belief is not displayed in scientific studies. Jódar-Sánchez et al. [12] showed indeed that a specialized nurse could solve most of the clinical urgencies detected, where only 8 of 40 cases needed a pneumologist intervention. Similar results were published by Vitacca et al. [13] reporting that in $63 \%$ of alerts, these could be resolved only by a nurse, and in the rest of them both physician and nurse gave the clinical response. As conclusion, it seems that there are external factors acting as barriers in the TM implantation, and further works are required to establish them. Motulsky et al. [14] and Cresswell et al. [15] pooled those external factors in three groups: (1) healthcare institutions policy, (2) the urge of guidelines about TM, and (3) the need of specific formation and educational resources.

Telemedicine offers four fundamental benefits [4]:

a. Improved access: Telemedicine has been used to bring healthcare services to patients in distant locations.

b. Cost efficiencies: Telemedicine reduces the number of hospitalizations and the cost related to these events. Telemedicine program reduce patient displacement to Hospital and reduced travel times.

c. Improved quality: Studies have consistently shown that the quality of healthcare services delivered via telemedicine is as good as those given in traditional in-person consultations.

d. Patient demand: The greatest impact of telemedicine is on the patient, their family and their community. Telemedicine could reduce travel time and related stresses for the patient. Almost all studies have shown that patient and caregiver's satisfaction is very high.

\subsection{Telemedicine platforms}

In general, there is a common objective in telemedicine programs; however, there are several platforms in which TM could be offered. Telemedicine platforms are related to ICT. The most common scheme in telemedicine (Figure 2) is the one that includes devices to measure different vital signs or questionnaires, in order to perform a teleconsultation or to send educational resources to patients. Those measures could be made by the patients, anywhere and anytime. Clinical information is sent to a call center or a health professional by different means (telephone, Internet, etc.), and the clinical response is made according to all information regarding.

Some of the ICT used in telemedicine platform are as follows:

Videoconference. Possibly this ICT was one of the most important technological advances as a telemedicine platform. Mahmud et al. [16] made a follow-up platform of patients with chronic diseases (heart failure, COPD, cerebrovascular disease). In seven cases, the number of emergency department visits and hospitalizations were reduced, and the authors did not found complications in the use of the videoconference platform. These results were confirmed in 2000 
by Johnston et al. [17] and by Nakamura et al. [18]. Johnston determined a reduction of $17 \%$ of home visits as well as a $27 \%$ reduction of costs in the telemedicine group. Moreover, Nakamura reported an improvement of daily activities in the telemedicine group. Recent studies have used videoconference to improve adherence to a telerehabilitation program [19], to follow-up patients with bipolar disorder [20] or to monitoring tuberculosis therapy compliance [21], among other topics. According to these studies, in our view the videoconference is a remarkable technology, facilitating the follow-up of patients to improve their adherence to treatment.

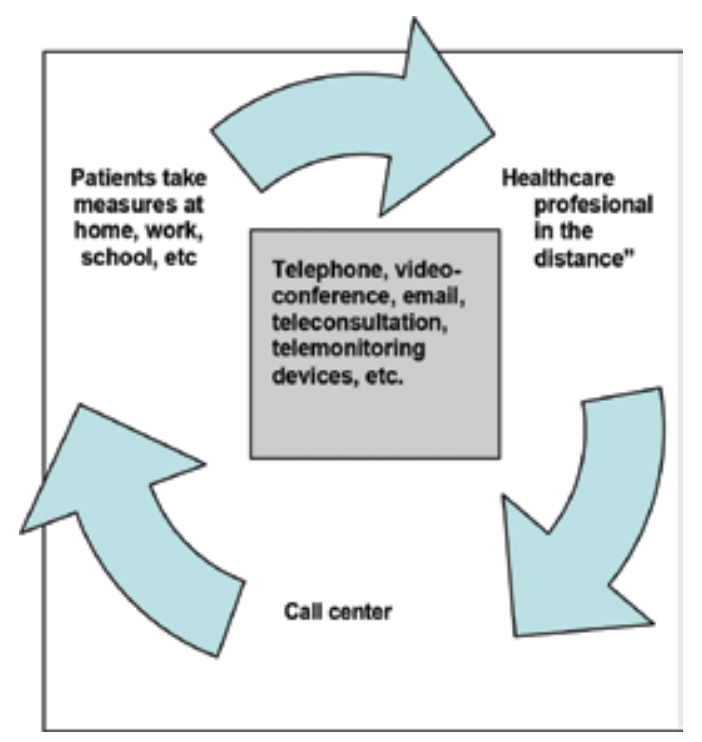

Figure 2. Telemedicine platform.

Telephone. Mainly, studies have focused in the telephone as a device to follow-up of patients but Balas et al. [22] described five possible actions that we could also do via telephone: (1) follow-up, (2) videoconsultation due to interactive telephone, (3) telephonic reminders of taking a medicine or doing an exercise, (4) calling health professionals if case of clinical deterioration, and (5) clinical investigation.

E-mail. Email is a rather quick tool for the patients to communicate with health professionals, making it easier for the latter to perform questionnaires so any given doubt of the patient or caregiver could be cleared up.

\section{Chronic obstructive pulmonary diseases}

It is now consensually agreed that an estimated number of 328 million people have COPD worldwide, that is, 168 million men and 160 million women. Moreover, COPD causes the death of 2.9 million people annually and it is projected to be the third cause of mortality by 2020 [23]. 
Whereas the three most important factors in individual patients that determine the economic and social costs of COPD are disease severity, presence of frequent exacerbations of disease and the presence of comorbidities, which are common (30-57\%) in COPD patients [24], the current short-term and long-term strategies to reduce the burden of COPD comprise the triad of smoking cessation, minimizing acute exacerbations and management and prevention of comorbidities [25].

Hence, a high priority should be given to interventions aimed at delaying the progression of disease, preventing exacerbations and reducing the risk of comorbidities in order to alleviate the clinical and economic burden of COPD in Western countries [26]. Among these interventions, telemedicine has shown some promising results although no conclusive evidence has been accomplished. The effects of telemedicine in COPD have been addressed in previous systematic reviews [27, 28]; however, their conclusions are not consistent since the types of tested interventions have been rather heterogeneous. These interventions range from simple telephone or video interviews to daily telemonitoring of physiological parameters or symptoms data, and that is why comparativeness of one study to the other does not come along easily.

So far, there is moderate evidence of the benefit of telemedicine in COPD, in terms of increasing quality of life and reducing hospital admissions. Basically, the problem has been that in previous years the studies included in systematic reviews were underpowered, had heterogeneous populations and had lack of detailed intervention descriptions and of the care processes that accompanied telemonitoring [29]. Another issue is the clinical scenario where patients are usually recruited. For instance, telemedicine can be offered to those patients prone to exacerbations that are in stable condition [30], or right after admission regardless of the number of previous exacerbations or $\mathrm{FEV}_{1}$ obstruction severity [31].

Regarding telemonitoring (understood as retrieving periodically clinical data such as oxygen saturation, heart rate, symptoms, etc.), recent data including randomized clinical trials of good quality are now available; however, some of them are still underpowered. In terms of hospital admissions, one of the latest systematic reviews on the matter, which included eight studies with 486 patients randomized to home telemonitoring or usual care, determined a significant lower risk of hospitalizations in the telemonitoring group. However, healthcare utilization in general was similar in both groups, since it was not clear whether the utilization was due to respiratory events specifically, and the lower range of compliance to telemonitoring reported by some studies may have influenced the ability of detecting clinical deterioration [32]. Moreover, even between this data retrieved on a daily basis there were different clinical features measured, which end up inevitability in being quite difficult to integrate quantitative variables because of missing or noncomparative data. Thus, the extrapolation of these results to the general population should be carried out with absolute caution. The usual problem with these systematic reviews is that, due to the heterogeneity of outcomes and the way the studies have assessed them, it is troublesome to determine the true effect of telemonitoring on COPD patients. For instance, adding a closer approach to patients with videoconsultations to the usual telemonitoring, which would be ideal in order to obtain higher rates of compliance or 
reduction of the use of healthcare resources in general, failed to demonstrate differences in hospital admissions or time to first admission or all-cause hospital admissions [33].

Detection and management of COPD exacerbations in early stages is an important step in order to reduce hospital admissions and the consequent increase of quality of life and reduction of health costs in general. So far, telemedicine has proven to be a useful tool to achieve this.

Physical activity, one of the strong mortality predictors in COPD patients, if not the strongest, has not been properly issued. Although no conclusive evidence of telemedicine benefit exists on this regard, the use of telehealthcare may lead to increased physical activity level [34]. A recent study that evaluated the feasibility of a telerehabilitation program compared to a regular outpatient program, showed an increase of physical activity measured by steps/day in the telerehabilitation group, with acceptable rates of satisfaction with the service, although no differences were found when the 6-minute walking test, dyspnea measured by the Medical Research Council or quality of life measured by the St. George's Respiratory Questionnaire were compared [35].

The cost-effectiveness of telemedicine in COPD is yet to be determined. In fact, a recent study carried out in the United Kingdom, which recruited 3230 patients where both at baseline and follow-up participants with COPD made up the largest telehealth intervention group, showed that costs of self-reported service use, combined with telehealth intervention costs, were greater for the group randomized to telehealth in addition to standard care than for the group randomized to usual care alone [36]. However, the validity of this conclusion may be biased for two reasons. First, the trial recruiters had foreknowledge of the allocation groups in many cases [37], and second, its transferability to other healthcare systems was not taken in consideration since the trial did not include all community and healthcare resources. Thus, a recent Danish trial (TeleCare North) will determine the real benefit of telemedicine in COPD in terms of health-related quality of life and the incremental cost-effectiveness ratio through a largescale, pragmatic, cluster-randomized trial with nested economic evaluation [38].

Quality of life, a paramount feature in COPD and a strong predictor of mortality, has been analyzed irregularly. Once again, the instruments used to determine the health related quality of life vary greatly among the telemedicine studies (i.e., Chronic Respiratory Disease Questionnaire, Chronic Respiratory Questionnaire, St. George's Respiratory Questionnaire (SGRQ), Clinical COPD Questionnaire, EURO-QOL-5D Questionnaire, Medical Outcome Study ShortForm 36 Questionnaire), so comparative data is deficient. Overall, no significant differences have been found between a home telemonitoring group and the usual care group [32].

The aim of telemedicine toward COPD patients should be to keep this population outside the hospital or the emergency rooms. Although there is evidence that this aim has been achieved in some studies, we are still in need of larger clinical trials which include a rigorous costeffectiveness analysis in terms of use of healthcare resources separated by respiratory diseases or not, quality of life, and mortality. Furthermore, a 6- or 12-month follow-up is insufficient to determine conclusive differences in favor of telemedicine. 


\section{Asthma}

Asthma is a worldwide disease affecting 300 million of people, and its economic and social costs are mostly related to emergency visits and hospital admissions. Self-monitoring of symptoms and peak flow, following a written action plan and attending regular visits to their physician, have demonstrated to improve asthma control [39], and that is why approaches through telemedicine have been done to increase its control and follow-up. It has been hypothesized that providing self-monitoring tools such as easy-to-use handheld electronic monitoring devices or symptom questionnaires, patients can gain insight into their level of asthma control which gives them suggestions for subsequent treatment adjustment [40]. This is why telemedicine for asthma appears to be a promising tool to achieve this so wished for self-control and management of the disease.

However, there are some pitfalls regarding telemedicine for asthma. If noncomparative data due to the different sort of interventions is a main issue for COPD, the problem is probably more serious for asthma. One of the most relevant systematic reviews in the matter included 21 studies, of which nine consisted in telephone calls, two in videoconferences, two in using the Internet, one in short text messaging, one in a combination of short text and Internet, and six more using other networked communications. This study demonstrated no improvement of quality of life and even a nonsignificant increase of emergency room visits in the telemedicine group, although a significant reduction of hospitalizations was observed [41]. However, some authors have stated some concerns about these meta-analysis conclusions. First of all, there were only few examples of a comprehensive telemanagement approach in asthma (defined as a treatment plan, self-monitoring of lung function by $\mathrm{FEV}_{1}$ and asthma control with feedback and e-communication with a professional to support this self-management), and second, patients in the control strategies often received an enhanced form of usual care, which makes it difficult to draw final conclusions on the effectiveness of telemanagement in asthma [40]. A more recent meta-analysis of 20 trials involving 10,406 asthmatic patients where common outcomes employed were healthcare utilization, quality of life and symptoms, concluded that the median effect of telemedicine was weakly positive, and that there were not differences between the types of interventions (telemonitoring, routine voice contact or videoconferencing). But the problem with this positive effect is that a publication bias exists due to the tendency of more positive results reported in earlier studies, which contained heterogeneous outcomes measurement and assessment [42].

Regarding cost-effectiveness we are still in need of studies addressing the topic specifically, situation that withholds the use of telemedicine for asthma unquestionably. Probably the only evidence of cost-effectiveness of Internet-based self-management compared with usual care, showed no significant differences during a follow-up of one year. However, this study had several limitations, acknowledge by the authors. First, the quality adjusted life year estimates were calculated out of only two measurements throughout one year. Second, patients were inevitable conscious of the allocated group, which may have influenced their utility ratings. And third, the economic evaluation was limited to one year only [43]. Regarding a specific feature of telemedicine, another study showed that telephone consultations led by experienced 
nurses enabled a greater proportion of asthma patients to be reviewed at no additional cost to the health service, although these findings should not be extrapolated as a thorough costeffectiveness analysis, compared to the comprehensive telemanagement as explained before $[44,45]$.

Despite the similar moderate evidence either for asthma or COPD, there are some differences when telehealthcare main purposes are compared between the two diseases. While in COPD telemedicine aims to reduce exacerbations or their early detection in order to avoid emergency rooms visits or hospital admissions, in asthma these objectives are usually directed at assuring a better symptoms self-control and adherence to treatment, considering that undertreatment is the most common problem in European asthmatic subjects [46], and its usual presentation at early stages of life. A fitter control of asthma has been reported possibly secondary to the opportunity of register symptoms continually, thus, the patient obtained a more accurate picture of his disease severity and complied to treatment with a closer and efficient selfmonitoring. However, this severity awareness led to an increased number of unscheduled visits and a harmful consumption of inhaled corticosteroids, which increased their adverse effects [47]. In a similar fashion, another study revealed that 43 patients under a mobile telephone interactive self-control system and compared with a control group, presented significantly higher mean daily dosage of either inhaled or systemic corticosteroids during the study period. Nonetheless, this system also demonstrated fewer unscheduled visits to the emergency department; higher peak expiratory flows at 4, 5, and 6 moths; higher $\mathrm{FEV}_{1}$ at 6 months; and better quality of life at 3 months after inclusion [48].

Compliance to new technologies is a relevant feature of telemedicine since not all of public health systems can afford them, and there are still underprivileged groups who are not familiar to these sorts of interventions. It seems that telemedicine for asthma is feasible, although when compared to a web based self-management, patients presented higher rates of adherence to the classic paper based strategies of self-control of symptoms and action plans, though other critical feature such as lung function data was not reliable when the patient wrote it down on his own [49].

In the pediatric population there is also lacking evidence of telemedicine benefit. Telemonitoring of lung function on daily home spirometry in 44 children with professional feedback did not reduce the frequency of exacerbations significantly when compared to conventional treatment, nor the number of unscheduled visits, $\mathrm{FEV}_{1}$, quality of life or use of inhaled corticosteroids [50]. This finding could be explained by the fact that a highly variable peak expiratory flow and $\mathrm{FEV}_{1}$ values at time of symptoms and a complete overlap in distributions between symptoms-free days and at times of symptoms [51], and also by the underpowered nature of the study.

In conclusion, even though telemedicine for asthma seems to be a useful and promising tool for empowering the asthmatic patients in order to guarantee the self-control of the disease, the evidence of its benefit is still unclear. The short follow-ups, the heterogeneity of subjects and the insufficient evidence of its cost-effectiveness, are paramount aspects that restrain the use of telemedicine for asthmatic patients. We advocate for the tailoring treatment to the individual 
needs as the cornerstone of telehealthcare, although more studies are called for so the real effect of this new technologies can be elucidated.]

\section{Sleep-related breathing disorders and obstructive sleep apnea}

Speaking of sleep-related breathing disorders, obstructive sleep apnea (OSA) is a prevalent disease that affects approximately $6-7 \%$ of global population, although these figures probably underestimate the real OSA prevalence. OSA is a sleep disorder in wich breathing repeatedly stops and starts, which lead to hypoxemia, subsequent arousals, sleep fragmentation, thus, a poor sleep quality in general. The main symptom is excessive daytime sleepiness, and is now acknowledge as an independent cardiovascular risk factor, increasing the probability of presenting hypertension, coronary artery disease, congestive cardiac failure, and stroke [52]. Attended full in-lab polysomnography (PSG) is the gold standard for OSA diagnosis, an expensive test that demands plenty of time as well as fully trained technicians, and that is why simplified sleep data recollection systems have been approved by the scientific societies for patients with high or low pretest probability of OSA, in order to reduce the waiting list for PSG [53]. Despite the increase of accredited sleep units, the demand of sleep studies has also increased over the years considering the prevalence of the disease. Therefore, waiting lists remain long [54]. Finally, continuous positive airway pressure (CPAP) is by far the recommended treatment for symptomatic or severe OSA, and it is known to reduce cardiovascular death and non-fatal cardiovascular events [55], however, adherence to treatment has been a troublesome factor in such a way that the first year of long-term treatment usually between 25 and $30 \%$ of patients drop out the device [56]. Having said this, there have been some efforts to reduce the long waiting lists and increase the rates of CPAP adherence through telemedicine.

Regarding OSA diagnosis, the evidence of telemedicine usefulness is limited. So far, the American Academy of Sleep Medicine has classified the sleep recording devices into four categories. Full-attended in-lab PSG would be type 1; comprehensive portable unattended PSG with a minimum of seven channels (including electroencephalogram, electrooculogram, chin electromyogram, electrocardiogram or heart rate, airflow, respiratory effort, and oxygen saturation) corresponds to type 2; type 3 comprises modified portable systems with a minimum of four channels monitored, including ventilation or airflow (at least two channels or respiratory movement, or respiratory movement and airflow), heart rate or electrocardiogram, and oxygen saturation comprise; and finally type 4 includes continuous single or dual bioparameters with one or two channels, typically including oxygen saturation or airflow [57]. Despite the limitations of sensor losses that lead to technically inadequate recordings, the inability to assess sleep time duration or the distinction of apneas (central or obstructive), and the vast heterogeneity of sensors and recorders, the studies have confirmed the overall usefulness of type 3 devices, especially if they focus on the outcome which results in earlier access to treatment for the patient, specially those at high-risk of OSA. An alternative to type 3 devices is the home-polysomnography (H-PSG), which enables the home centered care for patients and a complete sleep evaluation allowing the possibility of diagnosing a large panel of sleep disorders. Thus, this H-PSG intends to perform as well as a full-attended PSG though 
in an unattended surrounding, without continuous supervision. A technician hooks-up the device, and this factor limits the wide us of this technique [58]. Since the loss of data is still a big issue with type 2 or 3 devices, potential future developments include the use of assistive technology and telemedicine to allow real-time remote monitoring.

To enhance the quality of H-PSG signal, real-time telematics data transmission has been tested generating successful and high-fidelity recordings through a cell phone for an easily deployed home monitor device [59], and a failure rate of $11 \%$ of telemonitored in-hospital unattended PSG compared to a $23 \%$ failure for unattended H-PSG was observed in another study [60]. Moreover, a pilot study, where $90 \%$ of recordings were of excellent quality, consisted in a wireless device to obtain real-time remote supervision of H-PSG from the sleep lab [61]. With this amount of evidence, it seems telemedicine for sleep studies recordings is feasible and may be an important step to reduce the failure rates of home devices; however, there are important barriers for implementing telemedicine for sleep studies regularly. Telemonitoring devices are complex as well as their software; hence, incompatibility problems with other computer programs should be expected. Furthermore, the cost-effectiveness of these systems is yet to be determined considering the fact that the home must be equipped with a computer and Internet connection, along with high specifications for computer programs. However, investigations using integrated circuits available on the market (mobile telephony) have been conducted to simplify access to these technologies [62]. Last but not least, there are also problems related to privacy protection and security of medical data transmission [58]. An ongoing telehealth outof-laboratory "Fast Track for Sleep Apnea" program for veterans has been reported, that has helped to relieve clinical load at the central sleep program, improved local access to sleep care, and improved patient satisfaction with health care for sleep-related breathing disorders. Nonetheless, the following challenges have been acknowledged so far: the programs needed to be properly integrated with other data management systems and data storage devices must be interfaced with computers attached to the VA server; data loss; and maintaining quality control using metrics [63]. Either way, further research is required to determine the role of telemedicine in sleep-related breathing disorders diagnosis, especially for OSA.

CPAP has shown to wipe out the adverse effect of severe OSA, especially those effects related to cardiovascular diseases. However, the rates of adherence to CPAP are still far of being acceptable. That is way any measure to achieve CPAP adherence is needed, and new approaches such as telemedicine seems to be feasible and cost-effective. Compliance to CPAP is a complex process that involves the participation of the device itself, family support, physicians, health care personal, sleep unit, and government politics [64]. So far, low-quality evidence justifies the use of supportive interventions added to the usual clinical practice to increase CPAP adherence [65] and, similar to previous items, more clinical trials are called for to clear up the role of these interventions, where telemedicine is included. Earlier works presented contradictory results. A statistically significant higher adherence was found in a telemedicine-guided naïve to CPAP patients recently diagnosed with OSA along with greater satisfaction, concluding that telehealth might be cost-effective for CPAP adherence management [66]; while no differences were found in hours of CPAP use, functional status or client satisfaction in another study [67]. It is worth to mention that these two studies followed the 
patients for a 12-week and 30 days period, respectively. More recent clinical trials have added some light to the subject. A 12-month telemedicine intervention resulted in a median CPAP usage that was $0.9 \mathrm{~h} /$ night higher than that of an attention control group after 6 months, and $2.0 \mathrm{~h} /$ night higher after 12 months in a clinical trial including 250 patients, although the median adherence of all patients was low, with $19 \%$ of patients refusing the use of CPAP at all [68]. Another clinical trial of 75 patients, showed higher rates of adherence to CPAP after 3 months of telemedicine intervention, which was determined as a significant predictor of adherence, apart from age and sleepiness symptoms measured by the Epworth Sleepiness Scale [69]. Finally, although no difference in hours of CPAP use was found in a study including 139 OSA patients, telemedicine showed to be more cost-effective than the usual face-to-face management, with travel costs and lost work time being the most important sources of savings [70].

Improvement in case detection and the resulting higher healthcare demand has not been accompanied by any real improvement in OSA management. In addition, health resources assigned to OSA and its treatment have been found to be inadequate [71]. Telemedicine is an appealing approach that needs to be explored and taken into consideration in order to obtain a diagnosis and follow-up of sleep-related breathing disorders in a more timely fashion, which would help to achieve the desirable management of these diseases.

\section{Lung transplantation}

[Lung transplantation is offered for a great variety on respiratory diseases that have reached their end-stage, where no other treatment would obtain a reasonable survival. They are complex patients who are in need of aggressive immunosuppressive treatment for a lifetime that exposes them to opportunistic infections; so numerous complications are often taking place. By far, the major problem for every lung transplant patient is the allograft dysfunction, either acute or chronic (basically in its form of bronchiolitis obstructive syndrome). Allograft dysfunction is characterized for a functional decline of the implant, which is usually measured by $\mathrm{FEV}_{1}$ [72], and daily home spirometry has been shown to lead to earlier detection and staging of bronchiolitis obstructive syndrome when compared with standard pulmonary function testing [73]. Concerning the need of retrieving daily spirometric data, telemedicine has been studied as a feasible instrument, making some interesting progress conducive to a more efficient follow-up of patients and the prompt recognition of a possible complication.

Earlier works determined the telemonitored spirometry as feasible, valid, reliable, and repeatable, when compared to the regular in-clinic functional testing [74-76]. Although these studies were clearly underpowered due to the small samples included. While on earlier works the objective is to determine the technical aspects of collecting acceptable spirometries, recent works have carried out clinical trials to demonstrate that a computerized rule-based decision support algorithm for nursing triage of potential acute bronchopulmonary events is effective $[72,77]$, or the identification of these events taking decision rules developed using wavelet analysis of declines in spirometry and increases in respiratory symptoms [78]. In conclusion, the evidence of the increase of quality of life and reduction of hospital admissions seems fairly 
positive, though we are still in need of more studies [79] and the training process for both medical staff and patients needs to be thorough [80] A different approach was revised by another study where telemedicine was employed in a clinical trial for lung transplant candidates, and clinical outcome measures were monitoring adherence and level of communication (for monitor acceptability and utilization), hospital length of stay after transplantation and survival at 4 months. However, no significant differences in clinical outcomes between groups were determined [81].

Similar to the previous three respiratory conditions, telemedicine for lung transplant patients is feasible. Still and all, no cost-effectiveness has been demonstrated, thus, larger clinical trials are required to establish the position of these new techniques in lung transplantation.

\section{Conclusions}

Telemedicine is a helpful tool to improve chronic respiratory patient management. Almost all results shows reduction in Emergency visits and the number of hospitalizations but despite of these results its implementation is troublesome and with different kind of factors relationship with this slowly development. Most users report that the difficult to use the devices or technology platform is the most important factor related to refuse telemedicine by users. We need to work to improve its implementation through educational programs to healthcare professionals and patients.

\section{Author details}

Gonzalo Segrelles-Calvo ${ }^{1^{*}}$ and Daniel López-Padilla²

*Address all correspondence to: gsegrelles@hotmail.com

1 Pneumology Department, University Hospital Rey Juan Carlos, Mostoles, Spain

2 Pneumology Department, University Hospital Gregorio Maranon, Madrid, Spain

\section{References}

[1] Jaana M, Paré G, Sicotte C. Home telemonitoring for respiratory conditions: a systematic review. Am J Manag Care. 2009;15:313-20.

[2] Sabati N, Snyder M, Edin-Stibbe C, Lindgren B, Finkelstein S. Facilitators and barriers to adherence with home monitoring using electronic spirometry. AACN Clin Issues. 2001;12:178-85. 
[3] World Health Organization. http://www.who.it. Last up to date 21st December 2015.

[4] American Telemedicine Association (ATA). http://atmedad.org. Last up to date 21st December 2015.

[5] Bashur RL. On the definition and evaluation of telemedicine. J Telemed Telecare. 1995;1:19-30.

[6] Norris TG. Telemedicine and teleradiology. Radiol Technol. 1997;71:139-64.

[7] Bashur R, Lovett J. Assessment of telemedicine: results of initial experience. Aviat Space Environ Med. 1997;48:65-70.

[8] House AM, Roberts JM. Telemedicine in Canada. Can Med Assoc J. 1997;117:386-8.

[9] Kopec A, Salazar AJ. Generalities about telemedicine. In: Bustamante MA, Rodríguez $\mathrm{G}$, editors. Uses of telecommunication in Health in Andean region. Telemedicina. Perú: ORAS-CONHU; 2006.

[10] Segrelles-Calvo G, Chiner E, Fernández-Fabrellas E. Acceptance of telemedicine among healthcare professionals. Arch Bronconeumol. 2015;51:611-2.

[11] Mira-Solves JJ, Orozco-Beltrán D, Sánchez-Molla M, Sánchez-García J. Chronic patients satisfaction about telemedicine devices and the care received. ValCrònic Program. Aten Primaria. 2014;46:16-23.

[12] Jódar-Sánchez F, Ortega F, Parra C, Gómez-Suárez C, Jordán A, Pérez P, et al. Implementation of a telehealth programme for patients with severe chronic obstructive pulmonary disease treated with long-term oxygen therapy. J Telemed Telecare. 2013;19:11-7.

[13] Vitacca M, Bianchi L, Guerra A, Fracchia C, Spanavello A, Balbi B, et al. Tele-assistance in chronic respiratory failure patients: a randomised clinical trial. Eur Respir J. 2009;33:411-8.

[14] Motulsky A, Sicotte C, Lamothe L, Winslade N, Tamblyn R. Electronic prescriptions and disruptions to the jurisdiction of community pharmacists. Soc Sci Med. 2011;73:121-8.

[15] Cresswell K, Coleman J, Slee A, Williams R, Sheikh A; ePrescribing Programme Team. Investigating and learning lessons from early experiences of implementing ePrescribing systems into NHS hospitals: a questionnaire study. PLoS One. 2013;8:e71238-49.

[16] Mahmud K, LeSage K. Telemedicine-a new idea for home care. Caring. 1995;14:4850.

[17] Johnston B, Wheeler L, Deuser J, Sousa KH. Outcomes of the Kaiser Permanente TeleHome Health Research Project. Arch Fam Med. 2000;9:40-5.

[18] Nakamura K, Takano T, Akao C. The effectiveness of videophones in home healthcare for the elderly. Med Care. 1999;37:117-25. 
[19] Hoaas H, Andreassen HK, Lien LA, Hjalmarsen A, Zanaboni P. Adherence and factors affecting satisfaction in long-term telerehabilitation for patients with chronic obstructive pulmonary disease: a mixed methods study. BMC Med Inform Decis Mak. 2016;16:26.

[20] Bauer MS, Krawczyk L, Miller CJ, Abel E, Osser DN, Franz A, et al. Team-based telecare for bipolar disorder. Telemed J E Health. 2016 (in press).

[21] Story A, Garfein RS, Hayward A, Rusovich V, Dadu A, Soltan V, et al. Monitoring therapy compliance of tuberculosis patients by using video-enabled electronic devices. Emerg Infect Dis. 2016;22:538-40

[22] Balas EA, Jaffrey F, Kuperman GJ, Boren SA, Brown GD, Pinciroli F, et al. Electronic communication with patients. Evaluation of distance medicine technology. JAMA. 1997;278:152-9.

[23] Vos T, Flaxman AD, Naghavi M, Lozano R, Michaud C, Ezzati M, Shibuya K, Salomon JA, Abdalla S, Aboyans V, et al. Years lived with disability (YLDs) for 1160 sequelae of 289 diseases and injuries 1990-2010: a systematic analysis for the Global Burden of Disease study 2010. Lancet. 2012;380:2163-96.

[24] Mannino DM, Buist AS. Global burden of COPD: risk factors, prevalence, and future trends. Lancet. 2007;370:765-73.

[25] López-Campos JL, Tan W, Soriano JB. Global burden of COPD. Respirology. 2016;21:14-23. doi: 10.1111/resp.12660.

[26] Mannino DM, Higuchi K, Yu TC, Zhou H, Li Y, Tian H, Suh K. Economic burden of chronic obstructive pulmonary disease by presence of comorbidities. Chest. 2015;148:138-50.

[27] Polisena J, Tran K, Cimon K, Hutton B, McGill S, Palmer K, Scott RE. Home telehealth for chronic obstructive pulmonary disease: a systematic review and meta-analysis. J Telemed Telecare. 2010;16:120-7. doi: 10.1258/jtt.2009.090812.

[28] McLean S, Nurmatov U, Liu JL, Pagliari C, Car J, Sheikh A. Telehealthcare for chronic obstructive pulmonary disease: Cochrane Review and meta-analysis. Br J Gen Pract. 2012;62:e739-49. doi: 10.3399/bjgp12X658269.

[29] Bolton CE, Waters CS, Peirce S, Elwyn G; EPSRC and MRC Grand Challenge Team. Insufficient evidence of benefit: a systematic review of home telemonitoring for COPD. J Eval Clin Pract. 2011;17:1216-22. doi: 10.1111/j.1365-2753.2010.01536.x.

[30] Segrelles Calvo G, Gómez-Suárez C, Soriano JB, Zamora E, Gónzalez-Gamarra A, González-Béjar M, Jordán A, Tadeo E, Sebastián A, Fernández G, Ancochea. A home telehealth program for patients with severe COPD: the PROMETE study. Respir Med. 2014;108:453-62. doi: 10.1016/j.rmed.2013.12.003. 
[31] Gottlieb M, Marsaa K, Andreassen H, Strømstad G, Godtfredsen N. Feasibility of a telecare solution for patients admitted with COPD exacerbation: screening data from a pulmonary ward in a university hospital. Eur Clin Respir J. 2014;1:24193

[32] Cruz J, Brooks D, Marques A. Home telemonitoring effectiveness in COPD: a systematic review. Int J Clin Pract. 2014;68:369-78. doi: 10.1111/ijcp.12345.

[33] Ringbæk T, Green A, Laursen LC, Frausing E, Brøndum E, Ulrik CS. Effect of tele health care on exacerbations and hospital admissions in patients with chronic obstructive pulmonary disease: a randomized clinical trial. Int J Chron Obstruct Pulmon Dis. 2015;10:1801-8. doi: 10.2147/COPD.S85596.

[34] Lundell S, Holmner Å, Rehn B, Nyberg A, Wadell K. Telehealthcare in COPD: a systematic review and meta-analysis on physical outcomes and dyspnea. Respir Med. 2015;109:11-26. doi: 10.1016/j.rmed.2014.10.008.

[35] Paneroni M, Colombo F, Papalia A, Colitta A, Borghi G, Saleri M, Cabiaglia A, Azzalini E, Vitacca M. Is telerehabilitation a safe and viable option for patients with COPD? A feasibility study. COPD. 2015;12:217-25. doi: 10.3109/15412555.2014.933794.

[36] Henderson C, Knapp M, Fernández JL, Beecham J, Hirani SP, Cartwright M, Rixon L, Beynon M, Rogers A, Bower P, Doll H, Fitzpatrick R, Steventon A, Bardsley M, Hendy J, Newman SP; Whole System Demonstrator evaluation team. Cost effectiveness of telehealth for patients with long term conditions (Whole Systems Demonstrator telehealth questionnaire study): nested economic evaluation in a pragmatic, cluster randomised controlled trial. BMJ. 2013;346:f1035. doi: 10.1136/bmj.f1035.

[37] Steventon A, Bardsley M, Billings J, Dixon J, Doll H, Hirani S, Cartwright M, Rixon L, Knapp M, Henderson C, Rogers A, Fitzpatrick R, Hendy J, Newman S; Whole System Demonstrator Evaluation Team. Effect of telehealth on use of secondary care and mortality: findings from the Whole System Demonstrator cluster randomised trial. BMJ. 2012;344:e3874. doi: 10.1136/bmj.e3874.

[38] Udsen FW, Lilholt PH, Hejlesen O, Ehlers LH. Effectiveness and cost-effectiveness of telehealthcare for chronic obstructive pulmonary disease: study protocol for a cluster randomized controlled trial. Trials. 2014;15:178. doi: 10.1186/1745-6215-15-178.

[39] Gibson PG, Powell H, Coughlan J, Wilson AJ, Abramson M, Haywood P, et al. Self management education and regular practitioner review for adults with asthma (Cochrane review). In: The Cochrane Library, Issue 4. Chichester, UK: John Wiley and Sons, Ltd; 2003.

[40] Van Gaalen JL, Hashimoto S, Sont JK. Telemanagement in asthma: an innovative and effective approach. Curr Opin Allergy Clin Immunol. 2012;12:235-40. doi: 10.1097/ACI. 0b013e3283533700.

[41] McLean S, Chandler D, Nurmatov U, Liu J, Pagliari C, Car J, Sheikh A. Telehealthcare for asthma: a Cochrane review. CMAJ. 2011;183:E733-42. doi: 10.1503/cmaj.101146. 
[42] Wootton R. Twenty years of telemedicine in chronic disease management-an evidence synthesis. J Telemed Telecare. 2012;18:211-20. doi: 10.1258/jtt.2012.12021.

[43] van der Meer V, van den Hout WB, Bakker MJ, Rabe KF, Sterk PJ, Assendelft WJ, Kievit J, Sont JK; SMASHING (Self-Management in Asthma Supported by Hospitals, ICT, Nurses and General Practitioners) Study Group. Cost-effectiveness of Internet-based self-management compared with usual care in asthma. PLoS One. 2011;6:e27108. doi: 10.1371/journal.pone.0027108.

[44] Pinnock H, McKenzie L, Price D, Sheikh A. Cost-effectiveness of telephone or surgery asthma reviews: economic analysis of a randomised controlled trial. Br J Gen Pract. 2005;55:119-24.

[45] Pinnock H, Adlem L, Gaskin S, Harris J, Snellgrove C, Sheikh A. Accessibility, clinical effectiveness, and practice costs of providing a telephone option for routine asthma reviews: phase IV controlled implementation study. Br J Gen Pract. 2007;57:714-22.

[46] Raben KF, Vermeire PA, Soriano JB, Maier WC. Clinical management of asthma in 1999: the Asthma Insights and Reality in Europe (AIRE) study. Eur Respir J. 2000;16:802-7.

[47] Rasmussen LM, Phanareth K, Nolte H, Backer V. Internet-based monitoring of asthma: a long-term, randomized clinical study of 300 asthmatic subjects. J Allergy Clin Immunol. 2005;115:1137-42.

[48] Liu WT, Huang CD, Wang CH, Lee KY, Lin SM, Kuo HP. A mobile telephone-based interactive self-care system improves asthma control. Eur Respir J. 2011;37:310-7. doi: 10.1183/09031936.00000810.

[49] Araújo L, Jacinto T, Moreira A, Castel-Branco MG, Delgado L, Costa-Pereira A, Fonseca J. Clinical efficacy of web-based versus standard asthma self-management. J Investig Allergol Clin Immunol. 2012;22:28-34.

[50] Deschildre A, Béghin L, Salleron J, Iliescu C, Thumerelle C, Santos C, Hoorelbeke A, Scalbert M, Pouessel G, Gnansounou M, Edmé JL, Matran R. Home telemonitoring (forced expiratory volume in $1 \mathrm{~s}$ ) in children with severe asthma does not reduce exacerbations. Eur Respir J. 2012;39:290-6. doi: 10.1183/09031936.00185310.

[51] Brouwer AF, Brand PL, Roorda RJ, Duiverman EJ. Airway obstruction at time of symptoms prompting use of reliever therapy in children with asthma. Acta Paediatr. 2010;99:871-6. doi: 10.1111/j.1651-2227.2010.01715.x.

[52] Ge X, Han F, Huang Y, Zhang Y, Yang T, Bai C, Guo X. Is obstructive sleep apnea associated with cardiovascular and all-cause mortality? PLoS One. 2013;8:e69432. doi: 10.1371/journal.pone.0069432.

[53] Collop NA. Clinical guidelines for the use of unattended portable monitors in the diagnosis of obstructive sleep apnea in adult patients. J Clin Sleep Med. 2007;3:737e47. 
[54] Masa Jimenez JF, Barbé Illa F, Capote Gil F, Chiner Vives E. Resources and delays in the diagnosis of sleep apnea-hypopnea syndrome. Arch Bronconeumol. 2007;43:188e98.

[55] Wang J, Yu W, Gao M, Zhang F, Li Q, Gu C, Yu Y, Wei Y. Continuous positive airway pressure treatment reduces cardiovascular death and non-fatal cardiovascular events in patients with obstructive sleep apnea: a meta-analysis of 11 studies. Int J Cardiol. 2015;191:128-31. doi: 10.1016/j.ijcard.2015.05.003.

[56] Meurice JC. Improving compliance to CPAP in sleep apnea syndrome: from coaching to telemedicine. Rev Mal Respir. 2012;29:7-10. doi: 10.1016/j.rmr.2011.12.007.

[57] Chesson AL Jr, Berry RB, Pack A; American Academy of Sleep Medicine; American Thoracic Society; American College of Chest Physicians. Practice parameters for the use of portable monitoring devices in the investigation of suspected obstructive sleep apnea in adults. Sleep. 2003;26:907-13.

[58] Bruyneel M, Ninane V. Unattended home-based polysomnography for sleep disordered breathing: current concepts and perspectives. Sleep Med Rev. 2014;18:341-7. doi: 10.1016/j.smrv.2013.12.002.

[59] Kayyali HA, Weimer S, Frederick C, Martin C, Basa D, Juguilon JA, Jugilioni F. Remotely attended home monitoring of sleep disorders. Telemed J E Health. 2008;14:371-4. doi: 10.1089/tmj.2007.0058.

[60] Gagnadoux F, Pelletier-Fleury N, Philippe C, Rakotonanahary D, Fleury B. Home unattended vs hospital telemonitored polysomnography in suspected obstructive sleep apnea syndrome: a randomized crossover trial. Chest. 2002;121:753e8.

[61] Bruyneel M, Van den Broecke S, Libert W, Ninane V. Real-time attended homepolysomnography with telematic data transmission. Int J Med Inform. 2013;82:696e701.

[62] Dellaca R, Montserrat JM, Govoni L, Pedotti A, Navajas D, Farré R. Telemetric CPAP titration at home in patients with sleep apnea-hypopnea syndrome. Sleep Med. 2011;12:153e7.

[63] Hirshkowitz M, Sharafkhaneh A. A telemedicine program for diagnosis and management of sleep-disordered breathing: the fast-track for sleep apnea tele-sleep program. Semin Respir Crit Care Med. 2014;35:560-70. doi: 10.1055/s-0034-1390069.

[64] Shapiro GK, Shapiro CM. Factors that influence CPAP adherence: an overview. Sleep Breath. 2010;14:323-35.

[65] Wozniak DR, Lasserson TJ, Smith I. Educational, supportive and behavioural interventions to improve usage of continuous positive airway pressure machines in adults with obstructive sleep apnoea. Cochrane Database Syst Rev. 2014;1:CD007736. doi: 10.1002/14651858.CD007736.pub2. 
[66] Smith CE, Dauz ER, Clements F, Puno FN, Cook D, Doolittle G, Leeds W. Telehealth services to improve nonadherence: a placebo-controlled study. Telemed J E Health. 2006;12:289-96.

[67] Taylor Y, Eliasson A, Andrada T, Kristo D, Howard R. The role of telemedicine in CPAP compliance for patients with obstructive sleep apnea syndrome. Sleep Breath. 2006;10:132-8.

[68] Sparrow D, Aloia M, Demolles DA, Gottlieb DJ. A telemedicine intervention to improve adherence to continuous positive airway pressure: a randomised controlled trial. Thorax. 2010;65:1061-6. doi: 10.1136/thx.2009.133215.

[69] Fox N, Hirsch-Allen AJ, Goodfellow E, Wenner J, Fleetham J, Ryan CF, Kwiatkowska $\mathrm{M}$, Ayas NT. The impact of a telemedicine monitoring system on positive airway pressure adherence in patients with obstructive sleep apnea: a randomized controlled trial. Sleep. 2012;35:477-81. doi: 10.5665/sleep.1728.

[70] Isetta V, Negrín MA, Monasterio C, Masa JF, Feu N, Álvarez A, Campos-Rodriguez F, Ruiz C, Abad J, Vázquez-Polo FJ, Farré R, Galdeano M, Lloberes P, Embid C, de la Peña M, Puertas J, Dalmases M, Salord N, Corral J, Jurado B, León C, Egea C, Muñoz A, Parra O, Cambrodi R, Martel-Escobar M, Arqué M, Montserrat JM; SPANISH SLEEP NETWORK. A Bayesian cost-effectiveness analysis of a telemedicine-based strategy for the management of sleep apnoea: a multicentre randomised controlled trial. Thorax. 2015;70:1054-61. doi: 10.1136/thoraxjnl-2015-207032.

[71] Rotenberg B, George C, Sullivan K, Wong E. Wait times for sleep apnea care in Ontario: a multidisciplinary assessment. Can Respir J. 2010;17:170-4.

[72] Finkelstein SM, Scudiero A, Lindgren B, Snyder M, Hertz MI. Decision support for the triage of lung transplant recipients on the basis of home-monitoring spirometry and symptom reporting. Heart Lung. 2005;34:201-8.

[73] Robson KS, West AJ. Improving survival outcomes in lung transplant recipients through early detection of bronchiolitis obliterans: daily home spirometry versus standard pulmonary function testing. Can J Respir Ther. 2014;50:17-22.

[74] Finkelstein SM, Snyder M, Edin-Stibbe C, Chlan L, Prasad B, Dutta P, Lindgren B, Wielinski C, Hertz MI. Monitoring progress after lung transplantation from homepatient adherence. J Med Eng Technol. 1996;20:203-10.

[75] Lindgren BR, Finkelstein SM, Prasad B, Dutta P, Killoren T, Scherber J, Stibbe CL, Snyder M, Hertz MI. Determination of reliability and validity in home monitoring data of pulmonary function tests following lung transplantation. Res Nurs Health. 1997;20:539-50.

[76] Wagner FM, Weber A, Park JW, Schiemanck S, Tugtekin SM, Gulielmos V, Schüler S. New telemetric system for daily pulmonary function surveillance of lung transplant recipients. Ann Thorac Surg. 1999;68:2033-8. 
[77] Finkelstein SM, Lindgren BR, Robiner W, Lindquist R, Hertz M, Carlin BP, VanWormer A. A randomized controlled trial comparing health and quality of life of lung transplant recipients following nurse and computer-based triage utilizing home spirometry monitoring. Telemed J E Health. 2013;19:897-903. doi: 10.1089/tmj.2013.0049.

[78] Wang W, Finkelstein SM, Hertz MI. Automatic event detection in lung transplant recipients based on home monitoring of spirometry and symptoms. Telemed J E Health. 2013;19:658-63. doi: 10.1089/tmj.2012.0290.

[79] Fadaizadeh L, Najafizadeh K, Shafaghi S, Hosseini MS, Ghoroghi A. Using home spirometry for follow up of lung transplant recipients: "A Pilot Study". Tanaffos. 2013;12:64-9.

[80] Fadaizadeh L, Najafizadeh K, Shajareh E, Shafaghi S, Hosseini M, Heydari G. Home spirometry: assessment of patient compliance and satisfaction and its impact on early diagnosis of pulmonary symptoms in post-lung transplantation patients. J Telemed Telecare. 2016;22:127-31

[81] Mullan B, Snyder M, Lindgren B, Finkelstein SM, Hertz MI. Home monitoring for lung transplant candidates. Prog Transplant. 2003;13:176-82. 

Chapter 4

\title{
Mobile Health Monitoring
}

\author{
Niloofar Mohammadzadeh and Reza Safdari \\ Additional information is available at the end of the chapter \\ http://dx.doi.org/10.5772/64704
}

\begin{abstract}
Chronic diseases impose heavy burden and costs on the health industry in many countries. Suitable health procedures, management, and prevention of disease by continuous monitoring through modern technologies can lead to a decrease in health costs and improve people empowerment. Applying remote medical diagnosis and monitoring system based on mobile health systems can help significantly reduce health care costs and correct performance management particularly in chronic disease management. In this chapter, mHealth opportunities in patient monitoring with the introduction of various systems specifically in chronic disease are expressed. Also mHealth challenges in patient monitoring in general and specific aspects are identified. Some of the general challenges include threats to confidentiality and privacy, and lack of information communication technology (ICT), and mobile infrastructure. In specific aspect, some difficulties include lack of system interoperability with electronic health records and other IT tools, decrease in face-to-face communication between doctor and patient, ill-functioning of system that leads to medical errors and negative effects on care outcomes, patients, and personnel, and factors related to the telecommunication industry include reliability and sudden interruptions of telecommunication networks.
\end{abstract}

Keywords: monitor, challenge, advantage, mobile health, chronic disease

\section{Introduction}

Information technology, as a powerful tool, is the most important factor in increasing the efficiency and effectiveness of organizations. Various industries in order to maintain their existence in the current competitive environment and promotion of their outcomes have taken effective steps toward the use of these technologies. The health care industry is no exception from this rule. Different countries consider the information technology to promote the devel- 
opment of health information and health system outcomes with regard to the importance of care industry, direct and indirect impacts on various aspects of community development [1].

Advent of mobile devices with capabilities of caring handy and easy is one of the modern effects of IT that application of them is growing especially in the industrial sector. Some of the mobile devices include cell phones, smart phones (mobile phones processing capabilities, storage, and intelligence communications), and personal digital assistants (PDA). These devices are equipped with communication capabilities such as the ability to connect through GSM/GPRS, Wireless LAN, and Bluetooth networks; hence their utilization will provide comfort for their users.

Using mobile devices seems inevitable because the health industry is facing challenges such as resource constraints like focusing resources on specific areas, for example, in large cities [2], rising health care costs, the need for immediate access to various health care data types such as audio, video, text for early detection and treatment of patients, especially in emergency situations, and difficult in rural areas, and increasing remote aid in telemedicine and home care [3].

A study in Denmark on the necessity of using mobile devices in hospital wards showed hospital staffs want to use mobile devices because of the need to participate in different physical locations, have instant access to information, and immediately contact specific individuals while serving the patients [4].

Easy to carry and quick access to information on mobile devices make them perfect tools for health care providers. Mobile devices provide opportunities and play an important role in consulting, diagnosis, treatment [5], medical education and research [6], conducting quick access to information during shift change sectors [7], chronic disease management [8], patient empowerment [9], rapid establishment of communication regardless of distance restraints [10], and lead to increase efficiency, effective management measures, and promotion of health achievements [11].

In a similar investigation at a cancer treatment center in Spain, it was found that short telephone calls for 3-5 min between medical staff and patients decreased emergency department visits and patients' visit to the center by $24-42 \%$ [12].

Wakadha et al. in Kenya showed in rural western Kenya mobile phone-based strategies and short message services (SMSs) are potentially useful to deliver reminders, cash transfers, and achieve high, timely, and sustainable immunization coverage [13].

Today, the use of health information systems which are fixed terminals just does not seem sufficient. Because these systems do not provide necessary information for health care providers in real time, the continuous rapid delivery of services to patients is interrupted [7]. Studies indicate that lack of timely access to patient information [14], discontinuity of the communication, and lack of coordination between service provider and health care team members [15] are the main causes of medical errors. The use of mobile devices in terms of emergency situation and telemedicine is crucial for instant access to patient information, entry and data processing of medical records on time, and when the shift health care services changes for providers of health services [16, 17]. 
The use of mobile health programs is very interesting due to numerous benefits; however using these tools is still has many challenges. One of the approaches that significantly helps to reduce barriers is survey of advantages and obstacles of mobile devices usage. Studies of opportunities and strengthening them and identifying problems help to design proper planning and a roadmap for promoting the achievements of mobile health systems.

We begin the following section by discussing about the necessity of mHealth in chronic disease management especially in diabetes. In next part, the advantages of mobile health in patient monitoring at two groups of agent and nonagent based system are explained. After that, we describe the challenges of patient monitoring based on mobile health systems in general and specific aspects. Finally, we explain one project as a case study about developing framework for agent-based diabetes disease management system in national level based on user's perspective.

\section{Chronic disease management: necessity of mHealth approach}

In most countries, chronic diseases lead to high health care costs and reduced productivity of people in society [18]. Diabetes is a common chronic disease in nearly all countries [19] and one of the most common metabolic diseases with an increasing incidence. More than $15 \%$ of national health budget is dedicated to diabetic care [20]. Diabetes as a hidden disease causes many complications such as various types of heart disease, nephropathy, retinopathy, and so on, thus imposing direct and indirect high costs to society. In Iran, diabetes complications contributed to $53 \%$ of the aggregate excess direct costs of diabetes [21].

The quality of diabetic care improves, on one hand, if patient monitoring is done according to the nutrition program and physician orders that are placed with high quality [22]. On the other hand, fast and accurate diagnosis due to continuous monitoring through information communication technology (ICT) devices leads to prevent the death of diabetic patients [23]. Telemedicine as a main tool to remote health care delivery and home care has advantages such as real-time access to health information [3, 24], reducing medical errors [25], and increasing coordination and cooperation among health care teams [1], reducing travel of patients and their families in remote area [26], and useful education tool for patients, their families, and health care providers [27]. Therefore, this technology has a very important role in decreasing costs and taking appropriate management actions especially in diabetes management and other chronic disease [28, 29]. The use of innovative technologies such as mobiles to enjoy the most advantages of telemedicine is necessary. Mobile health systems can be a good option for health care industry because of reducing delay and error in patient treatment, avoiding test duplication, providing remote and timely access of health care professionals to organizational database and patient information especially in the emergency situations [26, 30]. 


\section{3. mHealth opportunities in patient monitoring}

In this study, electronic chronic disease management systems based on mobile technology were divided into two types: agent-based systems and nonagent-based systems. Some electronic health system based on agent that studied in this research are:

- Integrated mobile information system (IMIS) in Sweden through mobile network communication platform provides the possibility of self-treatment and home care supervision for the diabetic patient. This system has six databases: (1) database for patients including all necessary information about diabetic health care centers, medical journals, dietary, food habits, etc.; (2) database for care providers containing whole information about physicians, home care services; (3) tools or instrument base including all aiding functions for implementation health care such as visit reserve, alarms, monitor; (4) community network include all relevant actors like diabetes centers, consultation, and so on links to each other; (5) database for laws, rules, and norms applied in health care including all legal and cultural documents about health care therefore can help with privacy, security, and quality of services; and (6) database for labor division in health care that determines who (health care provider) and what to do, this ensures to provide all the different patient needs [31-34].

- M2DM Telemedicine Service system in European Commission with the aim of presenting correct knowledge to correct people at correct time. Two types of agents are used in the M2DM: (1) communication server that is responsible for communication between different user terminals and (2) application server that is responsible for data analysis and processing. The architecture of this system includes multiaccess server, common database management system (DBMS), multiaccess organizer, communication server agent, and application server agent. The overall goal of M2DM is increasing quality of care through improving communication between patient and health care providers $[35,36]$.

Also other nonagent and useful e-health system survey in this section are:

- Personal Health Monitor (PHM), University of Sydney, Australia, uses PHM with focus on e-health services based on mobile devices at local level for monitoring patient in various situations therapeutic. Architecture of PHM comprises BAN devices, sensor front end, mobile base unit, back end $[37,38]$.

- Mobi Health and Body Area Network [BAN], most of the European countries use this system for remote patient monitoring and provide appropriate care to patients. A consortium of 14 European countries was set up to implement the health system project [39]. This project has been implemented in four countries: Spain, the Netherlands, Sweden, and Germany for different groups of patients, including home care and trauma, where the patient is located in an outdoor center. It aims to improve patients' quality of life and freedom in their daily activities and complete mobility. BAN devices, sensor front end, mobile base unit, and back end are the architecture elements [37, 40-42]. 
- In 2009, the first virtual diabetes clinic in Iran was inaugurated at Tehran University of Medical Sciences with common database, multiaccess server architecture, and organizer server is discussed in this chapter [43-45].

Some benefits of nonagent-based system in Table 1 include disease prevention improvement, better self-care, increased life style quality, reduce unnecessary [re]hospitalizations, possibility of teleconsultation, and provide patients mobility to perform their daily works. Diabetes virtual clinic is used for monitoring system and as a proper tool that provides up-to-date, useful, relevant, and accurate information used to suitable self-care and remote health care. Access of all users to useful and necessary information about prevention, treatment, side effects, and ways to control diabetes and providing teleconsultation are most important advantages of a virtual clinic.

In PHM, data processing is done locally, and in Mobi health BAN processing can be done at server side. Some of the studied system implemented on PDA and mobile phone platforms,

\begin{tabular}{|c|c|c|c|c|c|c|c|}
\hline System & $\begin{array}{l}\text { Mul- } \\
\text { ti- } \\
\text { agent }\end{array}$ & $\begin{array}{l}\text { Develop- } \\
\text { ment meth- } \\
\text { od }\end{array}$ & Usage & $\begin{array}{l}\text { Access to data } \\
\text { technology }\end{array}$ & Devices & $\begin{array}{l}\text { Type of } \\
\text { communica- } \\
\text { tion }\end{array}$ & Some of the capabilities \\
\hline $\begin{array}{l}\text { Integrated } \\
\text { mobile in- } \\
\text { formation } \\
\text { system } \\
\text { (IMIS) [31- } \\
34]\end{array}$ & Yes & $\begin{array}{l}\text { User cen- } \\
\text { tered }\end{array}$ & $\begin{array}{l}\text { Diabetic home- } \\
\text { care, chronic, eld- } \\
\text { erly care }\end{array}$ & Internet, SMS & $\begin{array}{l}\text { Mobile com- } \\
\text { puters, No- } \\
\text { kia } \\
\text { communica- } \\
\text { tor, PDA, } \\
\text { stationary } \\
\text { computers } \\
\text { home }\end{array}$ & $\begin{array}{l}\text { Wired/wire- } \\
\text { less commu- } \\
\text { nications }\end{array}$ & $\begin{array}{l}\text { (1) Integrate and co-ordinate various } \\
\text { healthcare activities under the same funda- } \\
\text { mental activity system, (2) self-treatment, } \\
\text { (3) preparation before face-to-face diagno- } \\
\text { ses, (4) access and share the same and right } \\
\text { information on right time for a seamless } \\
\text { co-operative work among organizations } \\
\text { and among persons }\end{array}$ \\
\hline $\begin{array}{l}\text { M2DM Tel- } \\
\text { emedicine } \\
\text { service [35, } \\
36]\end{array}$ & Yes & $\begin{array}{l}\text { Merging of } \\
\text { telemedicine } \\
\text { with knowl- } \\
\text { edge man- } \\
\text { agement }\end{array}$ & Diabetes & $\begin{array}{l}\text { Internet, WebTV, } \\
\text { SMS, WAP,GPRS }\end{array}$ & $\begin{array}{l}\text { Mobile com- } \\
\text { puters, PDA, } \\
\text { palmtops, }\end{array}$ & $\begin{array}{l}\text { Wired/wire- } \\
\text { less commu- } \\
\text { nications }\end{array}$ & $\begin{array}{l}\text { (1) Telecare, (2) visit management, (3) } \\
\text { management of HER, (4) automatic gener- } \\
\text { ation of reports, (5) intelligent alarms, (6) } \\
\text { tele-education, (7) intelligent knowledge } \\
\text { management }\end{array}$ \\
\hline $\begin{array}{l}\text { PHM: Per- } \\
\text { sonal } \\
\text { health } \\
\text { monitor } \\
{[37,38]}\end{array}$ & No & $\begin{array}{l}\text { Local, per- } \\
\text { sonal } \\
\text { mHealth } \\
\text { services }\end{array}$ & $\begin{array}{l}\text { Cardiology, gen- } \\
\text { eral well-being, } \\
\text { chronic disease } \\
\text { management, re- } \\
\text { habilitation, moni- } \\
\text { toring: cardiac } \\
\text { rhythm monitor- } \\
\text { ing, cardiac reha- } \\
\text { bilitation, primary } \\
\text { prevention }\end{array}$ & $\begin{array}{l}\text { GPS,GSM,SMS,3G, } \\
\text { Internet }\end{array}$ & $\begin{array}{l}\text { Mobile } \\
\text { phone }\end{array}$ & $\begin{array}{l}\text { Wired/wire- } \\
\text { less commu- } \\
\text { nications } \\
\text { (Bluetooth) }\end{array}$ & $\begin{array}{l}\text { (1) Triage of life data which can be person- } \\
\text { alized to the application domain, (2) data } \\
\text { processing Viewing and reporting for } \\
\text { physician, (3) physician can update sensor } \\
\text { thresholds, (4) remote management of } \\
\text { PHM equipment and patients, (5) pass- } \\
\text { word protected viewing by the patient } \\
\text { [limited view], (6) synchronization be- } \\
\text { tween MBU and Back End }\end{array}$ \\
\hline $\begin{array}{l}\text { Mobihealth } \\
\text { BAN [37, } \\
40-42]\end{array}$ & No & $\begin{array}{l}\text { Telemoni- } \\
\text { toring or tel- } \\
\text { etreatment } \\
\text { services }\end{array}$ & $\begin{array}{l}\text { Cardiology, ob- } \\
\text { stetrics, trauma } \\
\text { care, rheumatolo- } \\
\text { gy, psychiatry, } \\
\text { pulmonary medi- } \\
\text { cine, gerontology, } \\
\text { neurology, tele- } \\
\text { monitoring, tele- } \\
\text { treatment }\end{array}$ & $\begin{array}{l}\text { SMS, WIFI, GPRS, } \\
\text { Internet, GPS }\end{array}$ & $\begin{array}{l}\text { Mobile } \\
\text { phones, } \\
\text { PDA, UMTS, } \\
\text { Any mobile } \\
\text { platform ca- } \\
\text { pable of run- } \\
\text { ning Java } \\
\text { VM and RMI }\end{array}$ & $\begin{array}{l}\text { Wired/wire- } \\
\text { less commu- } \\
\text { nications } \\
\text { (Bluetooth) }\end{array}$ & $\begin{array}{l}\text { (1) Application functionality specific to } \\
\text { each individual clinical application and } \\
\text { patient and HP user requirements, (2) } \\
\text { BAN devices have alarm button, (3) view- } \\
\text { ing, streaming and management services } \\
\text { for BANs and BAN data, analysis and in- } \\
\text { terpretation algorithms, alarms, geospatial } \\
\text { and location-based services, (4) various se- } \\
\text { curity and access control mechanism }\end{array}$ \\
\hline $\begin{array}{l}\text { Diabetes } \\
\text { virtual clin- } \\
\text { ic [43-45] }\end{array}$ & $\mathrm{NO}$ & User center & Diabetes & $\begin{array}{l}\text { SMS, WIFI, Inter- } \\
\text { net }\end{array}$ & $\begin{array}{l}\text { Computers, } \\
\text { mobile, PDA }\end{array}$ & $\begin{array}{l}\text { Wired/wire- } \\
\text { less commu- } \\
\text { nications }\end{array}$ & $\begin{array}{l}\text { (1) Self-care, (2) e-learning, (3) tele consul- } \\
\text { tation, (4) integrate and co-ordinate vari- } \\
\text { ous health care activities under the same } \\
\text { fundamental activity system }\end{array}$ \\
\hline
\end{tabular}

Table 1. Electronic health system characteristics in chronic disease management. 
and others implemented on mobile phone. Sending alarm to patients and health care providers and identify place of patients with GPS are possible in some of the studied systems. Wired and wireless communication in all system studied can be useful especially when mobility is desired.

Recently, health care systems shift toward fast achieving to right decision to solve problems with spending least costs. So to reach this goal, find suitable information from useful and reliable resources in the fastest time and the least possible effort for information searching, analyzing, and filtering is very important.

This requires high interoperability among different professionals and systems in various places. In fact for providing effective health care and shared information, all actions need to be coordinated. Facilitated decision making requires interoperability and effective communications between professionals. Finding standard software as a suitable solution for complex health challenges is not easy. Electronic health systems must be proactive in anticipating the health information needs and supporting communications.

Because of potential capabilities of agent technology like mobility [44], autonomy, interoperability, scalability and re-configurability, integrating disparate systems, improving distributed data and resources management, handling the complexity of solutions, modeling and organizing the interrelationships between components [31-36, 46-51], is very valuable tool for telemedicine and telecare.

Agent-based systems in this table increase quality of care management. For example in IMIS system, tasks were delegated and all users in each level can communicate with one another and share the relevant data. In M2DM system, various analytic ways through knowledge agent were combined and used for the identification of abnormal situations. Also sending alarms, analysis results and real-time feedbacks to users are some benefits of this system [31-36]. Agents can be implemented on portable and mobile devices like PDA and use web services to interact with other systems.

The IMIS platforM is based on the Internet and will be accessible by PC or wireless network PDA. Accessibility should be regulated by groups of users. Each step in this system by the user is followed with instant feedback. M2DM can be activated in three ways: based on user needs, with receiving data, and by system. This system uses inexpensive and widely accepted technologies. This system applies technologies such as WEB, WEB TV, and SMS that are supported with computers or mobile terminals. Also it combines innovative and advanced technologies like PDA, WAP, GPRS, and PALMTOPS. The use of such technologies is limited in small groups of users because of costs, accessibilities, and user skills required.

Overall, according to multiagent health systems advantages in comparison to other type of systems and challenges in health care systems especially in diabetics care management, it can be said that the use of agent technology as a new and modern technology to reach full advantages of telemedicine and telehealth is essential, and health systems in the world must move toward agent-based applications. 


\section{4. mHealth challenges in patient monitoring}

Although mHealth technology has a key role in health care systems, yet its uptake has faced with general and specific challenges. Some problems in general dimension include organizational challenges like organizational culture, support of high-level management; technological barriers such as lack of ICT and mobile infrastructure [52]; human challenges, for example, lack of trained and skilled personnel at health care centers in this field [28], user attitudes, technology acceptance [53,54], user characteristics like age, economic, social, and educational status [55]; and threats to confidentiality and privacy, legal, ethical, and administrative barriers, costs of system implementation and maintenance [28], dependence on IT [56], the cost of updating, costly modern systems [57], sufficient investment, delays in implementation and providing electronic devices and software [58]. Some barriers from specific aspects also include problems in interoperability between other health systems and information technology tools, poor and inappropriate design and implementation [59], effect on face-to-face communication between health care providers and patient [60], causes omission of human relationship and the negative effects of technology on relationships between individuals and social processes [56], designing of mHealth services content [55], failure to meet targets [58], virtual information control [61], medical errors due to malfunctioning of system [62], fault documentation [59] like data manipulation and rewriting, misrepresentation, and violation of patients' legal rights. Difficulties related to telecommunication industry such as reliability, sustainability of connections, sudden interruptions of telecommunication networks [63], device and sensor type that can be used, type of data and language presentation [56], scalability in terms of data rate, power and energy consumption; antenna design, quality of service, energy efficiency [64,65] wearable devices weight, type of devices that used for patient monitoring that sometimes lead to problem in data processing, accuracy of gathering information depends on where data were collected, and user training to use wearable system [66].

As aforementioned, one of the items that can help mHealth infrastructure development is application of agent-based systems in patient monitoring. We perform research in Iran about diabetes as one of the most challenging chronic diseases. The aim of this research is developing framework for agent-based diabetes disease management system through mHealth according to user's perspective. Some of the most important results are as follows:

\section{Case study}

Endocrinology and metabolism research institute of Tehran University of Medical Sciences in collaboration with Health Information Management Research center in this University conducted a research in 2012-2013. The goal of this research was to provide a model based on mobile health and agent technology in national level for diabetes management information. This framework must have capabilities of agent and support decision-making, create alerts and remote monitoring of patient status, and provide appropriate treatment and preventive recommendations for diabetes. 
A questionnaire was designed with a study of library resources and operation of major organizations in and out of the country and interviews with relevant medical experts.

To determine the validity of a questionnaire distributed among experts in three areas after analyzing the results, the reliability was evaluated. Questionnaire includes three parts. First section covers personal identification. Second section questions about the general features of agent-based systems for the management of diabetes. Finally, third section examines the specific features of the systems in hospitals. At the end of questionnaire, an open question captured the opinions of experts concerning diabetes management system structure based on agent technology. Results of the questionnaires were analyzed with SPSS17 and were plotted with FREEPLANE mind map software. Finally, essential agents according to tasks of diabetes management system were determined. Some of the results obtained from this study are explained below.

Most diabetics must monitor and measure their blood glucose levels during the day. Like measuring glucose after every insulin injection and record it, along with the amount of daily insulin injections and diet and information about their lifestyle. Using information technology tools and a telemedicine system helps process management of health service, allows real-time monitoring, and provides early treatment for diabetes. To achieve these goals are possible through multi agent systems can be performed with using different agents. Based on this study, a diabetes management system has necessary business process including:

1. Information processing

2. Monitor patient status

3. Consultation

4. Diagnosis

5. Archiving relevant documents and patient records

6. Decision support system

7. Appropriate interface for communication between patients and health electronic systems

8. Monitoring operations and service delivery and allocate tasks to perform

Important services and processes through the implementation of software systems in the field of diabetes management from the experts, perspectives are plotted (see Figure 1).

From the experts' point of view in this research, proposed framework must be used in priority order for home care, outpatient, and inpatient. Best development method to such system in priority order is telemonitoring or teletreatment services, user centered, merging of telemedicine with knowledge management, local and personal health services. Access to data technology in this system in priority order is mobile, SMS, Email, Internet in devices including web, phone, WIFI, and PDA. Also according to studies, to provide better health services, the communication should be used through wired or wireless connection tools. 


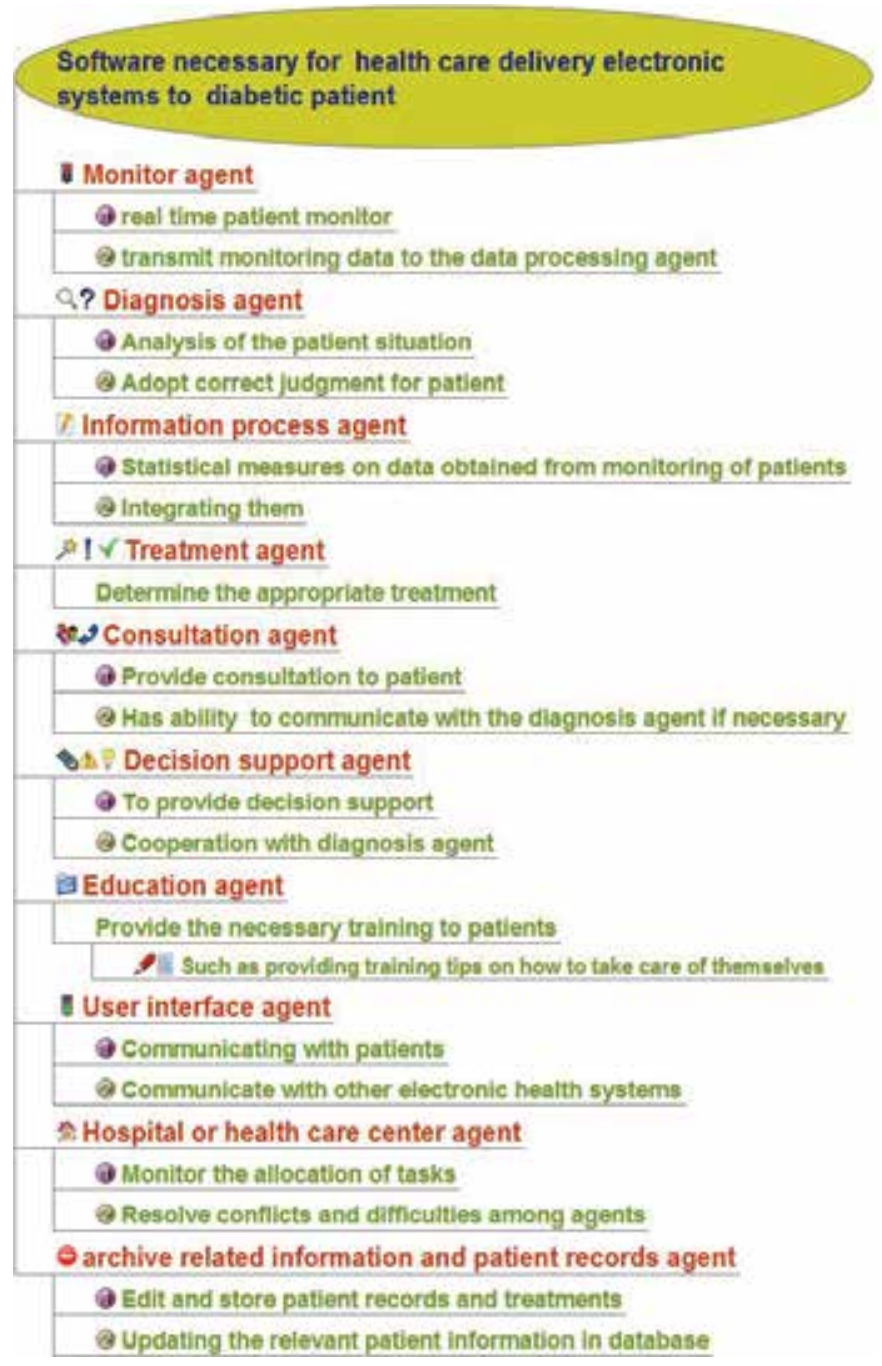

Figure 1. Software necessary for health care delivery electronic systems for diabetic patients.

Capabilities for diabetes management system based on agent technology in medical centers and hospitals section based on research findings with FREE PLANE software are depicted in Figure 2.

Also capabilities for diabetes management system based on agent technology for health care personnel based on research findings are: (1) remote education, (2) knowledge management, (3) intelligent alarms, and (4) electronic health records management. From the experts' point of view, diabetes management system based on agent technology must have these abilities for patients in the following order: (1) remote education, (2) intelligent alarms and reminders, (3) patient monitoring, (4) self-management, and (5) determining the exact location of medical centers and hospitals. 


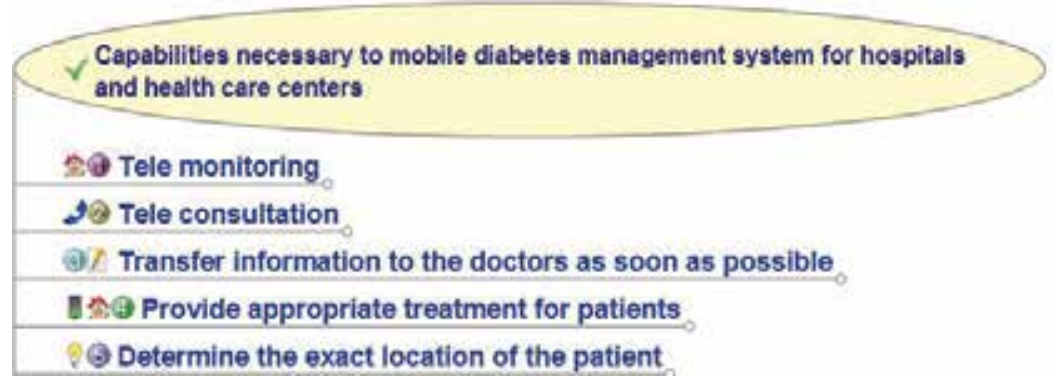

Figure 2. Capabilities necessary for mobile diabetes management system for hospitals and health care centers.

Experts in this research believed that proposed framework must be delivered through remote education to diabetes patients. Suitable remote education formats recommended in order of priority include imaging, audio, model questions and answers, and text tutorials. Patients on remote education should be able to search based on their needs, choice of content, and personalization and have the possibility to download the contents.

The weakness of this project is that benefits of experts surveyed only from health information management, software and physician in diabetic research center fields. To design and implement more appropriate conceptual models, involved experts should be from various fields such as telecommunication and addressing various aspects are very helpful, and the gained result is a more practical.

\section{Discussion}

Nowadays real-time access to reliable and proper information in order to deliver continuous health care and increase quality of care is very much in demand. So in order to achieve this goal, interoperability and coordination among providers involved in patient treatment for exchange of health information is a critical need. Chronic disease management especially diabetes based on IT tools has impressive benefits and some challenges. In this chapter, diabetic management system is classified into two groups: agent-based system and nonagent-based system.

Better self-care, improved prevention, increased quality life style, and teleconsultation are most important benefits of nonagent-based systems. Also these systems confront some challenges. The use of agent systems as a modern technology to decrease these barriers and take full advantages of telemedicine is essential and health systems must move using agentbased applications. In the second group, some of the benefits of agent technology in telemedicine services delivery include providing immediate feedback to patients, promoting interaction of the patient with organization that provides remote health care, reinforcing their motivation for the use of telemedicine systems and patients, and clinicians focusing on abnormal data that will prevent future occurrence of dangerous situations. 
Agent-based systems improve interoperability, maintain the autonomy of the collaborating participants, communicate between themselves for exchanging health information, provide expert knowledge management, and improve e-learning. Multiagent systems are inherently compatible with mobile devices. Architecture of these systems allows high interoperability and quality information management and appropriate sharing data. Diabetes virtual clinic in Iran is one of the nonagent systems that provides some important health services to the people and assist them to improve knowledge about diabetes care. This system needs to move toward the use of artificial intelligence tools and expert systems like agents for further development and increased capabilities. Our finding in 2013 research showed that to accelerate the development of diabetes management systems based on artificial intelligence tools, we must consider these items: (1) promote organizational cultural, (2) note to suitable technical infrastructure, (3) provide appropriate security and privacy, (4) adequate investment, (5) user participation, and (6) involvement of private sections. Also note to structure, proper system, and database design that can support different kinds of training formats and tasks, and provide backup are very important. Ease of use and user friendliness of system should be considered especially for elderly people. Also design of drug and injection reminders for patients in addition to the built-in alarm system is a key factor.

It should be noted that the use of agent systems only with technical view does not lead to elimination of obstacles. In delivering health care to diabetic patients or other chronic disease patients, paying attention to human aspect and social dimension is very important. Some users dislike computers and do not trust them. So these challenges in designing diabetes system based on mobile devices must be considered. In other words, note to all dimensions for implementation of mobile health systems especially agent system like user satisfaction, user acceptance, costs, motivation, structural and organizational factors, and standards, individual's affordability, identification challenges and opportunity, and so on are necessary. Also accelerating the application and implementation of multiagent diabetes management systems and use of mobile devices need to development of strategies to encourage health care providers for make greater use of mobile devices in deliver health care services to patients and providing the necessitate infrastructure and appropriate readiness. Stakeholders' support to apply of agent technology is essential.

\section{Conclusion}

Application of electronic health systems for patient monitoring has significant advantages. The use of these tools in health care organizations needs to study about these technologies, compare their benefits and limitations, note to organizational resources including human, technical, financial; suitable planning, and affordability of these facilities. Determining and decreasing challenges and identifying opportunities that affect on successful implementation of these technologies have critical roles in proper application of each of these systems.

Health care systems based on mobile technology are faced with important limitations such as user attitude and acceptance, budget, technical standard, equipment, and tools required for 
mobile communication, security and good infrastructure, increasing the accuracy of critical signals, interoperability between different systems, bandwidth limitations, quality of health services, battery life limited tools, and so on.

User acceptance is improved through the provision of advisable training and cultural awareness. It also provides an environment in which innovations in organizations are appreciated. Key factors to increase user acceptance include staff participation and involvement in all stages of the process from planning to implementation, clear and effective communication between managers and all staff members involved in the project, describing the advantages of technology and change management.

Note to important factors such as adequate bandwidth, preparation of standard tools that provide maximum mobility and flexibility for users, decreasing obstacles which interrupt network communications, insurance coverage, and supporting patients who use remote monitoring devices, data encryption while transferring, paying attention to legal and ethical aspects are all necessary in the success of these systems in health care organizations.

\section{Future trends}

For future work, we suggest that try to provide inexpensive mHealth services, so that more people can use these services. Insurance companies especially in developing countries consider situations and are motivated to cover these types of health care services. Decreased dependence of communication protocols with mobile device types can help generalize and extend the use of mobile health devices.

\section{Acknowledgements}

The authors would like to thank the anonymous reviewers for their valuable comments and suggestions, which improved this chapter.

\section{Author details}

Niloofar Mohammadzadeh and Reza Safdari*

*Address all correspondence to: rsafdari@tums.ac.ir

Department of Health Information Management, Tehran University of Medical Sciences, Tehran, Iran 


\section{References}

[1] Safdari R, Mohammadzadeh N. Multi-agent systems and health information management. In 2nd eHospital and Telemedicine Conference. Tehran University of Medical Sciences. Tehran. Iran. 2011.

[2] Kahn GJ, Yang SJ, Kahn SJ. 'Mobile' health needs and opportunities in developing countries. Health Affairs 2010.29(2):252-258. doi:10.1377/hlthaff.2009.0965.

[3] Tan J. Medical Informatics: Concepts, Methodologies, Tools, and Applications, Volume 1, Chapter 7.5. Securing Mobile Data Computing in Healthcare, Hershey, New York. 2009. p: 1930.

[4] Bøne E, Hasvold P, Henriksen E, Strandenæs T. Risk analysis of information security in a mobile instant messaging and presence system for healthcare. International Journal of Medical Informatics 2007.76:677-687. doi: http://dx.doi.org/10.1016/j.ijmedinf. 2006.06.002

[5] World Health Organization. mHealth New horizons for health through mobile technologies. 2011. ISBN 978924156425 0. Available from: http://www.who.int/goe/ publications/goe_mhealth_web.pdf [Accessed: 5 June 2013]

[6] Pawar P, Jones V, van Beijnum BJ, Hermens H. A framework for the comparison of mobile patient monitoring systems. Journal of Biomedical Informatics 2012.45(3):544556. doi: 10.1016/j.jbi.2012.02.007.

[7] Prgomet M, Georgiou A, Westbrook JI. The impact of mobile handheld technology on hospital physicians' work practices and patient care: a systematic review. Journal of the American Medical Informatics Association 2009.16:792-801. doi: 10.1197/ jamia.M3215.

[8] Strandbygaard U, Thomsen SF, Backer V. A daily SMS reminder increases adherence to asthma treatment: a three-month follow-up study. Respiratory Medicine 2010.104(2): 166-171. doi: 10.1016/j.rmed.2009.10.003.

[9] Suter P, Suter WN, Johnston D. Theory-based telehealth and patient empowerment. Population Health Management 2011.14(2):87-92. doi:10.1089/pop.2010.0013.

[10] Warren I, Weerasinghe T, Maddison R, Wang Y. Odin telehealth: a mobile service platform for telehealth. Procedia Computer Science 2011.5:681-688. doi:10.1016/j.procs. 2011.07.089.

[11] Bellini P, Boncinelli S, Grossi F, Mangini M, Nesi P, Sequi L. Mobile emergency, an emergency support system for hospitals in mobile devices: pilot study. JMIR Research Protocols 2013.2(1):e19. doi:10.2196/resprot.2293. 
[12] Ferrer-Roca O, Subirana R. A four-year study of telephone support for oncology patients using a non-supervised call centre. Journal of Telemedicine and Telecare 2002.8(6):331. doi:10.1258/135763302320939211.

[13] Wakadha H, Chandir S, Were Elijah V, Rubin A, Obor D, Levine OS, Gibson DG, Odhiambo F, Laserson KF, Feikin DR. The feasibility of using mobile-phone based SMS reminders and conditional cash transfers to improve timely immunization in rural Kenya. Vaccine 2013.31:987-993. doi:10.1016/j.vaccine.2012.11.093.

[14] Martins M, Henrique G. Mobilizing Health Information to Support Healthcare-related Knowledge Work. INSTICC Press: Portugal. 2009. p. 69

[15] Khairat S, Gong Y. Understanding effective clinical communication in medical errors. Studies in Health Technology Informatics 2010.160(Pt 1):704-708. doi: 10.3233/978-1-60750-588-4-704.

[16] Goldbach H, Chang AY, Kyer A, Ketshogileng D, Taylor L, Chandra A, Dacso M, Kung SJ, Rijken T, Fontelo P, Littman-Quinn R, Seymour AK, Kovarik CL. Evaluation of generic medical information accessed via mobile phones at the point of care in resourcelimited settings. Journal of the American Medical Informatics Association 2014.21(1): 37-42. doi:10.1136/amiajnl-2012-001276.

[17] Tubaro M. An organized system of emergency care for patients with myocardial infarction: a reality? Future Cardiology 2010.6(4):483-489. doi:10.2217/fca.10.25.

[18] Engelgau M, Rosenhouse S, El-Saharty S, Mahal A. The economic effect of noncommunicable diseases on households and nations: a review of existing evidence. Journal of Health Communication: International Perspectives 2011.16(2):75-81. doi: 10.1080/10810730.2011.601394.

[19] Zhang P, Zhang X, Brown J, Vistisen D, Sicree R, Shaw J, Nichols G. Global healthcare expenditure on diabetes for 2010 and 2030. Diabetes Research and Clinical Practice 2010.87(3):293-301. doi:10.1016/j.diabres.2010.01.026.

[20] World Health Organization. Global status report on non communicable diseases 2010. World Health Organization 2011 Reprinted 2011. ISBN 978924156422 9. ISBN 97892 $4068645 \quad 8 \quad$ (PDF). Available from: http://www.who.int/nmh/publications/ ncd_report_full_en.pdf [Accessed 30 June 2013].

[21] Esteghamati A, Khalilzadeh O, Anvari M, Meysamie A, Abbasi M, Forouzanfar M, Alaeddini F. The economic costs of diabetes: a population-based study in Tehran, Iran. Diabetologia 2009.52:1520-1527. doi:10.1007/s00125-009-1398-4.

[22] McAndrew LM, Napolitano MA, Pogach LM, Quigley KS, Shantz K, Vander Veur SS, Foster GD. The impact of self-monitoring of blood glucose on a behavioral weight loss intervention for patients with Type 2 diabetes. The Diabetes Educator 2013.39(3):397405. doi:10.1177/0145721712449434. 
[23] Paré G, Moqadem K, Pineau G, St-Hilaire C. Clinical effects of home tele monitoring in the context of diabetes, asthma, heart failure and hypertension: a systematic review. Journal of Medical Internet Research 2010.12(2):e21. doi:10.2196/jmir.1357.

[24] Barjis J, Kolfschoten G, Maritz J. A sustainable and affordable support system for rural healthcare delivery. Decision Support Systems 2013.56:223-233. doi:10.1016/j.dss. 2013.06.005. Available from: http://dx.doi.org/10.1016/j.dss.2013.06.005 [Accessed 24 June 2013].

[25] Skolnik NS. Electronic Medical Records: A Practical Guide for Primary Care. New York: Springer Humana Press; 2011. p: 1.

[26] Finn N, Bria W. Digital Communication in Medical Practice. London: Springer-Verlag; 2009. p: 70-73.

[27] Toledo FG, Triola A, Ruppert K, Siminerio LM. Telemedicine Consultations: an alternative model to increase access to diabetes specialist care in underserved rural communities. JMIR Research Protocols 2012.1(2):e14. doi:10.2196/resprot.2235.

[28] Khoumbati K, Dwivedi Y, Srivastava A, Lal B. Handbook of Research on Advances in Health Informatics and Electronic Healthcare Applications: Global Adoption and Impact of Information Communication Technologies. Hershey. New York: Medical Information Science Reference; 2010. p: 91, 10, 156.

[29] Safdari R, Mohammadzadeh N. Patient Health Monitoring Through Mobile Health Systems. Lecture in International Conference on 2012 Electronic Health (ICEH 2012). Medical Council of Islamic Republic of Iran. Tehran. Iran.

[30] McDaniel J. Advances in Information Technology and Communication in Health. Amsterdam: IOS Press; 2009. p: 467-471.

[31] Integrated Mobile Information Research. 2010. Available from: http://www.bth.se/ research/imis/ [Accessed 4 July 2013]

[32] Shaheen A, Ahmad Khan W. Intelligent Decision Support System in Diabetic eHealth Care From the perspective of Elders. [Master Thesis]. Computer Science. Blekinge Institute of Technology. Sweden. 2009. Available from: http://www.bth.se/fou/ cuppsats.nsf/all/89449be91369ee27c12575d60071c747/\$file/Master_thesis_asma.pdf [Accessed 4 July 2013]

[33] Zhang P. Multi-agent Systems in Diabetic Health Care. Blekinge Institute of Technology Licentiate Series. Issue 5. Karlskrona: Blekinge Institute of Technology. ISBN: 91-7295-060-9. 2005. Available from: http://www.bth.se/fou/forskinfo.nsf/all/ 07625d65f3f89ee6c1256fef00220c36?OpenDocument [Accessed 4 July 2013].

[34] Bellazzi R, Carson ER, Cobelli C, Hernando E, Gomez EJ, Nabih-Kamel-Boulos M, Rendschmidt T, Roudsari V, et al. Merging Telemedicine With Knowledge Management: The M2DM Project. Published in: Engineering in Medicine and Biology Society. 
Proceedings of the 23rd Annual International Conference of the IEEE, Volume 4, 2001. p: 4117-4120. doi:10.1109/IEMBS.2001.1019762.

[35] Hernando M E, Garsia A, Javiar Perdices F, Torralba V, Gomez E J. del Pozo F. Multi agent architecture for the provision of intelligent telemedicine services in diabetes management. Available from: http://cyber.felk.cvut.cz/EUNITE03-BIO/pdf/EHernando.pdf [Accessed 4 July 2013]

[36] Jones V, Gay V, Leijdekkers P. Body Sensor Networks for Mobile Health Monitoring: Experience in Europe and Australia. Accepted for 4th International Conference on Digital Society, ICDS 2010, February 10-16, 2010, ICDS '10. Fourth International Conference on. Netherlands: Digital Society; 2010.

[37] Leijdekkers P, Gay V. A Self-Test to Detect a Heart Attack Using a Mobile Phone and Wearable Sensors. 21st IEEE International Symposium on Computer-Based Medical Systems; 2008. p: 93-98. ISBN: 978-0-7695-3165-6.

[38] Jones M, Bults G, Konstantas D, Vierhout P. Healthcare PANs: Personal Area Networks for trauma care and home care, Proceedings Fourth International Symposium on Wireless Personal Multimedia Communications. [WPMC], Sept. 9-12, 2001, Aalborg, Denmark. 2001. Available from: http://wpmc01.org/, ISBN 87-988568-0-4.

[39] Otto C, Milenkovic A, Sanders C, Jovanov E.System Architecture of a wireless body area sensor network for ubiquitous health monitoring. Journal of Mobile Multimedia 2006.1(4):307-326.

[40] Halteren Aart V, Bults R, Wac K, Konstantas D, Widya I, Dokovsky N, Koprinkov G, Jones V, Herzog R. Mobile patient monitoring: the MobiHealth system. Journal on Information Technology in Healthcare 2004.2(5):365-373. ISSN 1479-649X.

[41] MobiHealth-Shaping the Future of Healthcare. Available from: http://www.ltu.se/ cms_fs/1.90345!/file/Mobihealth\%20brochure.pdf [Accessed 4 July 2013].

[42] Inaugurate first diabetes virtual clinic in Iran at Tehran university of medical sciences (in Persian). Available from: http://publicrelations.tums.ac.ir/news/detail.asp?newsID=13114 [Accessed 4 July 2013].

[43] For the first time in Iran, virtual clinic for diabetes opening in Shariati hospital. (in Persian). Available from: http://www.pezeshkan.ir/view.asp?id=99119 [Accessed 4 July 2013].

[44] Diabetes Virtual Clinic. Available from: http://emri.tums.ac.ir/pages/mainpage.asp? I=S54M5P2C1 [Accessed 4 July 2013].

[45] Annicchiarico R, Cortés U, Urdiales C. Agent Technology and e-Health. Switzerland: Birkhäuser Verlag; 2008. p: 141-148.

[46] Isabelle B, Sachin V, Ashlesha J, Lakhmi J.Computational Intelligence in Healthcare 4. Berlin: Springer-Verlag; 2010. p: 25-48. 
[47] Sánchez D, Isern D, Rodríguez Á, Moreno A. General purpose agent-based parallel computing. In: Omatu S, Rocha MP, Bravo J, Fernández F, Corchado E, Bustillo A, Corchado JM. [eds.] IWANN. LNCS, Heidelberg: Springer; 2009. vol. 5518, p: 231-238.

[48] Mohammadzadeh N, Safdari R. Artificial intelligence tools in health information management. International Journal of Hospital Research 2012.1(1):65-70.

[49] Isern D, Sánchez D, Moreno A. Agents applied in health care: a review. International Journal of Medical Informatics 2010.79:145-166. doi:10.1016/j.ijmedinf.2010.01.003.

[50] Safdari R, Mohammadzadeh N. Electronic Health Information Systems. Tehran: Mirmah; 2011. p: 152-156 (in Persian).

[51] Cripps H, Standing C. The implementation of electronic health records: a case study of bush computing the Ngaanyatjarra Lands. International Journal of Medical Informatics 2011.80(12):841-848. doi:10.1016/j.ijmedinf.2011.09.007.

[52] Cresswell K, Sheikh A. Organizational issues in the implementation and adoption of health information technology innovations: an interpretative review. International journal of medical informatics 2013.82(5):e73-e86. doi:10.1016/j.ijmedinf.2012.10.007.

[53] Venkatesh V, Thong J Y L, Xu X. Consumer acceptance and use of information technology: extending the unified theory of acceptance and use of technology. Forthcoming in MIS Quarterly 2012.36(1):157-178.

[54] Hardiker NR, Grant MJ. Factors that influence public engagement with eHealth: a literature review. International Journal of Medical Informatics 2011.80(1):1-12. doi: 10.1016/j.ijmedinf.2010.10.017.

[55] Taniar D. Mobile Computing: Concepts, Methodologies, Tools, and Applications. New York: Information Science reference; 2009. p: 791-792, 432-433. ISBN 978-1-60566-054-7 (hardcover)-ISBN 978-1-60566-055-4 (ebook).

[56] Blumenthal D. Stimulating the adoption of health information technology. The New England Journal of Medicine 2009.360:1477-1479. doi:10.1056/NEJMp0901592.

[57] Lucas H. Information and communications technology for future health systems in developing countries. Social Science \& Medicine 2008.66:2122-2132. doi:10.1016/ j.socscimed.2008.01.033.

[58] Lawler EK, Hedge A, Pavlovic-Veselinovic S. Cognitive ergonomics, socio-technical systems, and the impact of healthcare information technologies. International Journal of Industrial Ergonomics 2011.41:336-344. doi:10.1016/j.ergon.2011.02.006.

[59] Viitanen J, Hyppönen H, Lääveri T, Vänskä J, Reponen J, Winblad I. National questionnaire study on clinical ICT systems proofs: physicians suffer from poor usability. International Journal of Medical Informatics 2011.80(10):708-25. doi:10.1016/j.jimedinf. 2011.06.010. 
[60] Lluch M. Healthcare professionals' organizational barriers to health information technologies: a literature review. International Journal of Medical Informatics 2011.80(12):849-862. doi:10.1016/j.ijmedinf.2011.09.005.

[61] While A, Dewsbury G. Nursing and information and communication technology (ICT): a discussion of trends and future directions. International Journal of Nursing Studies 2011.48:1302-1310. doi:10.1016/j.ijnurstu.2011.02.020.

[62] Nykänen P, Brender J, Talmon J, de Keizer N, Rigby M, Beuscart-Zephir M, Ammenwerth E. Guideline for good evaluation practice in health informatics (GEP-HI). International Journal of Medical Informatics 2011.80:815-827. doi:10.1016/j.ijmedinf. 2011.08.004.

[63] Aggarwal NK. Applying mobile technologies to mental health service delivery in South Asia. Asian Journal of Psychiatry 2012.5:225-230. doi:10.1016/j.ajp.2011.12.009.

[64] Patel M, Jianfeng W. Applications, challenges, and prospective in emerging body area networking technologies. IEEE Wireless Communications. 2010.17(1):80-88. doi: 10.1109/MWC.2010.5416354.

[65] Klingeberg T, Schilling M. Mobile wearable device for long term monitoring of vital signs. Computer Methods and Programs in Biomedicine 2012.106:89-96. doi:10.1016/ j.cmpb.2011.12.009.

[66] Chan M, Estève D, Fourniols J, Escriba C, Campo E. Smart wearable systems: current status and future challenges. Artificial Intelligence in Medicine 2012.56:137-156. doi: 10.1016/j.artmed.2012.09.003 
Section 2

mHealth Applications 

Chapter 5

\title{
Mobile Cloud-Based Blood Pressure Healthcare for Education
}

\author{
Chin-Feng Lin, Shere-Er Wang, Yen-Chiao Lu, \\ Chung-I Lin, Chung-Cheng Chang, Tim Yeh, \\ Candice Lee, Jeffson Huang, Chic-Erh Weng, \\ Sue-Hsien Chen, Bing-Leung Sun, \\ Chao-Sheng Wang, Shiue-Li Cheng, Shiou-Yu Li and \\ Lan-Yu Wu
} Additional information is available at the end of the chapter

http://dx.doi.org/10.5772/63471

\begin{abstract}
Mercury, pneumatic, and electronic sphygmomanometers were widely used for traditional blood pressure (BP) measurement. Cloud BP database, and mobile information and communication technology (MICT) do not integrate to these BP measurement methods. Pen and papers were employed to record BP values for nurses and physicians, and recording errors are possible to occur. In the chapter, the cloudbased BP platform solution and advanced wireless hospital BP measurement technologies were studied. These cloud-based BT measurement technologies were used as teaching aids to train students of electrical and nursing fields for mobile BP healthcare and health promotion education, and hence interdisciplinary teaching and learning were conducted. The teachers include professors of electrical and nursing fields, physicians, hospital nurses, and the engineer and health management experts of Microlife. The interdisciplinary teaching and learning of mobile BP healthcare and health promotion for smart aging were conducted in the Department of Nursing Division, Chang Cung Memorial Hospital, Keelung Branch, Department of Nursing Ching Kuo Institute of Management and Health, School of Nursing Chung Shan Medical University, and Department of Electrical Engineering, National Taiwan Ocean University. The students of electrical and nursing fields participated for joint interdisciplinary learning. The concepts of interdisciplinary mobile BP healthcare learning and teaching involve nursing and technology, healthy aging, BP health care for smart aging, telenursing, BP care for smart aging, community/home telecare, and MICT. The objective of teaching and learning is training the design and making electrical engineers
\end{abstract}


to understand BP healthcare and health promotion, and nurses to understand mobile $\mathrm{BP}$ healthcare and health promotion system for smart aging.

Keywords: BP healthcare, smart aging , cloud-based BP measurement technologies, jointly interdisciplinary learning and teaching, mobile information and communication technology

\section{Introduction}

In this chapter, computers, Internet access, mobile computing, Web page systems, short messaging services, multimedia messaging services, and e-mails were examined with respect to students of medical, nursing, and health science disciplines [1]. The advanced technologies help health science students to access healthcare information and adopt effective methods to develop their skills. Mobile information and communication technology (MICT) has been used in the learning and teaching process of health and medicine science education, and has enabled learning and access to health education knowledge anywhere and at any time [2]. Mazzola et al. [3] demonstrated how physical activity, nutrition, and training through a combination of processes and mobile technologies are related to overweight teenagers and obesity in behavioral education. The People for Ecosystem-based Governance in Assessing Sustainable development of Ocean and coast (PEGASO) scenarios [3] include motion sensors to detect physical activity, GPS location service, and the smartphone acts as a communication gateway for these sensors with feedback functions and information. The awareness and self-management of obesity risks are important to motivate teenagers to engage in affective learning and trigger a behavioral change. Smartphone applications were exploited to improve participants' healthrelated quality of life and healthcare utilization for rheumatic diseases self-management [4]. Disease-associated self-management strategies can be designed using mobile health (mHealth) technologies. Azevedo et al. [4] reviewed several aims, platforms, and characteristics of smartphone applications for self-management of rheumatic diseases.

mHealth is a "medical and public health practice supported by mobile devices, such as mobile phones, patient monitoring devices, personal digital assistants, and other wireless devices" [5], and is recognized by the World Health Organization. Advanced mobile Web-based and Internet technologies have transformed current healthcare models with regard to monitoring of physical activity or encouraging physiological changes that stimulate positive health behaviors. Zhang et al. [6] illustrated how to extend a mobile Web-based app with multimedia features for psychiatry education in Singapore, and found out through a survey that MICT helped them save a significant amount of time in clinical activities. MICT must ensure that the physiological signals provided within are accurate and credible. Healthy behaviors (e.g., sports lifestyle, healthy eating habits, and blood pressure (BP) monitoring) help in reducing fatal health risk, disability, healthcare use and health-related costs [7]. Weight management, physical activity, smoking cessation, self-management of diabetes mellitus, and hypertension care using MICT were demonstrated [8]. MICT-supported health behavior interventions are designed to prevent or manage illness and lead to fundamental changes in health practices, 
thereby, providing an opportunity to stimulate and sustain healthy behaviors [6, 7]. Chan et al. [9] described that problem-based learning using multimedia, such as video clips, Web sites, images, or photos, was implemented in the health sciences learning process, and students could use their mobile Internet technology to access the knowledge and enhance their process of learning using laptops, tablets, and smartphone mobile devices on a cloud-based learning platform. Problem identification, problem description, problem exploration, applicability, and integration strategies were recommended in the problem-based learning approach [10].

Elliott et al. [11] implemented a mobile electronic health records (EHR) system for medical education. The functionality, connectivity, ease of use, and usage challenges of the developed EHR system in the hospital environment were investigated for learning. Davies et al. [12] developed a mobile learning model using a personal digital assistant (PDA) loaded with medical resources for undergraduate medical students in the clinical environment. MICT was used to provide new learning methods with respect to problem identification and solving skills. ISO/IEEE 11073 and Health Level 7(HL7) V2.6 protocols were used to develop and evaluate self-management mobile Personal Health Record mobile health application for Android 4.0 .3 by the Continua Health Alliance for continuous self-management of chronic disease patients [13]. It has the potential to promote new treatment and medical opportunities as well as to reduce medical costs and time for an aging society. It monitors their vital signs using mobile network technology (MNT); thereby, ensuring better healthcare. The user interface, applications, seamless transmission protocol, personal health record, and database managers were demonstrated for the application.

Wu et al. [14] proposed a cellular and iridium network-based blood pressure and body temperature remote measurement platform for mobile healthcare education. The overview of mobile telemedicine research fields was provided by Lin [15, 16]. In previous studies [17-21], 802.11n and ultra-wideband wireless telemedicine transmission schemes, multicode code division multiple access (CDMA) cellular mobile telemedicine transmission mechanism, and multi-satellites wideband CDMA and orthogonal frequency division multiplexing (OFDM) transport architectures were proposed. In this article, a cloud-based mobile blood pressure (BP) healthcare education program for smart aging is investigated.

\section{Teaching methodology and concept}

Our teaching team included professors from electrical and nursing fields, as well as physicians, the engineers, and health management experts for Microlife. Cloud-based and mobile BP healthcare knowledge was the focus of studies for students in electrical and nursing fields. The could-based and mobile BP platform of Microlife was used in the healthcare program for interdisciplinary learning. The tele-BP healthcare for smart aging course was offered through the Department of Electrical Engineering, National Taiwan Ocean University, and the School of Nursing Chung Shan Medical University, during February 2014 and June 2014. Fourteen students in the electrical field and 19 nursing students participated for joint interdisciplinary learning. The distance between National Taiwan Ocean University and Chung Shan Medical 
University is $180 \mathrm{~km}$. Facebook videoconferences were used for team discussions associated with problem-based learning and problem solving. The BP healthcare for smart aging course was offered through the Department of Electrical Engineering, National Taiwan Ocean University, and the Department of Nursing, Ching Kuo Institute of Management and Health, during September 2014 and January 2015. Thirteen students in the electrical field and 34 nursing students participated for joint interdisciplinary learning. In the learning teams, students in the electrical field provided the MICT know-how, and nursing students contributed user experience and healthcare knowledge. The course outline of tele-BP healthcare for smart aging is as follows:

- Nursing and technology

- Healthy aging

- BP healthcare for smart aging

- Telenursing

Video materials were recorded and uploaded to the course Web site for students enrolled in the course so that they could download the information to study anytime and anywhere.

Nursing and technology video material [22]: Lu discussed the relationship between nursing and technology, technology's effects on nursing, the connection between nurse's experiences with technology and new technology design, advanced nursing processes, future trends in nursing education, and future trends in the development of nursing technologies.

Healthy aging video material [23]: Lu defined aging and discussed the aging process, changes in bodily functions, longevity, elderly food intake and arrangements, elderly movement, and approaches to caring for the elderly, as well as definitions of healthy aging, aging attitudes, and planning.

BP healthcare for smart aging video material [24]: Lin discussed health and medical, issues, medical care for smart aging, cardiovascular disease, BP definition, the principles of BP changes, classifications of hypertension, techniques and times for measuring $\mathrm{BP}$, and principles and operational modes regarding mercury, pneumatic, and electronic sphygmomanometers. Other topics included risk factors, symptoms, and complications of hypertension, and preventive measures for the disease.

Telenursing video material [25]: Lu discussed the definitions of telehealth, telecare, telemedicine, and telenursing, community-based telecare, home-based telecare, and agency-based telecare, as well as the roles, opportunities, and challenges of telecare nurses.

The course outline of BP healthcare for smart aging is as follows:

- BP care for smart aging

- Community/home telecare

- MICT 
BP care for smart aging digital material [26]: Wang discussed the significance of low and high $\mathrm{BP}$, the factors influencing BP, the significance of BP tracking, the risk of brain/cardiovascular disease associated with $\mathrm{BP}$, and the challenge of telecare.

Community/home telecare digital material [27]: Wang discussed community-based telecare in Taiwan, the project model for telecare, physiological signal monitoring, locations and energy services for smart aging, health counseling and interpersonal assistance for smart aging, and design considerations for products for smart aging.

MICT digital material [28]: Lin discussed the definition and history of communication technology, definition and history of the Internet, introduction to multimedia communications and communications and network infrastructure in Taiwan, mobile communications and networks, the architecture of telecare, and the definition and history of telemedicine.

\section{Experiment-based and visit-based learning}

In the experiment-based learning process, interdisciplinary students can understand the principle and technology of mobile BP healthcare solutions for smart aging. Figure 1 shows several BP measurements for the same personal, taken in different situations. The systolic BP values for lying, sitting, standing, and walking are 122, 123, 128, and $136 \mathrm{mmHg}$, respectively. The diastolic BP values are 62, 70, 75, and $90 \mathrm{mmHg}$, respectively. We observed the range of the systolic and diastolic BP values by taking measurements in several situations. The maximum measurement value of BP is reported for walking, and the minimum measurement value is reported for lying.

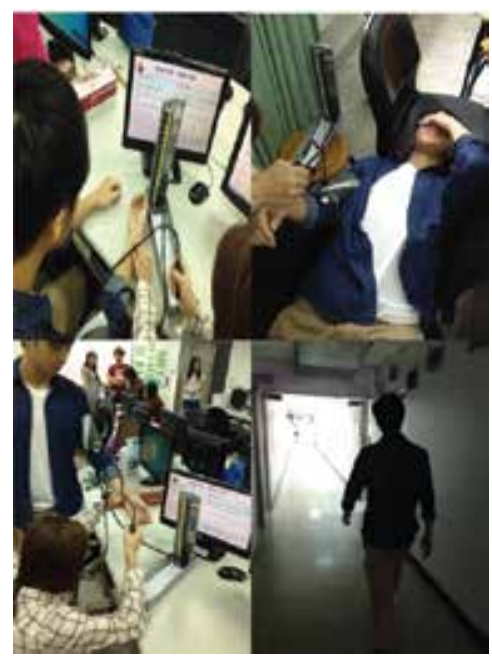

Figure 1. Several BP measurements for the same personal taken in different situations. 


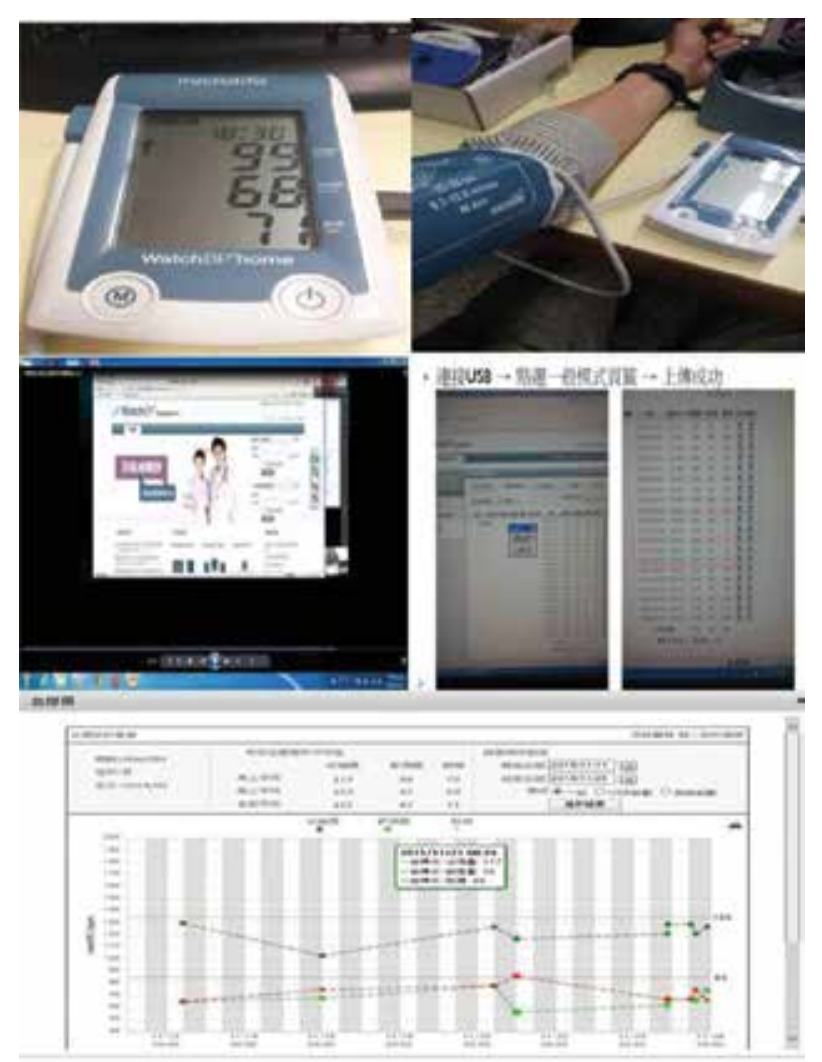

Figure 2. The cloud-based BP platform solution developed by Microlife [29]. Values are presented.

As shown in Figure 2, the cloud-based BP platform solution developed by Microlife was adopted in the course to train students in mobile BP healthcare [29]. The BP measurement times were before sleep and after getting up, and the times were recorded with a USB-based sphygmomanometer that can store 256 BP measurement times, as well as the values for pulse, diastolic, and systolic BP. These values can be uploaded to the cloud-based mobile BP platform from the USB-based sphygmomanometer using a USB transmission interface. In the cloudbased BP platform, the BP measurement time and pulse, diastolic, and systolic BP values are recorded, and the trend and changes of pulse, diastolic, and systolic BP are noted.

We can also obtain the sleep habits of the cloud-based BP platform users. The joint interdisciplinary learning process for cloud-based BP healthcare solutions in the courses of tele-BP healthcare and BP healthcare for smart aging is shown in Figure 3. The third-generation (3G) mobile cellular network was used to connect notebooks to the cloud-based BP platform at anytime and anywhere. Observation, interdisciplinary cooperation, reverse thinking and feedback, innovative design, and an applied science and technology learning methodology were utilized. Cloud-based BP healthcare solutions for smart aging were learned, using integration, innovation, design, and thinking skills. The interdisciplinary students posed and answered the following questions: 


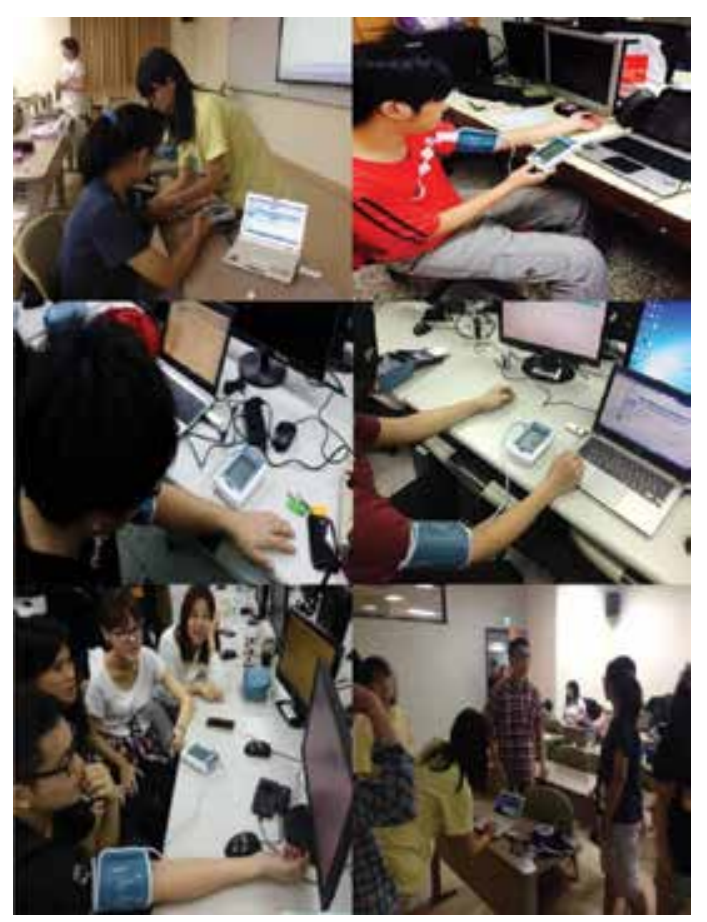

Figure 3. The joint interdisciplinary learning process for cloud-based BP healthcare solutions in the courses of tele-BP healthcare and BP healthcare for smart aging.

What healthcare services are available?

What kinds of smart aging groups are available?

Why are these kinds of smart aging groups suitable?

How are these kinds of smart aging groups used?

What kinds of carers and operators are needed?

What kinds of sensors and control devices are used?

What are the kinds of MICT devices, HMI, and network needs?

What are the functions of the cloud database?

What are the costs to be paid?

Who are the payers?

What are the self-management strategies of lifestyle and the treatment concept in mobile BP healthcare education for smart aging using MICT?

What are the advantages and disadvantages? 


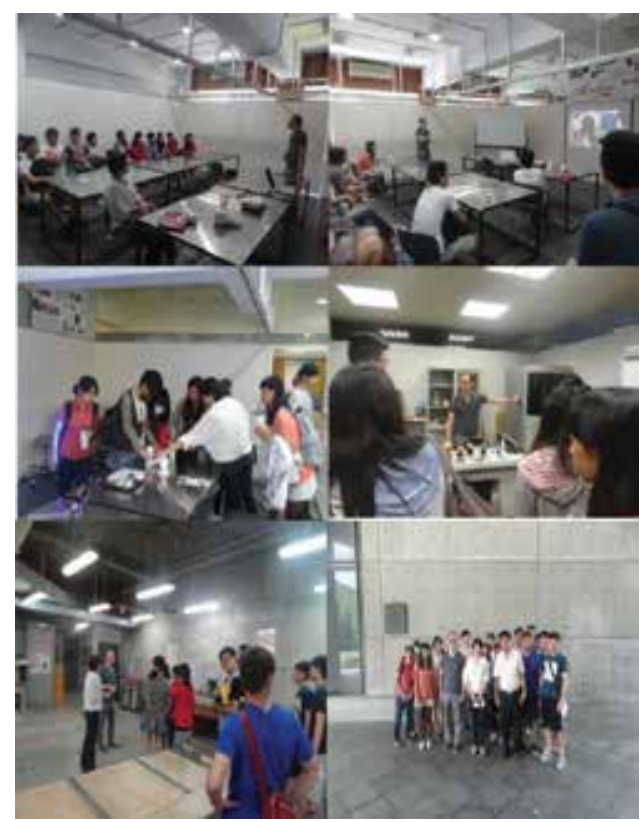

Figure 4. The interdisciplinary course outline of tele-BP healthcare for smart aging included a visit to the Department of Industrial Design, Shih Chien University, in July 2, 2014.

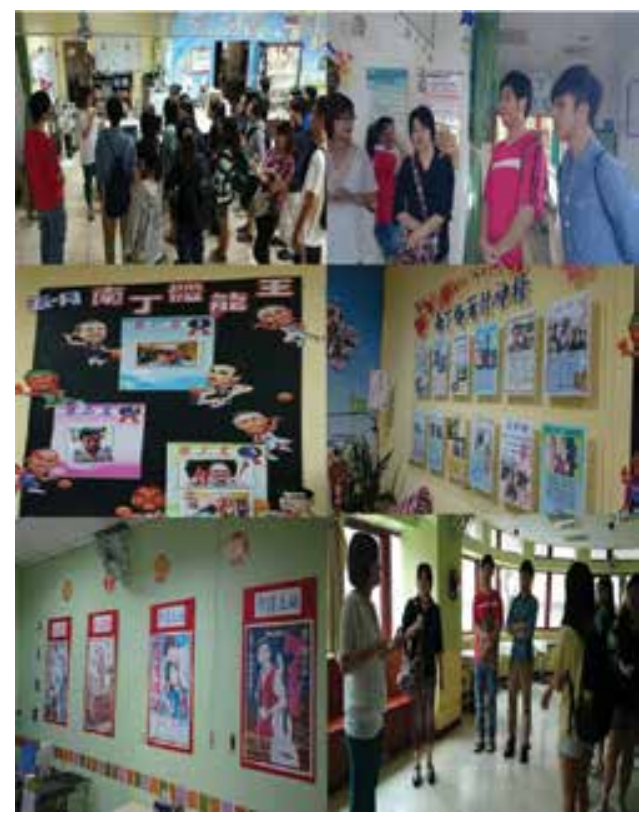

Figure 5. The interdisciplinary course outline of tele-BP healthcare for smart aging also included a visit to the Nightingale Nursing home for Smart Aging, Taichung, in June 2014. 
The interdisciplinary course outline of tele-BP healthcare for smart aging included a visit to the Department of Industrial Design, Shih Chien University, in July 2, 2014, as shown in Figure 4. Prof. Z.C. Wang presented the principle and technology of industrial design of nursing and a 3D printer. The course outline also included a visit to the Nightingale Nursing home for Smart Aging, Taichung, in June 2014, as shown in Figure 5. Students studied the life behaviors, diet, entertainment, and movement habits in the care center. In addition, the interdisciplinary course outline of BP healthcare for smart aging included a visit to a hospice and iodine 131 wards at Chang Cung Memorial Hospital, Keelung Branch, in November 2014, as shown in Figure 6, for an overview of the hospice practices. A video phone was used in an iodine 131 ward to provide real-time interaction between patients inside the ward and doctors, nurses, family members, and friends outside the ward. The video phone technology ameliorated the sense of helpless and anxiety felt by patients in the isolation iodine 131 ward. In addition, the cloud-based, wireless sphygmomanometers used in the Chang Cung Memorial Hospital, Keelung Branch, were observed. The medical record number, BP measurement time, and pulse, diastolic, and systolic BP values transmitted in real time to the cloud-based hospital care platform using the wireless transmission technology. Thus, the interdisciplinary students studied mobile BP healthcare for smart aging through visit-based learning.

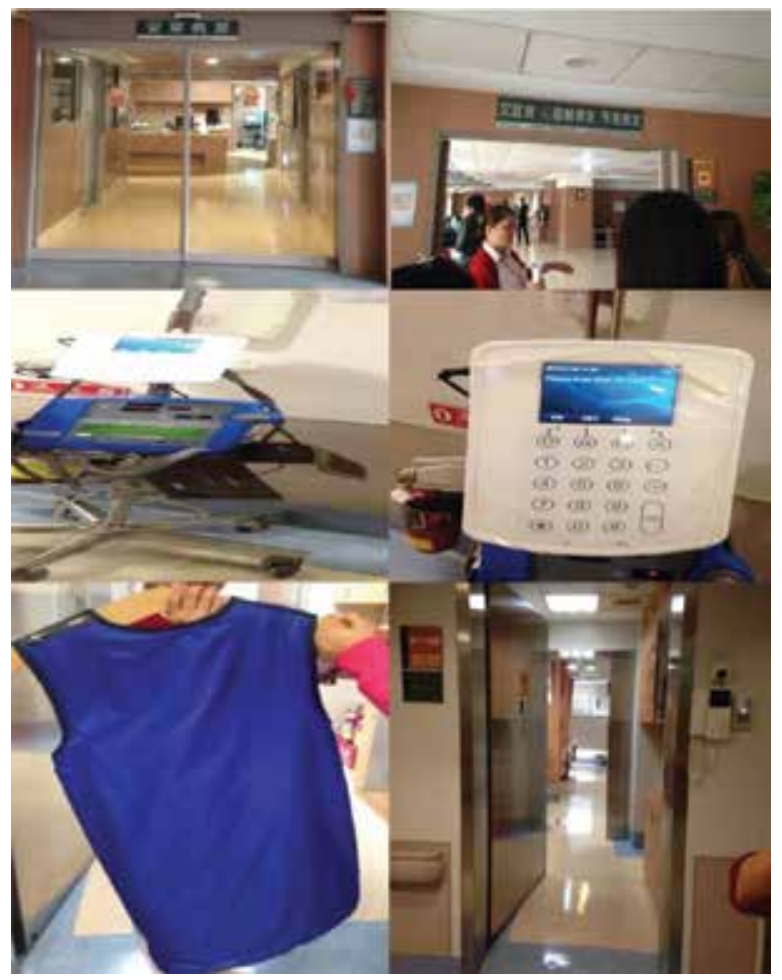

Figure 6. The interdisciplinary course outline of BP healthcare for smart aging included a visit to a hospice and iodine 131 wards at Chang Cung Memorial Hospital, Keelung Branch, in November 2014. 
According to the teaching and learning experience, as well as the visit-based experience described in the above explanation, the learning tool was developed for mobile hypertension education, as shown in Figure 7. The development learning tools included the proximal display software, a notebook, tablet, or personal computer with the Microsoft operating system, and a $3 \mathrm{G}$ mobile modem. The $\mathrm{C} \#$ program was used to develop the proximal display software. The adaptive screen with large font solutions for smart aging, cloud-based BP measurement solution of Microlife, cloud-based BP measurement solution of Sunshine Instrument [30], SKYPE videoconference solution [31], and Messenger Plus videoconference recording solution [32] were all integrated with each other. Cloud-based sphygmomanometer and electrocardiography instruments are approved by Food and Drug Administration (FDA), and Taiwan FDA medical equipment, respectively. The videoconference and videoconference recording solutions can be used for team discussions relating to problem-based learning and problem solving. The mobile hypertension care process was studied as regards nursing students, and the proximal display software technology and the principle of MICT were studied as regards electrical students.

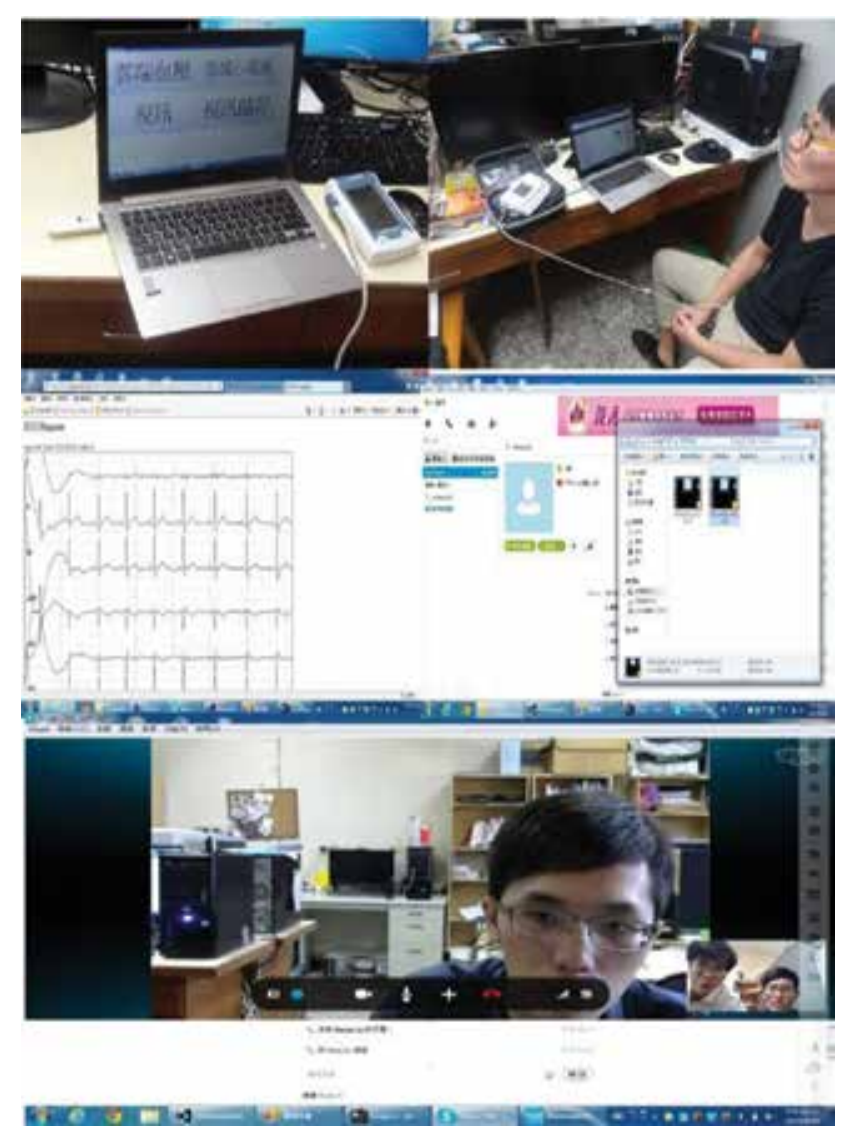

Figure 7. The learning tool was developed for mobile hypertension education. 
A learning tool developed by Microlife Corporation for 3G mobile agent and cloud-based multiuser real-time BP measurement system is shown in Figure 8. The 3G mobile agent and cloud-based multiuser real-time BP measurement system includes radiofrequency identification (RFID) cards, a Bluetooth-based sphygmomanometer, 3G gateway with Bluetooth network, 3G mobile modem, auto login sensor, and tablet. Each user has an RFID card, such as an Easycard, or a student card, to identify the user number. The Bluetooth-based sphygmomanometer is in a shutdown state. When the RFID-based student card senses the Bluetoothbased sphygmomanometer, the device is turned on, and the BP is measured. Real-time BP values are transmitted to the $3 \mathrm{G}$ gateway via the Bluetooth network, and a $3 \mathrm{G}$ mobile modem is used for transmission of these values to a cloud-based BP platform. When the RFID-based student card senses auto login, the auto login sensor uses the $3 \mathrm{G}$ mobile modem to login into the cloud-based BP monitoring Web page, and the real-time BP values in the Web page are displayed on the tablet. Each user can access BP reports on the cloud-based Web page at any instance from any global location.

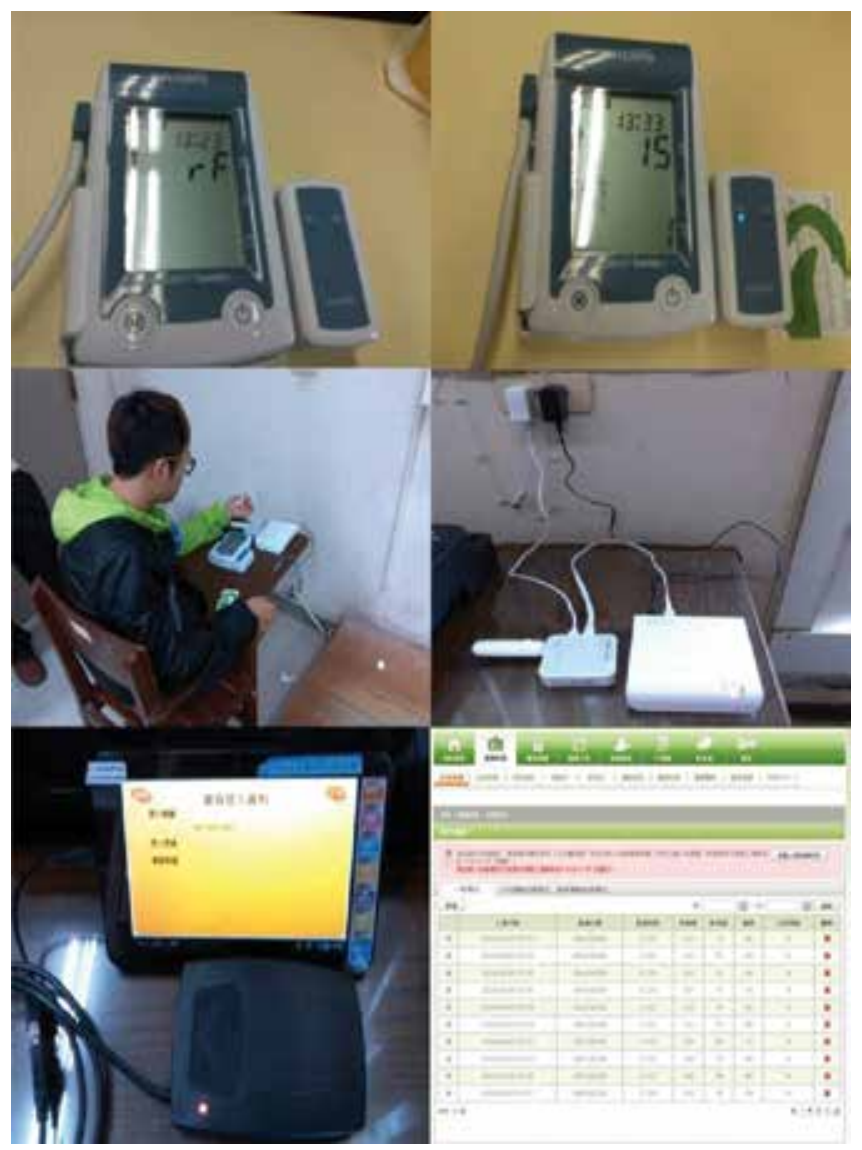

Figure 8. A learning tool developed by Microlife Corporation for 3G mobile agent and cloud-based multiuser real time BP measurement system. 


\section{Conclusion}

For students in electrical and nursing fields, mobile BP smart aging healthcare is a challenging area of joint interdisciplinary learning. A new educational model and innovative teaching methodology using a cloud-based mobile BP healthcare solution for BP healthcare smart aging education were proposed. Problem-based learning and a solving process, experiment-based learning, and visit-based learning were adopted. Facebook videoconferencing was used for team discussions of the problem-based learning and solving process among students in electrical and nursing fields. The cloud-based BP platform solution developed by Microlife was adopted in the course to train the students in mobile BP healthcare. This is a good learning and teaching program for mobile BP healthcare solutions for smart aging, and it is a beneficial contribution to the mobile BP healthcare industry of smart aging.

\section{Acknowledgements}

The author acknowledges the support of the Union Teaching of the Ministry of Education for Smart Aging, the Union Teaching of the Ministry of Education for Medical Electronics in Taiwan, and the valuable comments of the reviewers.

\section{Author details}

Chin-Feng Lin $^{1 *}$, Shere-Er Wang ${ }^{2}$, Yen-Chiao Luㄹ, Chung-I Lin ${ }^{4}$, Chung-Cheng Chang ${ }^{1}$, Tim Yeh" ${ }^{5}$ Candice Lee ${ }^{5}$ Jeffson Huang ${ }^{5}$, Chic-Erh Weng, ${ }^{6}$, Sue-Hsien Chen ${ }^{6}$, Bing-Leung Sun, Chao-Sheng Wang ${ }^{1}$, Shiue-Li Cheng ${ }^{1}$, Shiou-Yu Li ${ }^{1}$ and Lan-Yu Wu ${ }^{1}$

*Address all correspondence to: lcf1024@mail.ntou.edu.tw

1 Department of Electrical Engineering, National Taiwan Ocean University, Keelung, Taiwan 2 Department of Nursing, Ching Kuo Institute of Management and Health, Keelung, Taiwan 3 Department of Nursing, Chung Shan Medical University, Taichung, Taiwan

4 Health Center of Gongliao, New Taipei City, Taiwan

5 Microlife, Taipei, Taiwan

6 Department of Nursing Division, Chang Cung Memorial Hospital, Keelung Branch, Keelung, Taiwan

7 Department of Applied Information and Multimedia, Ching Kuo Institute of Management and Health, Keelung, Taiwan 


\section{References}

[1] Ducut E, Fontelo AP. Mobile devices in health education: current use and practice. J Comput High Educ. 2008; 20:59-68. DOI:10.1007/s12528-008-9003-2

[2] Juanes JA, Ruisoto P. Computer applications in health science education. J Med Syst. 2015; 39:97. DOI:10.1007/s10916-015-0283-6

[3] Mazzola M, Arslan P, Cândea G, et al. Integrated architecture for next-generation mHealth services (education, monitoring and prevention) in teenagers. In: Duffy VG, editor. Digital human modeling. Applications in health, safety, ergonomics and risk management . Springer; Germany. 2014, p. 403-414.

[4] Azevedo AP, Sousa HM, Monteiro JF, et al. Future perspectives of smartphone applications for rheumatic diseases self-management. Rheumatol Int. 2015; 35:419-431. DOI:10.1007/s00296-014-3117-9

[5] Martinez-Perez B, Torre-Diez I, Lopez-Coronado M. Mobile health applications for the most prevalent conditions by the world health organization: review and analysis. J Med Internet Res. 2013; 15(6):e120. DOI:10.2196/jmir.2600

[6] Zhang MWB, Tsang T, Cheow E, et al. Enabling Psychiatrists to be mobile phone app developers: insights into app development methodologies. JMIR mHealth uHealth. 2014; 2(4):e53. DOI:10.2196/mhealth.3425

[7] Burke LE, Ma J, Azar KMJ, et al. Current science on consumer use of mobile health for cardiovascular disease prevention a scientific statement from the American Heart Association. Circulation. 2015; 132:1157-1213. DOI:10.1161/CIR.0000000000000232

[8] Brennan PF. Telehealth: bringing health care to the point of living. Med Care. 1999; 37:115-116.

[9] Chan LK, Bridges S, Doherty I, et al. How do health sciences students use their mobile devices in problem-based learning? In: Bridges S, et al., editors. Educational technologies in medical and health sciences education, advances in medical education 5, ch 6 . Springer; 2016, p. 99-116. DOI:10.1007/978-3-319-08275-2_6

[10] Kamin CS, O'Sullivan PS, Deterding R, et al. A comparison of critical thinking in groups of third year medical students in text, video and virtual PBL case modalities. Acad Med. 2003; 78:204-211.

[11] Elliott K, Judd T, McColl G, et al. Utilising mobile electronic health records in clinical education, In: Bridges S, et al., editors. Educational technologies in medical and health sciences education, advances in medical education 5, ch 9. Springer; 2016, p. 159-179. DOI: 10.1007/978-3-319-08275-2_9

[12] Davies BS, Rafique J, Vincent TR, et al. Mobile medical education (MoMEd) - how mobile information resources contribute to learning for undergraduate clinical 
students - a mixed methods study. BMC Med Educ. 2012; 12:1. DOI: $10.1186 / 1472-6920-12-1$

[13] Park HS, Cho1 H, Kim HS. Development of a multi-agent m-health application based on various protocols for chronic disease self-management. J Med Syst. 2016; 40:36. DOI: 10.1007/s10916-015-0401-5

[14] Wu SM, Lin CF, Liu CC, et al. Cellular and iridium network based blood pressure measurement scheme for mobile healthcare education. In: Clary TS, editors. Horizons in computer science research. 13. Nova Science Publishers. USA.

[15] Lin CF. Mobile telemedicine: a survey study. J Med Syst. 2012; 36(2):511-520. DOI: 10.1007/s10916-010-9496-x

[16] Lin CF. An advance wireless multimedia communication application: mobile telemedicine. WSEAS Trans Commun. 2012; 9(3):206-215.

[17] Lin CF, Hung SI, Chiang IH. An 802.11n WLAN transmission scheme for wireless telemedicine applications. Proc Inst Mech Eng H. 2010; 224(10):1201-1208. DOI: 10.1177/0954411911434246

[18] Lin CF, Li CY. A DS UWB transmission system for wireless telemedicine. WSEAS Trans Syst. 2008; 7(7):578-588.

[19] Lin CF, Chang WT, Lee HW, et al. Downlink power control in multi-code CDMA mobile medicine system. Med Biol Eng Comput. 2006; 44:437-444. DOI:10.1007/ s11517-009-0458-8

[20] Lin CF, Chang KT. A power assignment mechanism in Ka band OFDM-based multisatellites mobile telemedicine. J Med Biol Eng. 2008; 28(1):17-22.

[21] Lin CF, Chen JY, Shiu RH, et al. A Ka band WCDMA-based LEO transport architecture in mobile telemedicine, In: Martinez L, Gomez C, editors. Telemedicine in the 21st century. Nova Science Publishers; USA. 2008, p. 187-201.

[22] Lu YC. Nursing and technology video material, 2014.

[23] Lu YC. Healthy aging video material, 2014.

[24] Lin CI. BP health care for smart aging video material, 2013.

[25] Lu YC. Telenursing video material, 2012.

[26] Wang SE. BP care for smart aging, 2014.

[27] Wang SE. Community/home telecare digital material, 2014.

[28] Lin CF. MICT digital material, 2014.

[29] WatchBP, Cloud-based Blood Pressure Healthcare System, Available from: https:// cloud.watchbp.com.tw/ 
[30] CMATE, Cloud-based ECG Healthcare System, Available from: http:// www.ecg.com.tw/ecg/

[31] SKYPE, Video Conference Software, Available from: http://www.skype.com/zh-Hant/ home/

[32] Messenger Plus, Video Conference Record Software, Available from: http:// www.msgplus.net/ 

Chapter 6

\title{
An mHealth Technology for Chronic Wound Management
}

\author{
Marcia R. Friesen, Bennet Gigliotti and \\ Tik Wai (Kiral) Poon \\ Additional information is available at the end of the chapter \\ http://dx.doi.org/10.5772/64010
}

\begin{abstract}
Increasingly, mobile consumer electronic devices are able to make meaningful applications in healthcare, and this chapter discusses the development of a mHealth app called SmartWoundCare, designed to document and assess chronic wounds on smartphones and tablets. Pressure ulcers (bedsores) were selected as the application area for SmartWoundCare due to their pervasiveness in healthcare and their associated impacts on patients' quality of life and mortality, and electronic documentation is considered as an important intervention in pressure ulcer prevention and treatment. The chapter reviews the design of SmartWoundCare on Android and iOS platforms. Its benefits over paper-based charting include automatically generated wound histories in graph and text formats, alerts and notifications for user-set conditions, wound image galleries, and positioning for telehealth consultation by transmitting wound data across sites. The mobile app was implemented in a user trial in a long-term care facility in Winnipeg, Canada, and the user trial illuminated that a key benefit of SmartWoundCare was the ability to take wound photographs. This feature had benefits for patients as well as caregivers. Consequently, algorithms were developed to analyse wound images for size and colour to provide additional indicators of wound progression.
\end{abstract}

Keywords: wound care, pressure ulcers, wound management, mHealth, mobile app

\section{Introduction and background}

Increasingly, mobile consumer electronic devices are able to make meaningful applications in mobile health or mHealth, defined as the delivery of healthcare and healthcare support through mobile devices. For example, there are apps that allow users to track diet and fitness, health 
condition monitoring (e.g. diabetes [1]; arthritis [2]), and using mobile devices to replace paper records and share information between multiple healthcare providers [3].

This chapter overviews the development of a mHealth app called SmartWoundCare, designed to document and assess chronic wounds on Android and iOS smartphones and tablets. The chapter reviews the design of SmartWoundCare, the results of a user trial in a long-term care facility in Winnipeg, Canada, and the subsequent development of algorithms to provide automated analysis of wound images for wound size and colour.

The initial application area is pressure ulcers, which is also known as bedsores. However, the app is easily applicable to other wounds as well, such as venous leg ulcers, diabetic foot ulcers, and surgical wounds.

\subsection{Pressure ulcers as the application area}

Decubitus ulcers are more commonly referred to as pressure ulcers or bedsores. They are injuries to the skin, or skin lesions which may extend to underlying tissues. Pressure ulcers typically occur over bony areas of the body as a result of skin pressure and friction when an individual sits or lies in one position for a long time. As such, pressure ulcers often occur in the elderly population and people who may be relatively immobile due to other illness or injury. Bedsores are preventable, but easily aggravated with heat and humidity at the wound site once they are present. Bedsores are also regrettably common, with the incidence of pressure ulcers reported to be as high has $30 \%$ in non-acute care settings, with an average incidence rate of $25 \%$ over all types of healthcare facilities $[4,5]$.

Pressure ulcers have numerous negative impacts on patients, both in immediate comfort and well-being and in long-term quality of life. When they develop after a patient is admitted to hospital for other conditions, they can lengthen the patient's overall stay and complicate their overall healing. There are also numerous quality of life impacts reported including the psychoemotional impacts of chronic pain and the negative impacts of social isolation when patients' movements are significantly impaired. A pressure ulcer starts as a seemingly minor skin wound and obscures its significant risk. Pressure ulcers are noted to be the second leading iatrogenic cause of death. From an institutional perspective, pressure ulcers treatment is also costly to the healthcare system [6-11].

There are many standard patient treatments used to prevent pressure ulcers in patients who are known to be at risk. These include regularly turning patients, optimizing diet and nutrition, caring for skin before pressure ulcers occur, and using pressure mattresses, pillows, and other supports to relieve pressure [12]. However, studies have also identified that due to the chronic and often long-term duration of pressure ulcers, significant information about the wound over time can become obscured when documentation is not standardized, when risk assessments are not integral to the regular wound assessment protocol, or when assessments are incomplete or lack detail. In part, standardized forms - designed to capture all possible types of pressure ulcers - often become too unwieldy for healthcare workers with heavy patient loads to use effectively [13-15]. 
In many other areas of healthcare delivery, electronic health (eHealth) is being examined for its promise to increase the overall efficiency of a healthcare system and to improve patient outcomes. As eHealth grows in scope and maturity, its potential includes improvements and enhancements to patient safety, health outcomes, financial efficiencies, and communication between multiple healthcare providers.

When considering the health burden of pressure ulcers, the area of electronic medical records (EMR) within eHealth is of particular interest. In the research literature, EMRs are reported to have positive impacts on the quality of care and to reduce the reliance or use of care [16].

Several studies examined the impact of EMRs relative to chronic wounds specifically. In one, an EMR system simplified wound evaluation and treatment. In this case, the impact is highly dependent on a standardized protocol for taking pictures of the wound [17]. In another study, the financial benefits of home telehealth in treating bedsores were examined. The findings indicated low-cost technologies did lead to cost savings, whereas high-cost technologies did not have that benefit. The study also determined that home telehealth could decrease the prevalence of advanced stage pressure ulcers [18]. However, not all EMR systems for wound care are effective. Other research identified that common problems with wound EMRs included redundancy or the opposite situation where the platform was not flexible or detailed enough to consider all potential types of wounds. Other issues included the lack of standard vocabulary, and custom-built EMRs which were not transferable to include or integrate with other medical records or across facilities [19].

While EMRs and other forms of electronic documentation are not a panacea, there is emerging evidence that when properly designed, they can potentially lead to better communication, better patient information and wound charting, and ultimately improved patient care and health outcomes. The work outlined in this chapter follows this anticipation that better compliance in documenting wound care, higher consistency in how a wound is documented, and the added intelligence provided by the app relative to alerts and information presentation can influence health outcomes.

\section{Mobile apps for wound management}

To date, many eHealth technologies have been and are being developed; however, they are not well-catalogued. Relative to wound care, MediSense, WoundRounds, and How2Trak offer web-based and/or mobile interfaces for wound management. In 2013, WoundMAP Pump, Ulcercare, and Wound Mender entered the stage of wound care apps in various stages of development [20].

\subsection{SmartWoundCare system design}

SmartWoundCare is similarly a mobile app for Android and iOS devices, developed in a computer engineering research lab at the University of Manitoba, Canada. SmartWoundCare was designed to replace the paper chart used in the Winnipeg Regional Health Authority 
(WRHA) for pressure ulcer management. The WRHA is a publicly funded system which includes both services and facilities. It serves over 700,000 people and supports referral services to another 500,000 people outside of its boundaries in hospitals, personal care homes, as well as a home care program. Over 28,000 people are employed by the WRHA in over 200 facilities.

As its core functionality, SmartWoundCare allows nurses and other healthcare providers to replicate the information that would be entered on a paper chart. A user can create a new patient record, view an existing patient's record, enter new wounds, and assess existing wounds using the Pressure Ulcer Scale for Healing (PUSH tool) [21], Braden Scale [22], and the Bates-Jensen tool [23]. Several configurations were considered, in that one device could be associated with a given patient, and each nurse or other healthcare provider who cares for that patient would enter information on that patient's unique device. However, the model chosen was to associate the device with an individual nurse or other healthcare provider, who would use the device with all of their patients on that shift, and then transfer the device to the healthcare provider on the next shift.

As with all software, some general design objectives were established. These included keeping the user interface as simple as possible, using colours and other cues to focus the user's attention on important information, minimizing the steps needed to complete tasks, aligning the flow of information with emerging standard expectations from users ("look and feel"), and using the user's input to guide them to the applicable areas (and conversely, using the user's input to skip over areas not relevant for the particular patient or the particular wound). In light of the small screen size of a smartphone or tablet device, free-form comments in data entry are discouraged by design. Entering data from pre-set menu options is designed to reduce errors and to enable better comparisons between assessments, even when completed by different people. In a large-scale rollout within a facility or a healthcare region, attention would also need to be given to battery life of the device, protocols for infection control, and the EMR as part of the legal medical record.

Beyond the duplication of paper-based charting, SmartWoundCare was designed for several intended benefits:

1. Data sharing between multiple healthcare providers:the potential to seek consultation between multiple healthcare providers, including wound clinicians, physicians, allied health professionals (e.g. occupational therapy), and other specialists as needed. This potential reduces the need to transport the patient between facilities, saving the patient considerable discomfort and stress, and saving cost in the overall wound treatment. Just as significantly, the timeliness of interventions and changes in the direction of care can be improved. Information sharing (i.e. a telehealth framework) can occur within a given facility, within the same community, or between major centres and remote communities where remote communities do not have specialized health services. In Canada, with a small population living in a large geographical area, this is of particular relevance.

\section{Data organization and interpretation:}

- Alerts: When logging into SmartWoundCare, the user will see a list of alerts, including wounds that are due for re-assessment and wounds that are deteriorating. The specific 
parameters for the alerts (days between assessments, criteria used to determine deterioration) can be set by the user.

- Because users have individual preferences on how they best understand data, SmartWoundCare presents wound histories in three formats: text, graph, and photographs. Text histories allow a user to scroll through a summary of the main wound parameters from one assessment to the next. Graph histories plot an overall wound score (e.g. generated from the PUSH tool) against time. Using the smartphone or tablet devices' built-in cameras, users can also add wound photographs to the record, and scroll through the images in a chronological gallery for each individual wound.

By design, the benefit of SmartWoundCare is its potential as an EMR, either on a stand-alone basis or integrated into a wider EMR system within a facility or region. As such, privacy of data is a non-negotiable concern. In its current form, SmartWoundCare requires each user to set up a unique user ID and password to facilitate a secure login and the login is restricted to that device. When envisioning a fully networked application within a facility or wider region, SmartWoundCare access rights would be confirmed by a secure connection to a server storing all information. Connections would be via cellular or $\mathrm{Wi}-\mathrm{Fi}$, relying on all standard Internet security protocols. In that case, all login IDs and passwords would be managed centrally by a server-side application rather than a device-based login. An additional benefit of a central server, which could be facility-specific or shared between several facilities, is the potential for additional data analysis in a Big Data framework. For example, when large datasets are available centrally in standard formats, they can be examined for anomalies, trends, and correlations that ultimately feed into the body of knowledge for pressure ulcer treatment.

Selected screenshots of SmartWoundCare (iOS version) are shown in Figures 1-5.

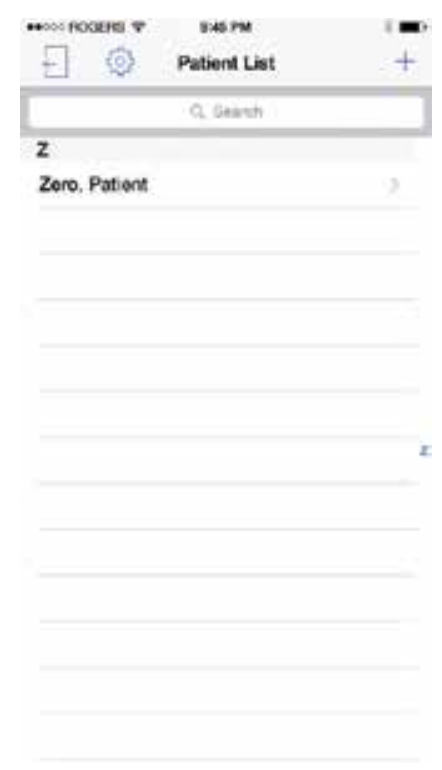

Figure 1. Patient list upon login (iOS). 

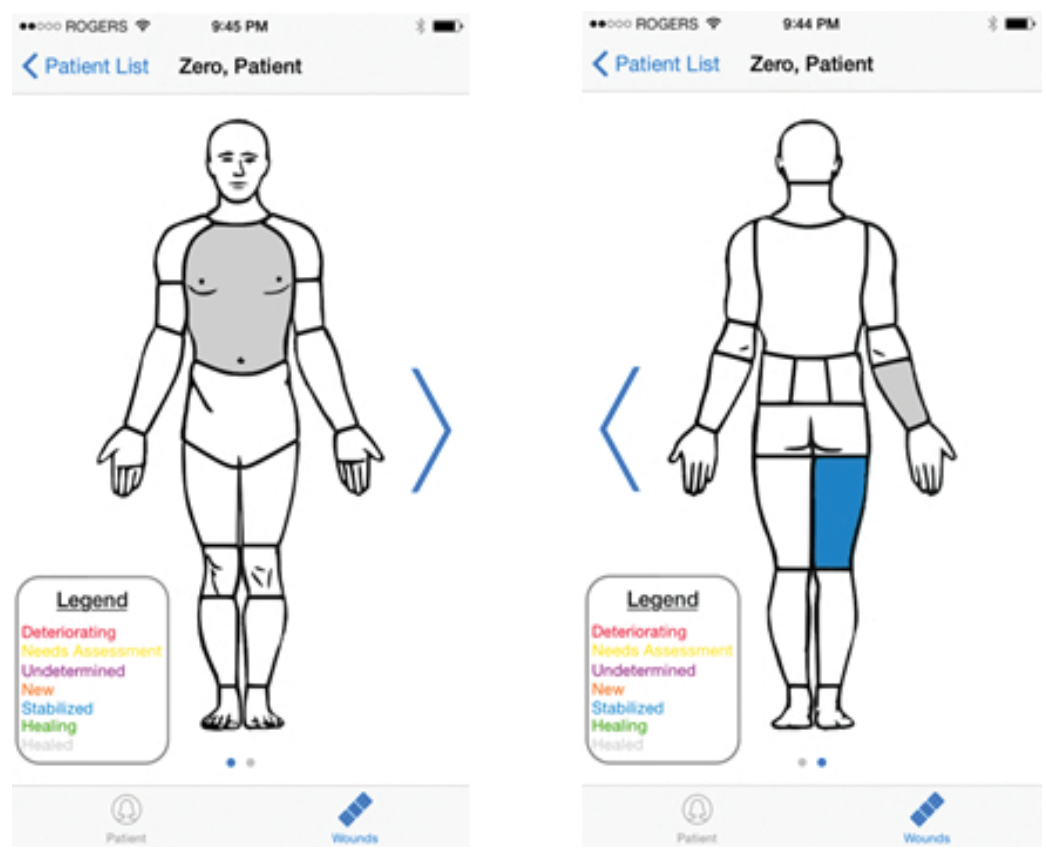

Figure 2. Wound locations and status (iOS).

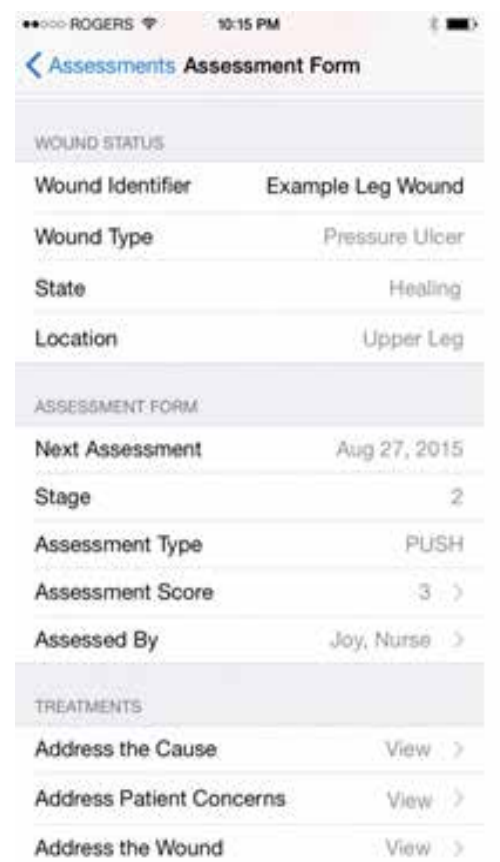

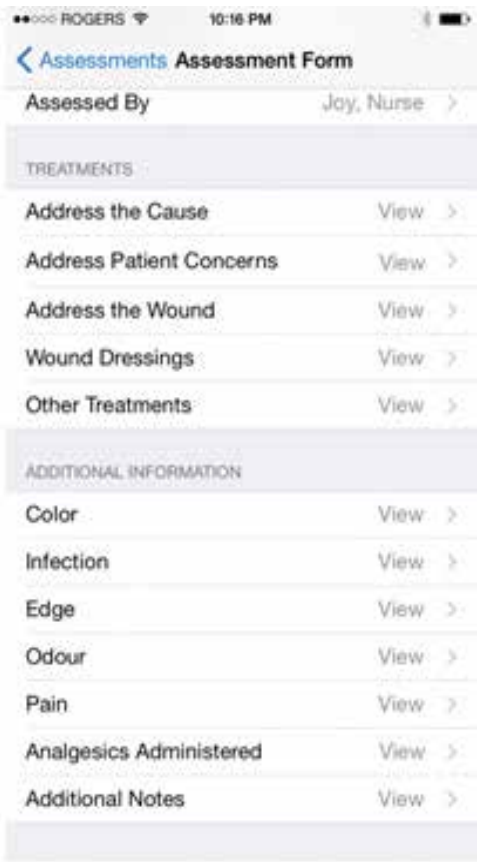

Figure 3. Assessment data entry screen (iOS). 

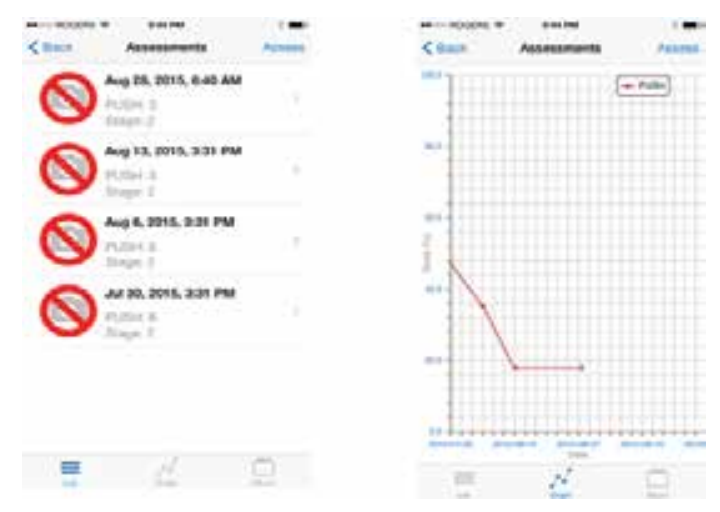

Figure 4. Single wound summary in list and graph format.

$\begin{array}{ccc}* 000 \text { AOGERS } & \text { 944 PM } & \\ \text { <Back } & \text { Assessments } & \text { Assess }\end{array}$

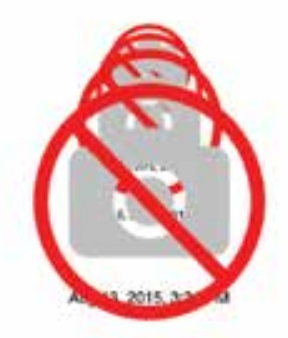

Aug 28, 2015, 6:40 AM

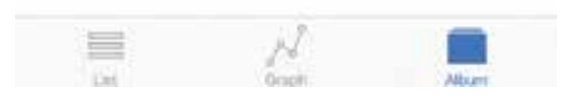

Figure 5. Chronological wound image gallery (iOS).

\subsection{User trial - SmartWoundCare on Android}

SmartWoundCare in a prototype Android version was subject to a small-scale user trial. Voluntary participants were nurses in a personal care home in Winnipeg, Canada, and they 
used the mobile app with their patients. The objective was to obtain nurses' impressions on the app's design, its functionality, and how it performed as a part of their daily clinical experiences in treating patients' wounds. Investigating patients' experiences and patients' health outcomes with the app was beyond the scope of the user trial.

The user trial took place in Riverview Health Centre (RHC) in Winnipeg, Canada. Riverview Health Centre provides rehabilitation, palliative, and long-term care. The facilities consist of hospital and personal care home units with almost 400 beds overall, as well as community programs and outpatient services. Riverview specializes in geriatric rehabilitation, brain injury, and stroke rehabilitation, palliative care, and complex long-term care.

All nurses at RHC were invited to participate in the user trial. Approximately 12 nurses expressed interest, and after timelines and the scope of the nurses' participation were established, eight nurses (three men and five women) remained willing to participate. Their participation was entirely voluntary and was not financially compensated. The nurses all had regular duties caring for patients with pressure ulcers or other wounds, and they were fulltime employees of RHC. The participants had a range of experience, ranging from less than 10 years nursing experience to over 20 years in a personal care home settings specifically, and ranged from 30 to 60 years in age.

Participants were also asked to judge themselves on their comfort with technology. Four participants judged themselves to be "very tech-savvy" while the other four judged themselves to be "comfortable with common features of phones and tablets". Participants' confidence with smartphone/tablet interfaces and with touch screens was self-assessed at 4.57/5.00 (range $=4.0$ 5.0; $\mathrm{SD}=0.53$ ) and 4.71/5.00 (range=4.0-5.0; $\mathrm{SD}=0.49$ ), respectively.

To preserve anonymity, the characteristics of participants were intentionally not crossreferenced with one another.

The nurses received a new Nexus 4 smartphone (four nurses) or a new Nexus 7 tablet (four nurses) with SmartWoundCare loaded and a training manual for the wound care app. They were given a 90-minute training and demonstration of the app. After this training session, the nurses took the mobile devices home and familiarized themselves with SmartWoundCare further before beginning the user trial.

The nurses used SmartWoundCare (Android version) during their nursing shifts. SmartWoundCare was only used for patients who had pressure ulcers and who had consented to participate in the user trial. Given the patient population, patient consent was provided either directly or through a designate such as a family member. Participants used SmartWoundCare for at least seven shifts. At times, vacation schedules interrupted data collection over consecutive shifts. In most cases, participants were able to use SmartWoundCare for a longer period (more than seven shifts), enhancing the depth and scope of their feedback. All data collection was completed within two-and-a-half months of the start of the user trial.

Using SmartWoundCare in nursing practice was an additional workload over the participants' regular nursing duties, because it did not replace but rather it duplicated the paper chart that forms the patient's official medical record. 
Once the nurses had been using SmartWoundCare for approximately 3 weeks, the nurses completed an anonymous on-line survey. This data collection instrument was timed to gain participants' immediate opinions and experiences of SmartWoundCare's functionality and design. The survey was administered via Surveymonkey and included open- and closedended questions on SmartWoundCare features, content, look and feel, usability, navigation between screens, assessment of its intended advantages over paper-based charting, as well as overall qualitative impressions of how well SmartWoundCare fits into nursing practice. An important part of the survey was for participants to assess the commensurability of the wound data entered into SmartWoundCare relative to data entered on paper-based forms (scope and format), as this forms the basis of the integrity of the app.

Six weeks later and after an initial analysis of the survey results, a focus group session was held with the participants and the researchers. The focus group was used to probe into the survey results. In that way, the findings of the user trial include both the immediate and the long-term impressions of the app's features and intended benefits, both of which are valuable to assess functionality. The research design complied with qualitative research norms, in which data and interpretations of data are validated by using triangulation and member checks.

The findings were then used to identify the key design issues for ongoing development of both the Android and a subsequent iOS version of SmartWoundCare.

\subsubsection{Findings}

The objectives of the survey and the focus group were to obtain feedback on the design and functionality of the app and to investigate the nurses' experiences in using the app. The main numerical findings discussed in this section are summarized in Table 1.

\begin{tabular}{|c|c|c|c|}
\hline $\begin{array}{l}\text { Survey parameter All parameters are ranked on a Likert-type scale } \\
\text { from } 1.0 \text { (low) to } 5.0 \text { (high) }\end{array}$ & $\begin{array}{l}\text { Mean } \\
\text { score }\end{array}$ & Range & $\begin{array}{l}\text { Standard } \\
\text { deviation }\end{array}$ \\
\hline $\begin{array}{l}\text { How well-matched is the scope and depth of the software } \\
\text { application to the Braden Scale tool? }\end{array}$ & 4.60 & $4.0-5.0$ & 0.55 \\
\hline $\begin{array}{l}\text { How well-matched is the scope and depth of the software } \\
\text { application to the PUSH tool? }\end{array}$ & 4.57 & $4.0-5.0$ & 0.53 \\
\hline Ease of entering a new patient record & 4.57 & $4.0-5.0$ & 0.53 \\
\hline $\begin{array}{l}\text { Ease of finding my existing patient's / resident's wound } \\
\text { record }\end{array}$ & 4.71 & $4.0-5.0$ & 0.49 \\
\hline Ease of adding a new wound to the patient's record & 4.50 & $3.0-5.0$ & 0.84 \\
\hline Ease of assessing a new wound for the first time & 4.57 & $3.0-5.0$ & 0.79 \\
\hline $\begin{array}{l}\text { Ease of assessing an existing wound that had been previously } \\
\text { assessed }\end{array}$ & 4.29 & $2.0-5.0$ & 1.11 \\
\hline Screens were presented in an expected and logical order & 4.17 & $3.0-5.0$ & 0.75 \\
\hline
\end{tabular}




\begin{tabular}{|c|c|c|c|}
\hline $\begin{array}{l}\text { Survey parameter All parameters are ranked on a Likert-type scale } \\
\text { from } 1.0 \text { (low) to } 5.0 \text { (high) }\end{array}$ & $\begin{array}{l}\text { Mean } \\
\text { score }\end{array}$ & Range & $\begin{array}{l}\text { Standard } \\
\text { deviation }\end{array}$ \\
\hline Text history: this presentation is easy to understand & 4.50 & $4.0-5.0$ & 0.55 \\
\hline $\begin{array}{l}\text { Text history: this presentation is helpful in understanding } \\
\text { wound progression }\end{array}$ & 4.50 & $4.0-5.0$ & 0.55 \\
\hline $\begin{array}{l}\text { Text history: this presentation adds to my understanding of } \\
\text { the history of the patient's/resident's wounds and wound care, compared to not } \\
\text { having this text-based history available }\end{array}$ & 4.50 & $4.0-5.0$ & 0.55 \\
\hline Graph history: this presentation is easy to understand & 3.67 & $2.0-5.0$ & 1.03 \\
\hline $\begin{array}{l}\text { Graph history: this presentation is helpful in understanding wound } \\
\text { progression }\end{array}$ & 3.83 & $3.0-5.0$ & 0.75 \\
\hline $\begin{array}{l}\text { Graph history: this presentation adds to my understanding of the } \\
\text { history of the patient's/resident's wounds and wound care, compared to not } \\
\text { having this graph-based history available }\end{array}$ & 3.67 & $2.0-5.0$ & 1.03 \\
\hline
\end{tabular}

Table 1. Numerical findings of a user trial on the android version of SmartWoundCare.

In general, findings over the user trial indicated that SmartWoundCare was easily learned and used in the participants' nursing duties, and that it was well-matched to the PUSH and Braden Scale tools. The benefit of the smartphone was that it was easily carried in the pocket of a uniform; however, a drawback was that the text size was difficult to read. On the other hand, tablet devices were more difficult to carry and store but had the advantage of readability.

The user trial used an Android version of the SmartWoundCare prototype, and as a custombuilt software application, it did not always conform to users' expectations of the look and feel of software and how one navigates through software. Areas that caused some initial confusion included cross-navigation between different parts of the app, and confirming saves and deletions of data. Subsequent development on the Android version and later the iOS version of SmartWoundCare was a marked shift to the expected "look and feel" of mobile apps, as opposed to a custom interface.

As an important part of validating the robustness of SmartWoundCare for its intended application, nurses confirmed a strong commensurability in content and data entry between SmartWoundCare and paper versions of the PUSH and Braden Scale tools. Participants reported that the intuitive guidance accurately reflected the fields necessary for a given patient and their wound condition.

However, SmartWoundCare was developed to do more than duplicate a paper chart, and the user trial also investigated the nurses' perceptions of the added intelligence in the app. Although the user trial took place over a relatively short period of time, the nurses indicated that they appreciated and recognized the potential of the wound histories. The text histories were met with slightly better perception than the graph histories (Table 1), although not to an extent of statistical significance $(p=0.05)$. 
A suggestion for additional features in SmartWoundCare is centred on developing a glossary of specialized terms. This was identified as a useful feature even for experienced wound care nurses.

Another feature of SmartWoundCare over and above paper charts are the alerts that display to the user upon login. These alerts received mixed reviews by the users, with the primary complaint being that the alerts needed a more prominent place within the app rather than their location within a menu with five other menu options. In the subsequent iOS version, alerts follow a more standard format for iOS mobile apps.

\subsubsection{Wound images as the key benefit}

The strongest finding of the user trial was the value and benefit of wound images (photographs) in SmartWoundCare. Through both the survey and the focus group, nurses identified numerous benefits for the nurse at the bedside, for the patient and their family, and for the physician and allied health professionals. Nurses appreciated the ability to photograph the wound and the associated ability to show the wounds to the patient on the device.

There are several benefits of wound images. At times, wounds are located on body parts that a patient cannot directly observe, such as buttocks, heels, or the soles of feet. The wound photo allowed them to see the wound and get a sense of its size and severity. Often, this led to a better understanding for patients and their families regarding the importance of wound hygiene and treatments.

Another reported benefit is the time saved with each wound assessment, which could add up to significant time during a shift. It can take up to 20 minutes to undress, treat, and re-dress a wound. If another healthcare provider (e.g. physician, physical therapist, wound clinician) asks to see the wound, the dressings need to be removed and the wound redressed after consultation. As a first option, the nurses could show the wound photograph to others in the healthcare team, and then a judgement was made as to whether the wound needed to be undressed or whether the photograph met the needed information within the healthcare team. A further advantage is when the healthcare team is consulting on a wound, the additional information that the wound photograph provided in comparison to solely having a verbal or written description of the wound.

Overall, the ability to add a wound history from photographs to the patient record was recognized for its potential to reduce the number of dressing changes and thus promote healing. The finding also supported SmartWoundCare's potential impact in telehealth.

The findings of the user trial also corresponded to other research findings related to the value of wound photograph, which is contingent on the quality of camera equipment, photomicrography (the art of photographing small objects in large scale), the orientation of the camera lens relative to the wound, flash settings relative to consistent lighting, and duplicate photographs [17]. Two separate studies examined measurements of wounds taken in traditional ways compared to measurements taken from photographs. In those studies, the wounds were venous leg ulcers and diabetic foot ulcers, respectively [24, 25]. The conventional technique to measure wounds is to lay a transparent film over the wound, to trace the wound margin on 
the film, and then to lay the film over graph paper and count the number of squares. When comparing this technique to measurements derived from digital images, the latter method resulted in improved accuracy, lower inter-observer variations, and improved ease of use. Because the film physically touches the patient's wound and can cause irritation, the digital photograph also had the advantage of being a non-contact method. Another study explored the potential of telehealth, specifically videoconferencing, compared to in-person assessment for pressure ulcer assessment. Both procedures led to very similar assessment of the stage of the wound. However, the telehealth approach led to an overestimate of wound size and volume when compared to in-person assessment [26].

\section{Algorithms for wound image analysis: wound size and colour}

Given the key finding of the user trial of the significant value of wound photographs, further work focussed on developing algorithms that would add intelligence to SmartWoundCare relative to image analysis.

The objective of the image analysis work was to develop algorithms to determine the size of the wound in both relative and absolute terms, and to analyse the colour breakdown of a wound, all from an image of the wound taken by a smartphone or tablet camera. Further, this objective was to be carried out without any peripheral or ancillary devices. Such devices, as seen in related literature, might include templates or positioning boxes by which the user would help the patient to position themselves and the wound, or it may include ultrasonic transducers and additional lenses for the mobile device. Carrying out the image analysis independent of any ancillary devices contrasts work by other researchers which, for example, control the lighting and wound position with an image capture box when performing image analysis of diabetic foot ulcers [27].

The application represented a general objective applicable to other fields, in that the work was intended to produce non-contact measurements of irregularly-shaped images taken with a smartphone or tablet camera, where the target range for error is $<10 \%$ for images taken from distances of up to $30 \mathrm{~cm}$. Relying only on the internal smartphone sensors to generate highaccuracy measurements brings novelty to the work and specifically to the field of wound management.

Each new smartphone and tablet that comes to market generally has a higher-resolution camera than the previous version of the device, and these progressions are often evident in short to medium timeframes of 6-18 months. Nonetheless, consumers are still hesitant to rely on on-board cameras for any application that requires high precision and accuracy. In prior work, the state of image analysis from photographs was reviewed [28]. At first instance, several mobile apps were identified which claim to measure objects and distances in the $0.5-20 \mathrm{~m}$ range $[29,30]$, as well as ultrasonic-transducer that ranges for measurements in the 1-6 cm range [31], and infrared distance measurements in the 4-30 cm range [32]. Depth-of-field cameras were also considered [33-35]. That early research also explored one method for determining distance from the camera to the wound and two algorithms to determine the size 
of the wound. Although both methods are promising, the specifications for error were not met [28].

It is foreseeable that smartphones with dual-lens camera will enter the market within a timeframe of 6-24 months [36]. This development would create new and significant potential for high-resolution images and subsequent analysis for accurate and precise characterization. The analysis techniques would build on the existing work in other fields, such as stereoscopic cameras in manufacturing. Google's Project ARA, a collaborative effort to develop modular smartphone hardware may also provide a future framework by which to include dual-lens cameras in mobile devices.

\subsection{Overview}

Three components of the image analysis work are outlined in the following sections. In the first component referred to as Mask Image, the objective is to obtain the relative dimensions of an object in the image (in this case, a wound), in which the size determination is relative to the previous image of the same object. The second component, referred to as Camera Calibration, reconstructs an image taken on an angle and references it back to a two-dimensional (2D) plane, in this way facilitating a measurement of the absolute or actual size of the object in the image. The third algorithm determines the range of colours present in an image. The algorithm separates the image into three component colours by extracting components from the redgreen-blue (RGB) format of the image, and by doing so, makes possible an inference of the wound stage.

The software framework (Figure 6) in a high level abstraction consists of modules including acquisition of the wound image, pre-processing of the wound image, segmentation of the wound image, recognition of the wound type, and classification of the wound. In reference to the three major components of the analysis indicated previously, the Mask Image component lies within the image acquisition module. Grabcut (a segmentation method [37]) and the

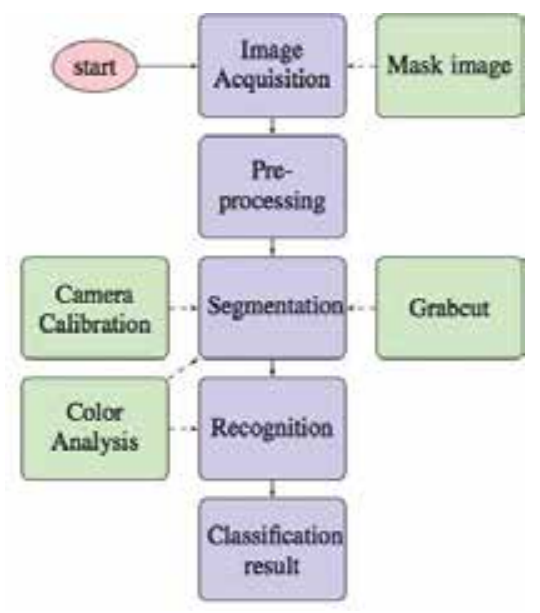

Figure 6. Basic application model. 
Camera Calibration component both lie within the segmentation module, and the colour analysis component lies within both the segmentation and the wound recognition modules.

Although the wound photographs are taken with the cameras built into a mobile device (smartphone or tablet as per Table 2) or a webcam, all of the processing takes place on a computer. Computation times are generally in the order of seconds. Further work to have the processing take place on the mobile device itself is ongoing, and comes with the usual challenges of carrying out computation- and memory-intensive processes on mobile devices.

Processing the photograph on a computer allows for both static and dynamic environments. In this case, a static environment denotes an environment where both the camera setup relative to the wound position is fixed (e.g. known, constant distance and angle, often with the use of staging devices) and the light source is stable. A dynamic environment refers to a mobile camera (i.e. smartphone or tablet) and/or the wound in a natural position at varying distances and angles to the camera and in varying lighting conditions.

With a series of photographs taken in a static environment, the Camera Calibration component, which corrects for angle by reconstructing an image in three-dimensional (3D) space back to a $2 \mathrm{D}$ plane, only needs to be done once and the correction can be applied to the entire series of photographs. In a dynamic environment where distance and angle between the wound and the camera vary with each photograph, the Camera Calibration component needs to be done for each image.

Table 2 summarizes the hardware and software specification applied in this work.

\begin{tabular}{ll}
\hline Nexus 4 (LG-E960) & MacBook Pro \\
\hline Krait Quad-core 1.5 GHz & Processor 2.6 GHz Intel Core i7 \\
Display resolution $1280 \times 768$ & Memory 8 GB 1600 MHz DDR3 \\
Camera resolution $8 \mathrm{MP}(3264 \times 2448)$ & Graphics Intel Iris Pro 1024 MB \\
High Performance Adreno $320 \mathrm{GPU}$ & Software OS X 10.9.5 (13F34) \\
Bluetooth 3.0 BLE & \\
Wi-Fi $802.11 \mathrm{a} / \mathrm{b} / \mathrm{g} / \mathrm{n}$ & Software \\
& Android 4.2 (Jelly Bean) \\
Samsung Galaxy S4 & Android NDK r9d \\
ARM Cortex-A15 Quad-core $1.9 \mathrm{GHz}$ processor & OpenCV 2.4.9 Android SDK \\
Display resolution $1080 \times 1920$ & Python 2.7.10 \\
13+ megapixel camera & Numpy \\
Bluetooth 4.0 & Matplotlib \\
802.11 a/b/g/n & OpenCV 3.0.0 \\
& Matlab \\
\hline
\end{tabular}

Table 2. Hardware and software specifications. 


\subsection{Mask image for relative size}

The first two components of the image analysis work, Mask Image and Camera Calibration, are used to determine the relative size and the absolute size of a wound, respectively, from the wound photograph. Figure 7 expands the first two modules of basic software framework in Figure 6, specifically the image acquisition module and the image pre-processing module. The Mask Image component is situated within these modules.

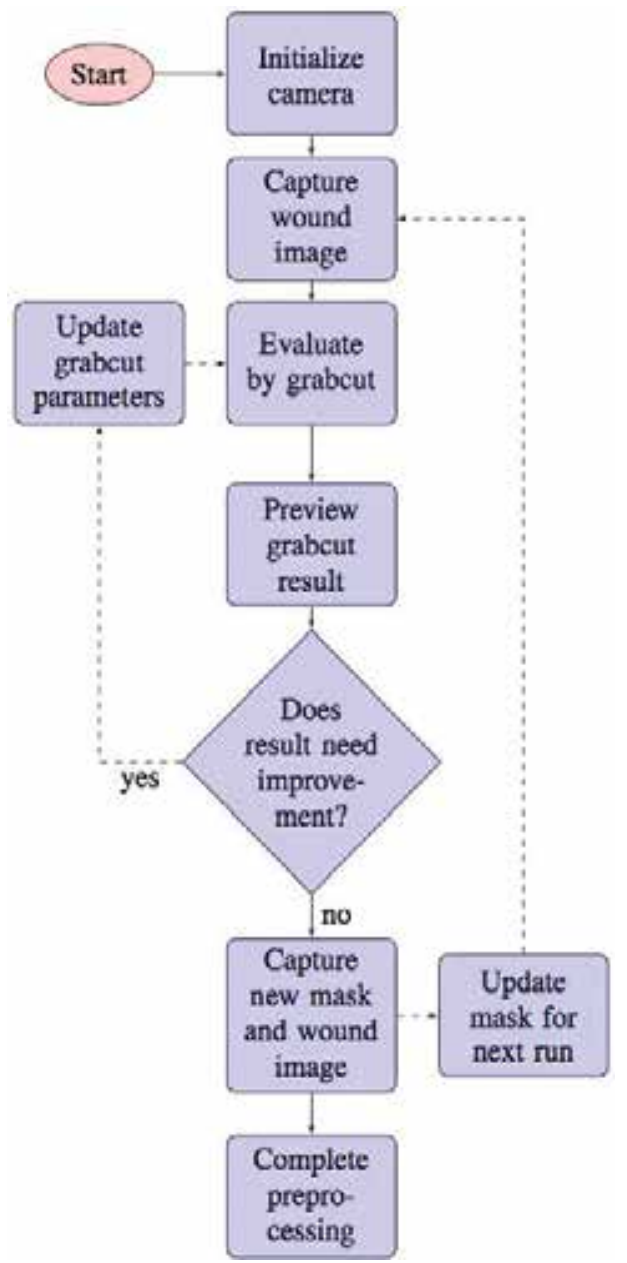

Figure 7. Image acquisition and pre-processing flowchart.

Wounds are generally three-dimensional, with volume below the skin surface. Wounds can also exhibit undermining, which refers to a wound that is larger at its base (below the skin) than the opening at the surface of the skin suggests, creating a cavity below the surface of the skin. Tunnelling refers to wounds, similar to undermining, which have channels (rather than cavities) below the skin surface. 
As noted earlier, conventional methods to measure wound dimensions and/or area often use contact methods, in which adhesive strips or transparent films are laid around or on the wound, respectively, and wound edges are noted on the strips or films. The strips or films are then read directly for size or overlaid on to graph paper or rulers for measurement. The depth is generally measured with a cotton-tipped applicator to the deepest part of the wound.

Two approaches in the literature to automatically determine the size of a wound include grid capture and scanner capture. Grid capture is a hybrid of conventional contact methods and digital image analysis. In this case, a transparent film with a marked grid is placed on the wound and the wound perimeter is traced on to the film. The film with the tracing on a known grid is then the basis from which the dimensions and area of the wound can be calculated with a software application [38]. This approach has the advantage of basing the calculation on a real tracing of the wound perimeter and a known grid, thus capturing the near-real orientation of the wound. However, the disadvantage remains the potential for discomfort to the patient when the film rests on the wound.

In another approach denoted as scanner capture, a box with two internal mirrors is constructed as a template. The box has openings for a mobile device and an LED light source. In the scanner capture approach developed by others, a box with two mirrors inside is placed at 45 degrees relative to the horizontal, with openings for a smartphone and an LED light source [27]. The patient rests their foot in the box, and in this way, the setup maintains a constant distance between camera and wound and constant lighting conditions. While the computation remains intensive, the advantage of this method is that these two conditions serve to simplify the image processing requirements. The disadvantage of this method is the reliance on ancillary staging devices, and the setup will be impractical for certain areas of the body.

In this work, the objective of the Mask Image component is to obtain the comparative dimensions of an object in the image relative to a previous image of the same wound. An initial photograph is taken, from which a transparent digital 'mask' of the wound is created. The user then overlays or aligns this digital mask to the wound for the subsequent assessment and photograph (Figures 8 and 9). While most of the perimeter is expected to align between the mask image and the wound in its current state, one can reasonably anticipate that if the wound is either healing or deteriorating, portions of the perimeter between the digital mask and the wound in its current state will differ. The algorithm compares the digital mask to the current wound image, recognizing and aligning wound perimeter, and estimating the relative size difference. From this size difference, either healing, deterioration, or no change is inferred. The result is given as a percentage change in the area of the most current image relative to the previous digital mask image.

The mask image or mask overlay essentially serves to provide a point of reference when aligning the wound for the current assessment with its previous condition. As such, the point of reference does not necessarily need to be the transparent mask overlay. A medical tattoo could also act as a point of reference. In this case, it would be either a temporary or permanent skin marker or pattern (e.g. three dots) close to the wound. This marker or pattern would be used each to create a digital overlay which would provide the point of reference when aligning the camera for all subsequent photographs. 


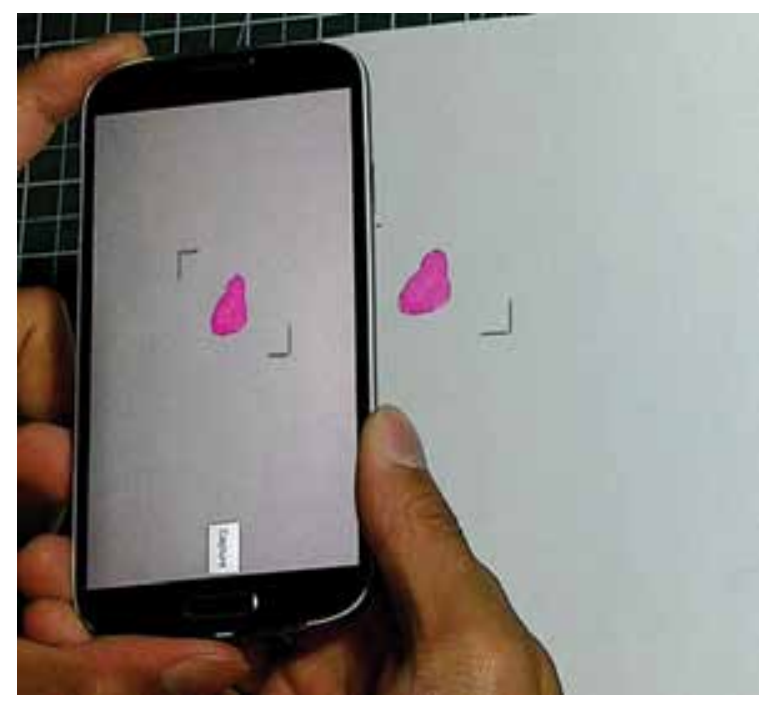

Figure 8. Creating a mask image from the wound.

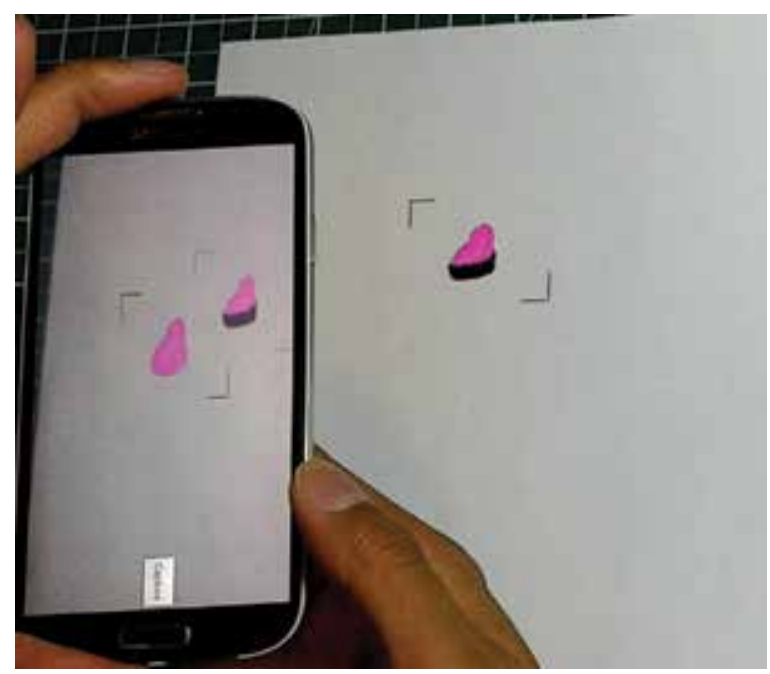

Figure 9. Overlay of mask image to new wound.

The Mask Image component of the work provides the relative size of the wound from one assessment to the next. Users can choose to create one digital mask and compare all subsequent photographs to the initial digital mask; alternately, users can create a new digital mask at each wound assessment so that wound size comparison is always to the most recent assessment. A combination of the two methods is also possible. The advantage of the method is the absence of direct contact with the wound, thus preventing patient discomfort. Another advantage is that no additional devices to the camera or to the patient (e.g. props) are required. The error 
inherent in the approach is largely determined by the user's dexterity in aligning the digital mask over the current wound. A limitation of the method is that wound depth is not considered in the calculation. A further limitation of the method is that the outcome is a relative size of the wound rather than an absolute size. When an absolute size of the wound is desired, the Camera Calibration component is implemented.

\subsection{Camera calibration for absolute size}

Figure 10 shows the Camera Calibration component within the basic software framework outlined in Figure 6.

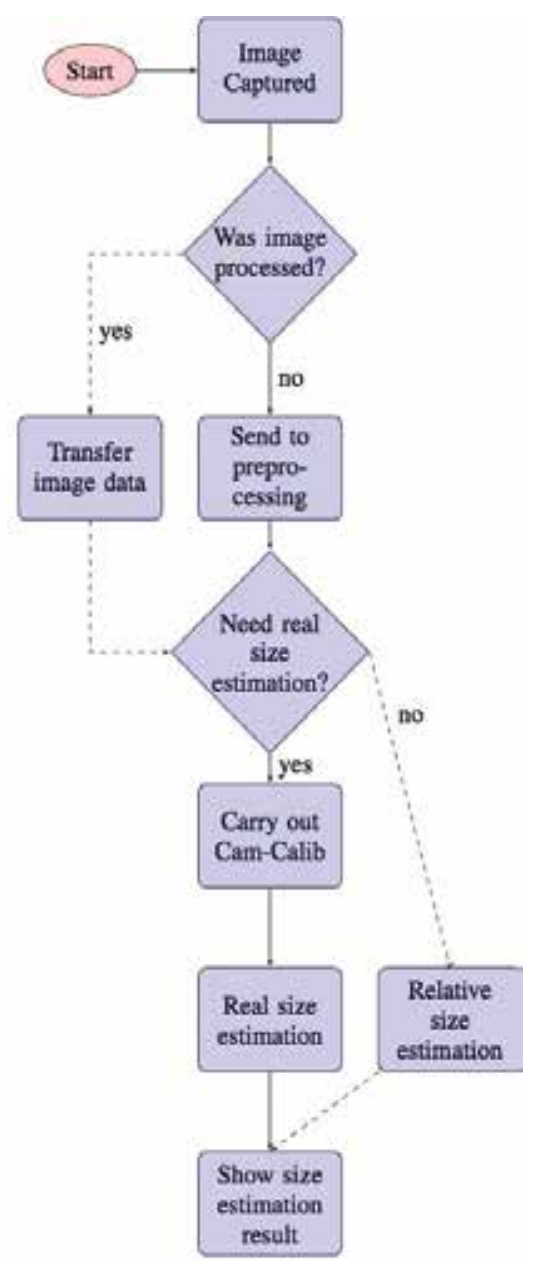

Figure 10. Size estimation with segmentation flowchart.

Grabcut, a segmentation method used to differentiate an object (in this case, a wound) in the foreground from its background (in this case, the surrounding skin or body part), is applied 
in this module. Grabcut accomplishes this by using colour information to compare side by side pixels and also by using edge or contrast information to identify an object in an image. Further, Grabcut uses progressive iteration and runs the process multiple times to optimize the results. The result is a segmented image (the foreground object, in this case, a wound). This segmented image is then used in the Camera Calibration component as well as the third component of colour analysis. While other segmentation algorithms are available, Grabcut is considered an efficient algorithm and has the benefit of minimal user interaction [37], which was a requirement in this work. An example of Grabcut applied to wound photographs is found at https:// youtu.be/Iyvochswrws.

The purpose of the Camera Calibration component is to take an image photographed on an angle and reconstruct or reference it back to a two-dimensional plane. Essentially, the Camera Calibration module computationally achieves one of the objectives of the scanner capture box [27] in terms of aligning the wound to known and fixed positions relative to the camera. The Camera Calibration component uses a known pattern with 13 or more fixed reference points, and applies the Tsai2D algorithm $[39,40]$ to obtain a reconstructed image of the wound. Since the distance between the points are known from the calibration model, the view angle can be calculated and the image can be reconstructed on a 2D plane. From here, the size of the wound can be calculated. Like the Mask Image component, the Camera Calibration component also does not identify depth or volume of wounds. This is a known limitation, given that surface size and area alone are an incomplete descriptor of wounds.

A chessboard pattern was chosen as the pattern. This was found to be effective for photographs taken in static and dynamic conditions. Similar to the conventional approach of placing an adhesive ruler near the wound to measure size, the chessboard pattern is placed close to the wound and then photographed. The inherent assumption is that the wound and the pattern are in the same two-dimensional plane. Given that the chessboard pattern is known and fixed, the planar orientation of the pattern in the photograph can be calculated and then the image corrected accordingly. This approach has been shown to be effective in calculating the dimensions of a soccer field, in which a top (plan) view of the field was reconstructed from images taken on an angle, using Camera Calibration [41]. In this work, the chessboard pattern is used for calibration to obtain the extrinsic matrix of the wound. The extrinsic matrix provides information on the camera location and the view direction, allowing for translation and rotation to the two-dimensional plane.

Figure 11 demonstrates the Camera Calibration sequence at a high level. The red lines denote the objects which were detected, i.e. the dark squares. The algorithm finds the centre of each square and applies the Tsai $2 \mathrm{D}$ algorithm to process the coordinates. The blue lines show the scanning sequence. The green lines are the re-projected lines from the model points to the real world coordinates, as an indication of the success of the Camera Calibration algorithm. If the green lines were curved or otherwise irregular, this would indicate that the projection back to a two-dimensional plane was not successful.

Figure 12 shows the Camera Calibration component applied to a wound. The wound was photographed at an angle and then re-projected on a two-dimensional plane at 90 degrees to the viewer. 


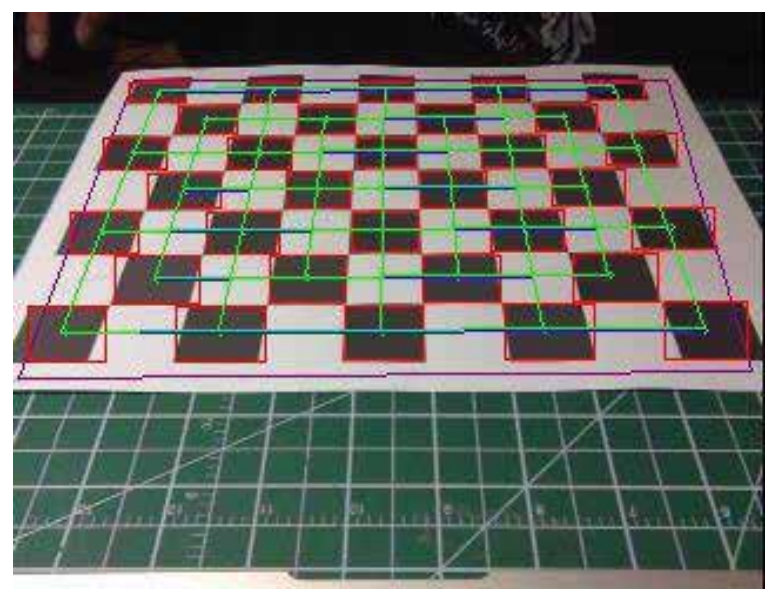

Figure 11. Original and re-projected planes.
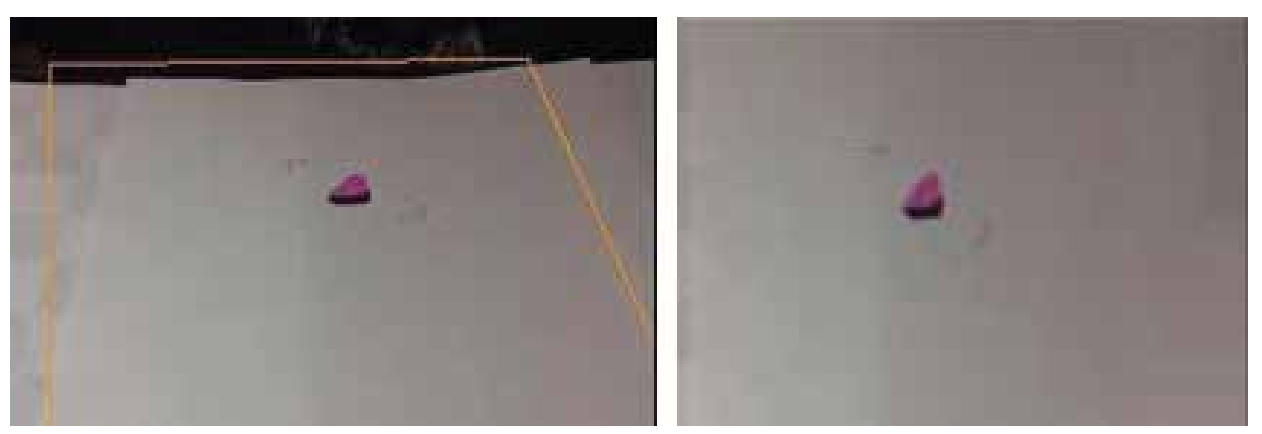

Figure 12. Wound image before (left) and after (right) reconstruction.

While the Mask Image component results in a relative size of the wound and the Camera Calibration component results in a corrected orientation and an absolute size of the wound, taken together, they allow for more accurate calculations. When applied to a Canadian dollar coin (26.5 mm diameter with eleven edges), the actual size was determined with an error of $<1 \%$.

A demonstration of the Camera Calibration module is available at https://youtu.be/ OiJk3nMymSE.

\subsection{Colour analysis}

The third algorithm focuses on colour analysis of the wound. It determines the range of colours present in an image, separating the image into three component colours by extracting components from the red-green-blue (RGB) format of the image and presenting them in a histogram. These data can then be fed into an expert system to infer the stage of the wound. Figure 13 shows the Colour Analysis component within the software framework outlined in Figure 6. 


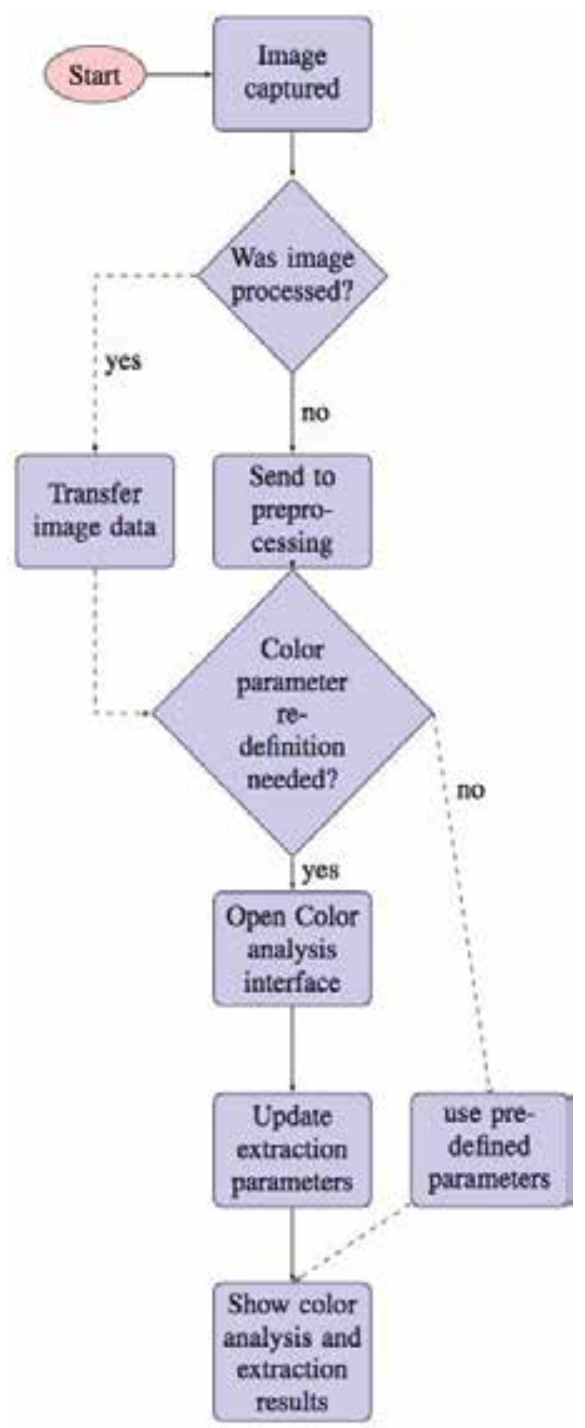

Figure 13. Colour analysis flowchart.

Pressure ulcers will be assessed as one of six stages (stage I through IV, Suspected Deep Tissue Injury, and Unstageable) [42]. Because the current work is unable to calculate the depth of the wound, the last two categories (both of which are wounds with some depth below the skin surface) have been combined as Unstageable. In addition to wound depth, other factors that determine the stage of a wound include skin condition (intact or broken), tissue loss, the colour of the skin, tissue, and wound bed, and the presence and nature of discharge.

To analyse the colour of a wound, the algorithm uses an RGB format of the image and determines the presence of the three component colours. Each component colour has a defined 
range, although the user can adjust that range or calibrate the range for variable lighting conditions.

While segmentation is not mandatory, the results of the colour analysis component are much more accurate if done on a segmented image, as this allows the algorithm to disregard the background (Figure 14 images taken from http://reference.medscape.com/features/slideshow/ pressure-ulcers).

Users can also consider hue, saturation, value (HSV) and red-yellow-black (RYB) formats for colour analysis. Hue, saturation, value (HSV) format responds to lighting, and as such, it may be a good option when one wants to tune the colour more specifically. RYB (red-yellow-black) has a fitting relationship to wound stages, and RGB results can be converted to RYB. The approximate ratios of red, yellow, and black correlated to wound stages are shown in Figure 15. Wound stages I and II rely only on red, but are differentiated on the intensity of the red in the image. The subsequent wound stages are differentiated on the proportions of each of the three colours in the image. The error inherent in this method depends to some extent on the definitions of colours set by the user. A recommendation is to associate this component with a machine learning component, once a large enough data set is collected. In this way, colour parameters can be more precisely defined.

Finally, expert systems can be developed to determine wound stages from the RGB and/or RYB data. This again relies on collecting a sufficiently large data set. Alternatively, support vector machine (VSM) or another machine learning algorithm can be applied to determine the
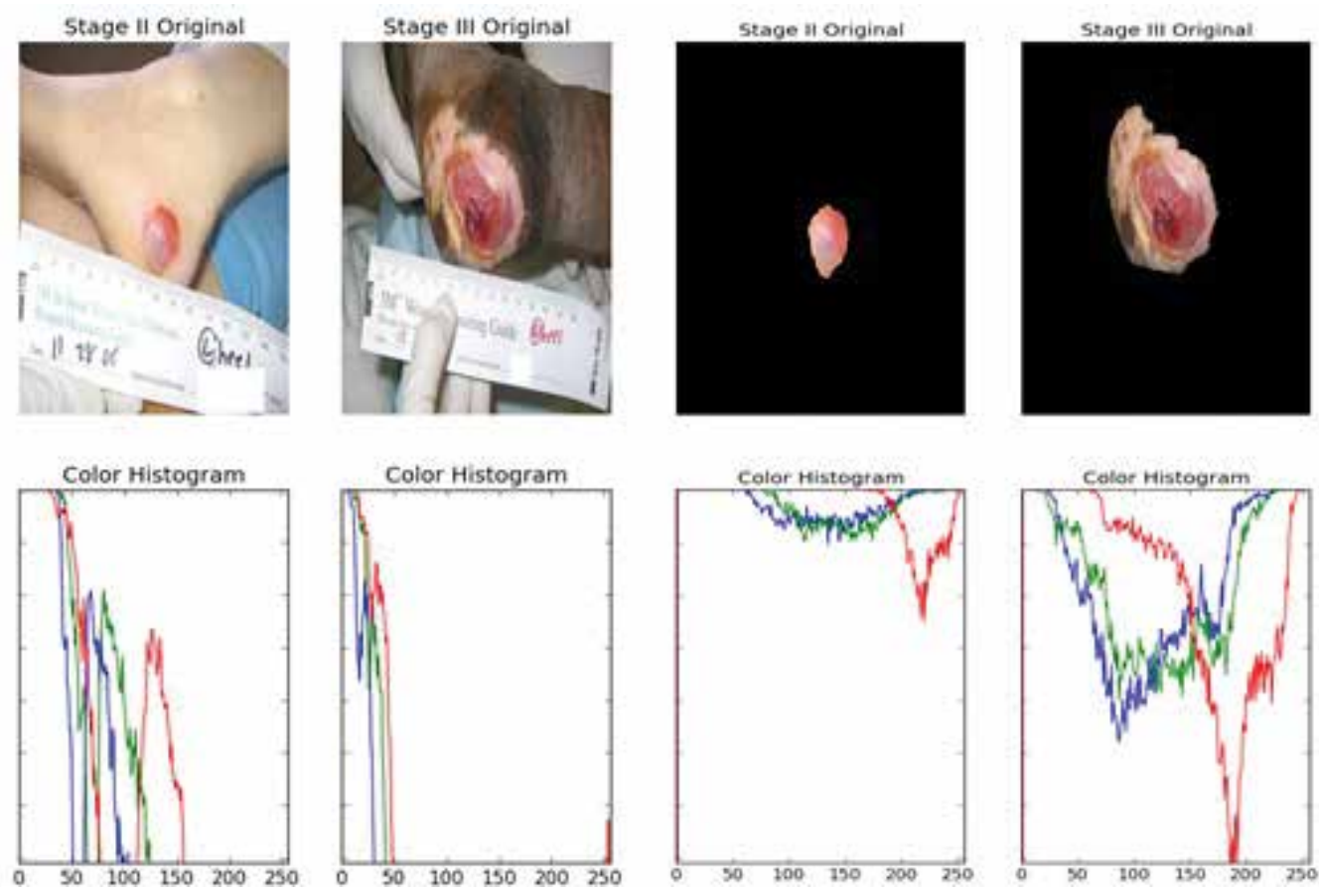

Figure 14. Histogram results before and after segmentation. 
stages of a wound. In the current work, the framework for an expert system is in place. The next step is to collect and populate the expert system with training data.

An example of the colour analysis on wound photographs can be viewed at https://youtu.be/ Iyvochswrws.

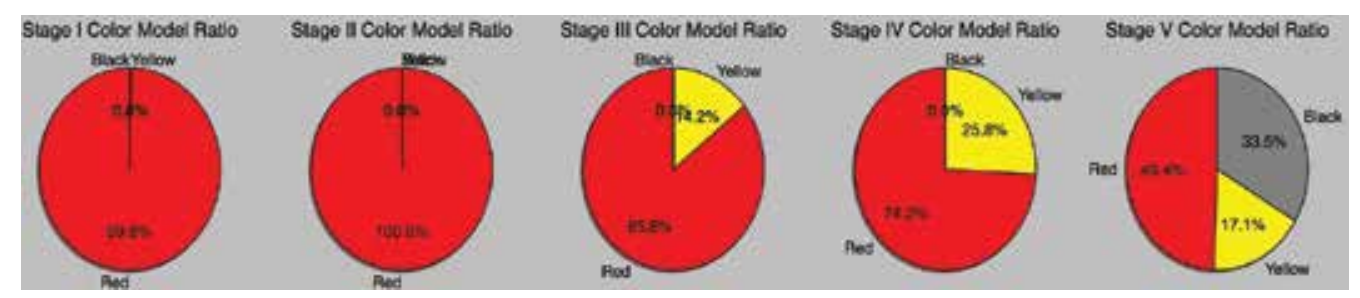

Figure 15. RYB output correlated to wound stage.

\section{Conclusion}

SmartWoundCare as a mobile wound management prototype demonstrates the wide relevance of mHealth for applications within healthcare facilities and their integration with larger EMR and eHealth systems, as well as the application of telehealth to connect underserved communities. Community health and home-based care is an equally important and in some way a more urgent implementation. For example, nurses of the Winnipeg Regional Health Authority alone carry out 450,000 wound visits per year in its Home Care program in clients' homes. Particularly in home-based care, the integration of SmartWoundCare with a suite of mHealth tools is a natural extension. A logical partner app for SmartWoundCare is diabetes monitoring, as well as novel pre-emptive applications such as an early warning system for injury or damage to diabetic feet due to neuropathy [43].

SmartWoundCare and other mHealth applications also illuminate opportunities in Big Data, in which a community of users generate data - in this case, a wound database - from which relevant trends in wound diagnosis and healing can be extracted and form part of the body of knowledge in wound care.

\section{Author details}

Marcia R. Friesen*, Bennet Gigliotti and Tik Wai (Kiral) Poon

*Address all correspondence to: marcia.friesen@umanitoba.ca

Electrical \& Computer Engineering, University of Manitoba, Winnipeg, Manitoba, Canada 


\section{References}

[1] Cafazzo JA, Casselman M, Hamming N, Katzman DK, Palmert MR. Design of an mHealth app for the self-management of adolescent type 1 diabetes: A pilot study. Journal of Medical Internet Research. 2012;14(3): e70. DOI: 10.2196/jmir.2058

[2] RheumMate [Internet]. Available: http://gvu.gatech.edu/research/projects/rheummate [Accessed 2015-06-15].

[3] Health Outcomes Worldwide [Internet]. Available: http://healthoutcomesww.com [Accessed 2015-06-15].

[4] Canadian Association of Wound Care [Internet]. Available: www.cawc.net [Accessed 2015-07-15].

[5] Woodbury MG, Houghton PE. Prevalence of pressure ulcers in Canadian healthcare settings. Ostomy Wound Management. 2004;50: 22-38.

[6] Gorecki C, Brown J, Nelson A, Briggs M, Schoonhoven L, Dealey C, Defloor T, Nixon, J. Impact of pressure ulcers on quality of life in older patients: A systematic review. Journal of the American Geriatrics Society. 2009;57: 1175-1183.

[7] Groeneveld A. The prevalence of pressure ulcers in a tertiary care pediatric and adult hospital. Journal of Wound, Ostomy Continence Nursing. 2004;31: 108-120.

[8] Reddy M, Gill SS, Rochon PA. Preventing pressure ulcers: A systematic review. JAMA. 2006;296: 974-984.

[9] Landi F, Onder G, Russo A, Bernabei R. Pressure ulcer and mortality in frail elderly people living in community. Archives of Gerontology and Geriatrics. 2007;44: 217-223.

[10] Allman RM, Goode PS, Burst NBS, Bartolucci AA, Thomas DR. Pressure ulcers, hospital complications, and disease severity: Impact on hospital costs and length of stay. Advances in Wound Care. 1999;12: 22-30.

[11] Allman RM. Pressure ulcer prevalence, incidence, risk factors, and impact. Clinics in Geriatric Medicine. 1997;13: 421-436.

[12] Keast DH, Parslow N, Houghton PE, Norton L, Fraser C. Best practice recommendations for the prevention and treatment of pressure ulcers: update 2006. Wound Care Canada. 2006;4: 31-43.

[13] Van Gilder C. Results of nine international pressure ulcer prevalence surveys: 19892005. Ostomy and Wound Management. 2008;54: 40-54.

[14] Gallagher P. Prevalence of pressure ulcers in three university teaching hospitals in Ireland. Journal of Tissue Viability. 2008;17: 103-109.

[15] Gunningberg L, Stotts N. Tracking quality over time. What does pressure ulcer data show? International Journal for Quality in Health Care. 2008;20: 246-253. 
[16] Chaundry B, Wang J, Wu S, Maglione M, Mojica W, Roth E, Morton SC, Shekelle PG. Systematic review: Impact of health information technology on quality, efficiency, and costs of medical care. Annals of Internal Medicine. 2006;144: 742-752.

[17] Rennert AB, Golinko M, Kaplan D, Flattau A, Brem H. Standardization of wound photography using the wound electronic medical record. Advances in Skin and Wound Care. 2009;22: 32-38.

[18] Smith MW, Hill ML, Hopking KL, Kiratli, BJ, Cronkite RC. A modeled analysis of telehealth methods for treating pressure ulcers after spinal cord injury. International Journal of Telemedicine and Applications. 2012. Volume 2012, January 2012, Article ID 729492, 10 pages. DOI : 10.1155/2012/729492. Epub 2012 Aug 28.

[19] Harrison J, Harrison DG. It is possible to standardize wound ostomy continence documentation with a mobile app. Journal of Wound, Ostomy, and Continence Nursing. 2013;40: 537.

[20] mHealthNews [Internet]. Available: http://www.mhealthnews.com/news/onc-nameswinners-pressure-ulcer-app-challenge [Accessed 2015-10-25].

[21] PUSH Tool [Internet]. Available: http://www.npuap.org/resources/educational-andclinical-resources/push-tool [Accessed 2015-12-24].

[22] Prevention Plus: Home of the Braden Scale [Internet]. Available: http://www.bradenscale.com/index.htm [Accessed 2015-11-04].

[23] Harris C, Bates-Jensen B, Parslow N, Raizman R, Singh M. The Bates-Jensen Wound Assessment Tool (BWAT): Development of a pictorial guide for training nurses. Wound Care Canada. 2009;7: 33-38.

[24] Samad A, Hayes S, French L. Digital imaging versus conventional contact tracing for the objective measurement of venous leg ulcers. Journal of Wound Care. 2002;11(4): 137-140.

[25] Rajbhandari SM, Harris ND, Sutton M. Digital imaging: An accurate and easy method of measuring foot ulcers. Diabetic Medicine. 1999;16(4): 339-342.

[26] Hill ML, Cronkite RC, Ota DT, Yao EC, Kiratli BJ. Validation of home telehealth for pressure ulcer assessment: A study in patients with spinal cord injury. Journal of Telemedicine and Telecare. 2009;15(4): 196-202.

[27] Wang L, Pedersen PC, Strong DM, Tulu B, Agu E, Ignotz R. Smartphone-based wound assessment system for patients with diabetes. IEEE Transactions on Biomedical Engineering. 2015;62(2): 477-488. DOI: 10.1109/TBME.2014.2358632

[28] White PJF, Podaima BW, Friesen MR. Algorithms for smartphone and tablet image analysis for healthcare applications. IEEE Access. 2014;2(1): 1-10. DOI: 10.1109/ ACCESS.2014.2348943 
[29] Multi Measures; TapeMeasure! [Internet]. Available: https://play.google.com [Accessed 2014-12-20].

[30] SmartMeasure; Ruler. [Internet]. Available: https://itunes.apple.com [Accessed 201412-18].

[31] Robot Electronics - Ultrasound Rangers [Internet]. Available: http://www.robotelectronics.co.uk/products/sensors/ultrasonics.html [Accessed 2015-10-07].

[32] Active Robots - IR Distance Measuring [Internet]. Available: http://www.robotelectronics.co.uk/products/sensors/infrared-range.html [Accessed 2015-10-07].

[33] Lytro - "You'll never think about pictures the same way" [Internet]. Available: https:// www.lytro.com/camera [Accessed 2015-10-24].

[34] Toshiba putting focus on taking misfocusing out of photos [Internet]. 2012. Available: http://ajw.asahi.com/article/economy/business/AJ201212270054. [Accessed 2015-1125].

[35] Dent S. Nokia's Refocus Lens camera app promises infinite depth of field control [Internet]. 2013. Available: http://www.engadget.com/2013/10/22/nokias-refocus-lenscamera-app/. [Accessed 2015-11-24].

[36] Pinto S. Dual-Lens smartphone camera: Killer feature or just a gimmick? [Internet]. 2014. Available: http://www.techtree.com/content/news/5615/dual-lens-Smartphonecamera-killer-feature-gimick.html. [Accessed 2015-11-24].

[37] Rother C, Kolmogorov R, Blake A. GrabCut interactive foreground extraction using iterated graph cuts. Microsoft Research, Cambridge, UK [Internet]. Available: http:// cvg.ethz.ch/teaching/cvl/2012/grabcut-siggraph04.pdf [Accessed 2015-11-24].

[38] Foltynski P, Ladyzynski P, Wojcicki JM. A new smartphone-based method for wound area measurement. Artificial Organs. 2014;38(4): 346-352.

[39] Zhang Z. A flexible new technique for camera calibration. IEEE Transactions on Pattern Analysis and Machine Intelligence. 2000;22(11): 1330-1334. Available: http:// research.microsoft.com/en-us/um/people/zhang/Papers/TR98-71.pdf [Accessed 201504-20].

[40] Tsai RY. A versatile camera calibration technique for high-accuracy 3D machine vision metrology using off-the-shelf TV cameras and lenses. IEEE Journal of Robotics and Automation. 1987;3(4): 323-344. DOI: 10.1109/JRA.1987.1087109

[41] Anderson J, Baltes J. A pragmatic global vision system for educational robotics. In: AAAI Spring Symposium: Semantic Scientific Knowledge Integration; 2007. Available: www.aaai.org/Papers/Symposia/Spring/2007/SS-07-09/SS07-09-001.pdf [Accessed 2015-07-18]. 
[42] NPUAP Pressure Ulcer Stages/Categories [Internet]. Available: http:// www.npuap.org/resources/educational-and-clinical-resources/npuap-pressure-ulcerstagescategories/ [Accessed 2015-08-08].

[43] Jegede OD, Ferens K, Griffith B, Podaima BW. A smart shoe to prevent and manage diabetic foot diseases. In: Proceedings of the 2015 International Conference on Health Informatics and Medical Systems; 26-30 July 2015; Las Vegas, NV, USA. p. 47-54. 


